$\therefore$

o

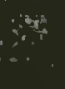

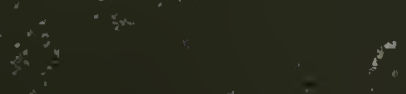

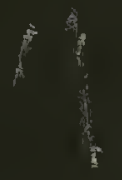

$\therefore$

a 
$\varepsilon$

$195-a$

616

80918

$\checkmark$

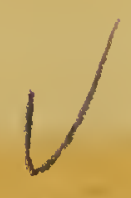


<smiles>[Li]</smiles>

<.

$\cdot$ 
BACTERIA IN DAILY LIFE 



\section{BACTERIA \\ IN DAILY LIFE}

BY

\section{MRs. PERCY FRANKLAND}

FELLOW OF THE ROYAL MICROSCOPICAL SOCIETY; HONORARY MEMBER OF BEDFORD COLLEGE, UNIVERSITY OF LONDON;

JOINT AUTHOR OF "MICRO-ORGANISMS IN WATER," "THE LIFE OF PASTEUR," ETC.

"Spirits, when they please,

Can either sex assume, or both; so soft

And uncompounded is their essence pure,

Not tied or manacled with joint or limb,

Nor founded on the brittle strength of bones,

Like cumbrous flesh; but, in what shape they choose,

Dilated or condensed, bright or obscure,

Can execute their aery purposes,

And works of love or enmity fulfil."

Milton.

LONGMANS, GREEN, AND CO.

39 PATERNOSTER ROW, LONDON

NEW YORK AND BOMBAY

1903

All rights reserved 



\section{PREFACE}

THE title of this little volume sufficiently explains its contents; it only remains to add that much of the text has already appeared from time to time in the form of popular articles in various magazines. It has, however, been carefully revised and considerably added to in parts where later researches have thrown further light upon the subjects dealt with.

G. C. FRANKLAND

NORTHFIELD, WORCESTERSHIRE,

November, IgO2 



\section{CONTENTS}

PAGE

BACTERIOLOGY IN THE ViCTORIAN ERA . . . I

What We Breathe . . . . . 34

SUNSHINE AND LIFE . . . . . 65

BaCteriology AND Waté • • • 93

Milk Dangers AND-Remedies. . . , I 8

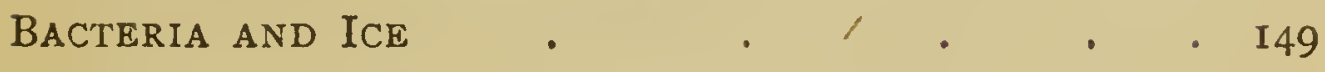

Some Poisons and Their Prevention . . . I68 



\section{BACTERIA IN DAILY LIFE}

\section{BACTERIOLOGY \\ IN THE VICTORIAN ERA}

A LiTTLE more than sixty years ago the A scientific world received with almost incredulous astonishment the announcement that "beer yeast consists of small spherules which have the property of multiplying, and are therefore a living and not a dead chemical substance, that they further appear to belong to the vegetable kingdom, and to be in some manner intimately connected with the process of fermentation."

When Cagniard Latour communicated the above observations on yeast to the Paris Academy of Sciences on June I2, I837, the whole scientific world was taken by storm, so great was the novelty, boldness, and originality of the conception that these insignificant particles, hitherto reckoned as of little or no account, should be 
endowed with functions of such responsibility and importance as suggested by Latour.

At the time when Latour sowed the first seeds of this great gospel of fermentation, started curiously almost simultaneously across the Rhine by Schwann and Kützing, its greatest subsequent apostle and champion was but a schoolboy, exhibiting nothing more than a schoolboy's truant love of play and distaste for lessons. Louis Pasteur was only a lad of fifteen, buried in a little town in the provinces of France, whose peace of mind was certainly not disturbed, or likely to be, by rumours of any scientific discussion, however momentous, carried on in the great, far-distant metropolis. Yet, some thirty and odd years later, there was not a country in the whole world where Pasteur's name was not known and associated with those classical investigations on fermentation, in the pursuit of which he spent so many years of his life, and which have proved of such incalculable benefit to the world of commerce as well as science.

Thanks to Pasteur, we are no longer in doubt as to the nature of yeast cells; so familiar, in fact, have we become with them, that at the dawn of the twentieth century we are able to select at will those particular varieties for which we have a predilection, and employ those which will produce 
for us the special flavour we desire in our wines or in our beers.

Large and splendidly-equipped laboratories exist for the express purpose of studying all kinds and descriptions of yeasts, for finding out their characteristic functions, and cultivating them with all the tenderness and care that a modern gardener bestows upon the rarest orchids.

All this is now an old story, but some sixty years ago the great battle had yet to be fought which was to establish once and for all the dependence of fermentation upon life, and vanquish for ever those subtle arguments which so long refused to life any participation in the work of fermentation and other closely allied phenomena.

When, however, Pasteur finally cleared away the débris of misconception which had so long concealed from view the vital character of the changes associated with these processes, the bacterial ball, if we may so call it, was set rolling with a will, and information concerning these minute particles of living matter was rapidly gathered up from all directions.

The recognition so long refused to bacteria was now ungrudgingly given, for it was realised at last that, in the words of M. Duclaux, "Whenever and wherever there is decomposition of organic matter, whether it be the case of a weed or an oak, of 
a worm or a whale, the work is exclusively performed by infinitely small organisms. They are the important, almost the only, agents of universal hygiene; they clear away more quickly than the dogs of Constantinople or the wild beasts of the desert the remains of all that has had life; they protect the living against the dead. They do more; if there are still living beings, if, since the hundreds of centuries the world has been inhabited, life continues, it is to them we owe it."

Fortunately, the provisions made by Nature for the preservation of the bacterial race are of so lavish a description that no fear need be entertained that this useful and indispensable world of life will be wiped out. The fabulous capacity for multiplication possessed by them (a new generation arising in considerably less than an hour), the powers of endurance which some of them exhibit in presence of the most trying vicissitudes of heat and cold (they have been known to survive exposure lasting for seven days to a temperature of about $-200^{\circ} \mathrm{C}$.), the inability of starvation or desiccation to undermine their constitution, combine to render the question of the extinction of bacteria as remote as it is undesirable.

Tempted by the prospects of exploring in this newly-revealed world of life, investigators rushed 
into the field, and the bacterial fever has been hardly less pronounced in these last years than that rush for a material golden harvest which has characterised so many enterprises in southern latitudes.

The scientific results of this microbe fever have happily, however, been of a more solid and substantial character than can be said to have followed the more tangible but sordid ventures in South African mines. Vague hypotheses have given place to facts, and bacteria have been brought more and more within the horizon of human knowledge, thanks to the genius and untiring zeal of investigators all over the world.

By mechanical improvements in microscopes, and subtle methods for colouring bacteria, enabling us to study their form with precision, by ingenious devices for supplying them with suitable food materials, or, in other words, by the creation of bacterial nurseries, providing the means for watching their growth and observing their distinctive habits and character, this important branch of the vegetable kingdom has been raised from obscurity to one of the principal places in our catalogue of sciences, and Bacteriology has won for itself an individual footing in the scientific curriculum of our great educational institutions, and is represented in literature by such famous 
serials devoted to the publication of bacterial and allied researches as the Annales de l'Institut Pasteur, the Centralblatt fiir Bakteriologie, the Zeitschrift fiur Hygiene, the Annali d'Igiene Sperimentale, and other well-known journals which constitute an essential but ever-increasing burden upon the library shelves as well as pocket of the investigator.

Museums of bacteria have been established where not only specimens of particular varieties of a permanent character for comparison and reference can be obtained, but living cultivations of hundreds of different micro-organisms are maintained; and only those who have had the charge of bacteria can realise the enormous amount of skilled labour involved in the catering for such a multitude, in which individual likes and dislikes in regard to diet and treatment must, if success is to be secured, be as carefully considered as is necessary in the case of the most delicate and highly pampered patient.

Bacteria, by means of these depôts, can, in fact, be bought or exchanged by collectors with as much facility as postage stamps, with the allimportant difference that this collecting of bacteria is not a mere mania or speculation, but serves a most useful purpose.

To the busy investigator who cannot afford 
either the time or space in which to maintain a large bacterial family, it is of immense convenience to be able to obtain at a moment's notice a trustworthy culture, say, of typhoid or tuberculosis, or specimens of obscurer origin from air or water for purposes of investigation. These bacterial cultures are all guaranteed pure, free from contamination or admixture with other and alien micro-organisms, and are strictly what they are represented to be. Although such a declaration is attached to many commodities at the present day with ludicrous incongruity, in the case of micro-organisms such a breach of faith is unknown, and the antecedents of a microbe may be said to be regarded as of as much moment and to be as jealously preserved as is the pedigree of the most ambitious candidate for honours at a cattle or dog show!

Amongst some of the curiosities to be found on the shelves of microbe-museums may be mentioned bacteria which give out light, and thus, like glowworms, reveal themselves in the dark. These light-bacteria were originally discovered in seawater and on the bodies of sea-fish, and cultures of them have been successfully photographed, the only source of light being that provided by the bacilli themselves. The amount of light emitted by a single bacillus might indeed defy detection 
by the most sensitive plate procurable, but when gathered together in multitudes, the magnitude of which even eight figures fail to express, these phosphorescent bacteria enable the dial of a watch to be easily read in the dark, whilst photographs of the face of a watch taken in such bacterial light have been so successful that the time at which the photograph was taken could be distinctly seen.

Of bacteria it may indeed truly be said, as has Maeterlinck of the labours of bees- "though it be here the infinitely little that without apparent hope adds itself to the infinitely little, though our eye with its limited vision look and see nothing, their work, halting neither by day nor by night, will advance with incredible quickness!"

Mention may perhaps appropriately be made here of the highly interesting fact discovered by Professor Percy Frankland, that ordinary bacteria which do not phosphoresce are capable of affecting a photographic film in absolute darkness, and can by this means produce a picture of themselves. If, however, a transparent piece of glass is placed between the bacteria and the film no photograph results, showing that glass interferes with their activity in this respect. The author points out that as this action upon the photographic film does not take place through glass, it is in all 
probability due to the evolution by the bacteria of certain volatile chemical substances which either directly or indirectly enter into reaction with the sensitive film. Similar phenomena have been discovered in regard to many metals as well as organic substances, but this is the first observation which has been recorded of the action of living structures on sensitive films in the dark.

We have already referred to the important services which Pasteur has rendered by distinguishing between different varieties of yeast, and separating them out according to their functions and properties-pioneer work which has been followed up by and borne such splendid fruit in the hands of the renowned Danish investigator, Emil Christian Hansen of Copenhagen. This work of isolating out individual varieties of micro-organisms has been not only pursued with the energy familiar to all in the case of bacteria associated with disease, but has been pursued in various other, though perhaps less well known, directions.

A great deal of activity has lately been exhibited in so-called dairy bacteriology, and a long list has already been compiled of milk, cheese, and butter microbes; and agricultural authorities, even in this country, are slowly awakening to the fact that, in order to compete on modern lines with foreign dairy produce, dairy schools must 
be established, where bacteriology is taught, and where instruction is given in the principles of scientific butter and cheese making.

But bacteria of the brewery and of the dairy are not the only useful germs which are to be found on the shelves of microbe museums. Wine and tobacco manufacturers on application may respectively obtain the bacterial means of transforming the crudest must into the costliest claret, and the coarsest tobacco into the most fragrant Havana. Already considerable progress has been made in the isolation of particular varieties of wine-yeast, whilst highly encouraging results have been obtained by Suchsland and others in the separation of various valuable tobacco-fermenting organisms. Agricultural authorities, again, owe a debt of gratitude to those distinguished investigators whose labours have discovered the art of imprisoning the micro-organisms which play such an important part in the fertilisation of the soil. Bacterial fertilisers are amongst the latest achievements which bacteriology has accomplished in this wonderful half-century, and the purchase of special varieties of bacteria to suit the requirements of particular kinds of leguminous plants is now fast becoming a mere everyday commercial transaction. But efforts for the amelioration of the conditions under which plant 
life is carried on have not been confined to providing plants with suitable bacterial friends; vigorous and successful efforts have been made to remove from their entourage those bacterial enemies and undesirable parasites which have for so long played so important a part in the crop-returns of many an agriculturist.

For the identification and separation of the plant-parasites of various kinds we have largely to acknowledge our indebtedness to American investigators, and the encouragement and support which Dr. Erwin Smith, amongst others, has received from the Government of the United States in the prosecution of these researches indicates how great is the public importance attached to them. There are in America alone fifty experiment stations where plant diseases are studied, whilst at a number of the colleges and universities more or less attention is given to the subject. Some idea of the loss occasioned to agriculturists by these plant pests may be formed by a recent announcement that the Department of Agriculture in Queensland was prepared to offer a reward of $£ 5,000$ for the discovery of a means to eradicate the prickly-pear disease. Plant pathology has not yet had a distinct chair allotted to it in any of the great universities, but the subject is of such vast 
industrial importance, that doubtless before long some seat of learning will do itself the honour to establish one, and so set the example.

A striking instance of the advantages of taking stock, so to speak, of the attributes of bacteria will occur to everyone in the revelation which has followed of their powers to solve one of the most knotty problems of the day-the efficient manipulation of those vast subterranean rivers of sewage which honeycomb every city of the world.

The purification which sewage underwent by passing it through the pores of the soil, or, in other words, by filtration, was recognised about the year I870, soon after the Rivers Pollution Commissioners had begun to make their classical investigations on the land treatment of sewage; but although the rapid transformation of ammonia into nitrates which followed the passage of the sewage through a few feet of soil was noted, yet the mechanism of this nitrification process remained a mystery until I877, when two French chemists-MM. Schloesing and Muentz-made the then astounding discovery that this change was dependent upon the vital energies of microorganisms.

The part played by bacteria in the purification of sewage thus became an established fact, and the later experiments have been devoted to study- 
ing the necessary conditions under which the maximum amount of work is obtainable from these novel bacterial labourers.

Two different classes of bacteria are required to carry on the purification of sewage: those which flourish in the absence of air and are known as anaërobic bacteria, and those to which the presence of air is essential for the exercise of their functions, the latter being therefore called aërobic bacteria.

The work of the anaërobic labourers consists in breaking down the complex organic compounds present in sewage, whilst the completion of the process of purification is left to the aërobic varieties. In the ordinary course of nature both these processes are going on side by side, but it has been found advisable to separate these two different classes of bacteria as far as possible, and allot distinct premises to the anaërobic and aërobic varieties respectively engaged in the purification of sewage, for by so doing experience has shown that the work is not only more expeditiously, but also more efficiently, carried out.

Now the anaërobic bacteria are supplied along with the sewage, and the retention of their services offers practically no difficulty as long as an ample allowance of space and time is given them in which to carry on their labours. The aërobic bacteria, 
however, besides demanding space and time, insist upon their workshops being well ventilated, and if the supply of fresh air is in any way curtailed they stop work entirely. Hence the ventilation of the aërobic workshops becomes a matter of primary importance if the valuable services of these labourers are to be retained. To ensure a sufficient supply of air being provided, it has been found advisable to have two or more aërobic workshops or bacteria contact beds, and the sewage is passed from one on to a second, and so on, until the purification is complete. Under proper management the sewage should leave the works as an inodorous, almost pellucid liquid, incapable of putrefaction, which may be turned into rivers or other waterways without fear of rousing the wrath of local riparian authorities.

But whilst the commercial side of bacteriology, so to speak, has made such great strides, the purely scientific applications which have been made of the facts it has furnished have by no means lagged behind. Chemists, from Pasteur downwards, have made use repeatedly of special bacteria to perform delicate operations in the laboratory which other methods have either failed to accomplish or have performed in a clumsy and less expeditious manner.

There can be no doubt that, as our knowledge 
grows from day to day, we shall find more and more how much depends upon the work of individual bacteria, and how much importance attaches to the selection of just those varieties which are of value, and the banishment of those which are detrimental; and thus the many applications which bacteria already admit of render their easy access a matter of increasing consequence, enhancing the value of bacterial institutions such as already exist on the Continent.

But whilst the easy access of bacteria for experimental and scientific purposes is of great importance to the investigator, their indiscriminate distribution would equally be a source of uneasiness and danger to the community at large. Already sensational fiction has made considerable capital out of the pathogenic microbe, and with the winged aid of penny publications it does not take long for suggestions of such kinds to spread in society and assume practical shape, and whilst the administration of bacterial poisons offers comparatively but little difficulty, their identification would be a far greater problem for experts than that presented by particular chemical poisons. To cope with this danger to the public, specimens of disease-germs from these bacterial depôts may not be supplied to applicants unless the latter can prove to the satisfaction of the director that 
they are connected with responsible public institutions.

In recent times, indeed, one of the most remarkable practical uses to which bacteria have been put is that of poisoning-agents on a large scale, or in other words vermin exterminators; if this new rôle for bacteria becomes extended, as no doubt it will, the law for the sale of noxious drugs and preparations will also doubtless be amended to cover the distribution of bacterialpoisons.

It was in the year I889 that Professor Loeffler, while experimenting with mice in his laboratory at Greifswald, discovered a micro-organism which was extremely fatal to all kinds of mice. The happy idea occurred to the Professor that this lethal little microbe, which he christened Bacillus typhi murium, might be turned to excellent account in combating plagues of field mice in grain-fields, where the devastation committed by these voracious rodents had become in parts of Greece and Russia a serious source of loss to agriculturists. Experiments were accordingly made on a small scale to test the efficiency of this bacterial poisoner in destroying field mice, and so successful were the results that Loeffler confidently announced the possibility of keeping down these pests by distributing food material 
infected with these bacteria over fields which were invaded by them. The Greek Government took up the question, and Loeffler's method was applied with brilliant results; the disease was disseminated with extraordinary rapidity and severity, and the mice were readily destroyed.

It is highly satisfactory to find that the character of this mouse-bacillus has stood the test of time, for after a period of more than ten years most encouraging reports concerning its efficiency still continue to be received. In one of the latest of these, drawn up by the Director of the Experimental Agricultural Institute in Vienna, we read that in no less than seventy per cent. of the cases in which it was employed it was completely successful in its work of extermination, and it is interesting to note that in a considerable number of these instances it was the domestic mouse against which its energies were directed. The rat has, however, until recently escaped the hand of the bacterial executioner, but his knell has also now been sounded in the announcement that a rat-bacillus has been discovered.

Considering the undesirable notoriety which these rodents have of late obtained in connection with their undoubted culpability in the dissemination of plague, this discovery, if correct, should be warmly welcomed. That there is plenty of work 
awaiting such a micro-organism may be gathered from the fact that during the outbreak of plague in Sydney the crusade against rats which followed led to the slaughter in one year of over 100,000 .

The discoverer of this useful member of the microbial community is Tssatschenko, of the University of St. Petersburg, and in his memoir he states that, whilst highly virulent as regards rats, it is quite harmless to domestic animals of various kinds. Thus cats, dogs, fowls, and pigeons when fed with food infected with the bacillus suffered no ill effects whatever, whilst its administration in large quantities to farm stock, such as horses, oxen, pigs, sheep, geese, and ducks, was also without result; hence its distribution, according to its discoverer, offers no danger to other animals.

This idea of employing bacteria as executioners was not original, for Pasteur had already in I888 suggested to the Intercolonial Rabbit Commission in Australia that chicken-cholera microbes should be employed for destroying the rabbits, which then, as now, are such a source of difficulty and pecuniary loss to the country. No active measures appear to have been taken, however, to carry out this suggestion, one of the principal objections raised being the undesirability of introducing a disease which was at that 
time believed to be a stranger to the colony. Recently the idea has been revived by Mr. Pound, the Government bacteriologist at Brisbane, in consequence of his discovery that chicken-cholera, far from not existing in Australia, has infested poultry yards more or less extensively for several years past, although it has only lately been accurately diagnosed as such. This chicken-cholera microbe is particularly well suited for the work in question, inasmuch as, whilst extremely fatal to rabbits, it produces, like Loeffler's bacillus, no ill effect whatever on farm-stock of various kinds, and is perfectly harmless to man, so that its handling by the uninitiated is not attended with any personal danger.

This brings us to what may be designated the human side of bacteriology, i.e. its relation to disease and its prevention. In these important departments of life the services already rendered by this infant prodigy of science can as yet be only approximately appreciated. Anthrax, tuberculosis, cholera, typhoid, plague, influenza, tetanus, erysipelas, are only a few of the diseases the active agents of which bacteriology has revealed to us. Bacteriology has, however, not been content to merely identify particular micro-organisms with particular diseases, it has striven to devise means by which such diseases may be mastered, and one 
of the most glorious achievements of the past sixty years is the progress which has been made in the domain of preventive medicine.

The classical investigations of Pasteur on the attenuation of bacterial viruses such as those of chicken-cholera and anthrax, and his elaboration of a method of vaccination with these weakened viruses whereby the power of the disease over its victim is removed or modified, are too well known to require repetition here. The success which followed Pasteur's researches in this direction led him to undertake that great and difficult task, the prevention of rabies in the human subject - a task well-nigh superhuman in its demands, and one which only he could accomplish in whose life the pregnant words of a modern writer found expression- "il ne suffit pas de posséder une vérité, il faut que la vérité nous possède." The victory over this disease, which crowned a long life replete with brilliant achievements, has been universally recognised, and numerous institutes have arisen in all quarters of the globe for extending the benefits of this discovery for the relief of suffering humanity. These Pasteur or bacteriological institutes also furnish highly important centres where original research work of various kinds is carried on, and the stimulus which has thus been given to experimental science in the re- 
motest parts of the world cannot be overestimated.

Methods for the prevention of disease have, however, not been confined to the elaboration and employment of modified or weakened bacterial viruses; the subject has been still more recently approached from another and quite different side. This new departure we also originally owe to France, although its practical development has been worked out in Germany.

It was in I888 that two Frenchmen, Richet and Héricourt, communicated a memoir to the Comptes rendus of the Academy of Sciences, describing the curious results they had obtained with rabbits purposely infected with a disease microbe, the Staphylococcus pyosepticus. Some of the rabbits died after being inoculated with this micro-organism and some remained alive, and they proceed to point out how it was that such different results were obtained. Before the inoculations were made some of the animals received injections of blood taken from a dog, which a few months previously had been infected with this same microbe, but had recovered. The rabbits which received the dog's blood all survived the inoculations, whilst those which did not, succumbed in every case to the action of the Staphylococcus pyosepticus. So struck were the 
authors by these remarkable results that they repeated them, and their further investigations fully confirmed those originally obtained, proving that they were not "un fait exceptionnel."

Here we have the first steps in the direction of serum-therapy, that new treatment of disease which during the last few years has been so prominently before the public in the cure of diphtheria, tetanus, and other maladies, and for the development of which we owe so much to the labours of Behring, Roux, Kitasato, and other investigators.

The astounding fact that the blood of animals which have been trained to artificially withstand a particular disease becomes endowed with the power of protecting other animals from that disease is only in the earliest stages of its application. The results, however, which have already been accomplished are of so encouraging a character that the hope is justified that serumtherapy is destined to revolutionise the treatment of disease. One of the latest uses which has been made of this method of combating disease is the employment of serum for the cure of bubonic plague. During the recent outbreak of plague in India, Yersin, formerly a student and assistant at the Paris Pasteur Institute, was despatched to India to superintend the administration of this 
new remedy, and the serum he employed was that derived from horses which had been subjected to, and had recovered from, inoculations with the plague bacillus. The treatment of snake bites by means of curative serum will be dealt with in more detail later on; it only remains to cite it here as another instance of the success which is attending the new methods of protection against disease.

Another and highly ingenious application of serum has been brought forward by Pfeiffer, Gruber, Widal, and others. This is the so-called sero-diagnosis of disease, and has been employed already with success in the identification of typhoid fever as such. The method sounds simple in the extreme, and consists in taking a few drops of blood from a patient supposed to be suffering from typhoid fever and mixing them with a recent cultivation in broth of genuine typhoid bacilli. If the blood is derived from a typhoid-infected person, then the bacilli should exhibit a curious and characteristic appearance when examined under the microscope. Instead of moving about as individuals in various parts of the microscopic field, they should be seen gathering or clumping together in numerous small heaps, their movements the while becoming paralysed.

The State Board of Health of Massachusetts has recently taken up the official sero-diagnosis of 
typhoid fever, and issues in response to applications a simple outfit with instructions how to collect specimens of blood and a form which they request shall be returned filled in with all the details concerning the case under observation. Only a few drops of blood are required for the examination, and these before being despatched to the State Laboratory are collected on slips of paper and allowed to dry. If the addition of this suspected blood in the proportion of one to twenty to a young and vigorous culture of typhoid bacilli succeeds in paralysing their movements, producing the characteristic clumping together or agglutination of the bacilli, then the reaction is considered positive and the case one of typhoid fever.

That, however, some risk attends the placing of too implicit a reliance on this method of diagnosis alone is evident from the fact that a negative reaction, or in other words absence of all agglutinising phenomena, is sometimes associated with blood throughout what is beyond all question a well-defined case of typhoid fever, whilst in the first week of this disease the test is frequently negative in character. Rouget, who has made a very careful inquiry into the value to be attached to the sero-diagnosis of typhoid fever, states that he has found in a large number of examinations of blood derived from undoubted 


\section{IN THE VICTORIAN ERA}

typhoid patients the agglutination phenomena fail altogether; it is, therefore, not surprising that the sero-diagnosis of this disease is still the subject of much discussion and investigation.

An interesting example of how particular serums may be employed for the detection of particular poisons has been furnished by Dr. Calmette. In some districts of India the natives have an ugly custom of wreaking their vengeance on their enemies by poisoning their cattle, and to effect this both expeditiously and secretly they employ subtle poisons which they know can only be detected with great difficulty. Serpent venom is a favourite substance, whilst abrine, a highly toxic vegetable poison, is another. The method adopted for the application of this abrine is highly original, and consists in taking small bits of wood shaped like miniature clubs, so diminutive in size that they can be concealed in the hand. In the head of the club small holes are bored, and tiny pointed rodlets of a hard greyish substance are fitted into them. Armed with these crude instruments, the natives scratch the cattle in several places, and, although but little external sign of injury is to be seen, the rod-points penetrate the skin and are broken off, and the poison is left to work its lethal way through the animals' system. Mr. Hankin forwarded some of these broken-off rod-points to Dr. Calmette for 
the identification of their composition, and he diagnosed the material employed as abrine in the following original manner. He first introduced some of this rod material into animals, and found that their symptoms were suggestive of abrine poisoning. To confirm his suspicions, however, he took some more of this rod material, and, before inoculating it into animals, he mixed it with serum derived from animals which had been artificially rendered immune to abrine poison. Instead of the animals into which this mixture of serum and "rod material" had been introduced dying like the previous ones, they remained alive. Had the "rod material" consisted of some poison other than abrine, the abrine serum would not, according to Dr. Calmette, have negatived its action, and it has thus been indicated how protective serums may be successfully employed for the detection of poisons.

Foremost, however, among the beneficent reforms which have followed in the wake of bacteriology must be placed the antiseptic treatment of wounds, or Listerism, as it is now universally designated in recognition of its renowned champion, the former President of the Royal Society. "Lister comprend," in the words of Dr. Roux, "que les complications des plaies sont dues aux germes 
microbiens venus du dehors et il imagine les pansements antiseptiques. Avec l'antiseptie commencent les temps nouveaux de la chirurgie." It only remains to add that, with the modesty characteristic of a great man, its brilliant author delights in repeating how any good which he may have been permitted to do he owes entirely to the inspiration which he received from the labours of Louis Pasteur.

But if the Victorian era has been productive of so many important applications of bacteriology to commerce and medicine, this period has been also fraught with results of the highest moment in the progress of hygiene.

The terms of intimacy, so to speak, which we have been now able to establish with bacteria has enabled us to discover details of their life and habits which before were shrouded in mystery. Their distribution in air has led to renewed endeavours on the part of sanitary authorities to procure efficient ventilation in our hospitals and public institutions; dust has acquired a fresh horror since it has been shown how disease germs may be disseminated by its means; whilst the important part which flies and lice may play in the spread of epidemics has opened up a new field for research, and made us conscious of a fresh source of danger in our daily life. 
The general public, however, is hardly yet fully alive to the capacity for mischief possessed and exercised by the common house-fly. True, it is universally execrated and regarded as a tiresome attendant upon the summer months, but it is not usually considered in any more serious light. That however, the comparative indulgence with which this homely insect pest has been treated is decidedly misplaced and fraught with danger to health, the researches of numerous scientists have now conclusively proved.

As long ago as the year i 888 Professor Celli showed that the germs of consumption, anthrax, and typhoid fever could pass through the digestive organs of flies and reappear in the excreta of the latter not only alive but in full possession of their disease-producing powers. Dr. Sawtschenko made similar experiments with cholera germs. Healthy flies were placed under glass shades and fed with broth in which these micro-organisms were growing, and the latter were not only subsequently recovered from the digestive organs of the flies but also from their excreta in a living and virulent condition.

This is, however, not the only means whereby these insects can distribute deadly and other microbes, for it has been shown that in crawling over substances containing bacteria these may become attached to the feet of flies, and are in 
this manner transferred to other materials upon which they may alight, just as Pasteur showed many years earlier silkworms can communicate the fatal plague of pébrine by crawling over each other's bodies, carrying in their disease-laden feet the infection from one worm to another. During the recent outbreak of bubonic plague in the East the part played by flies in disseminating the virus has been repeatedly emphasised. Yersin was the first who called attention to the presence in large numbers of virulent plague bacilli within the bodies of flies which he collected in the vicinity of plague-stricken persons, and it was found that flies which had fed on plague-infected material and were then isolated lived for several days afterwards, during which time virulent plague bacilli were present in their bodies in immense numbers; thus were these insects converted into winged messengers of evil of the most repulsive type.

I am not aware whether any experiments on the vitality and transmissibility of diphtheria and consumption germs by means of flies have been made; but in view of the overwhelming evidence of the culpability of these insects in spreading plague, it is not unreasonable to presume a responsibility on their behalf in regard to other diseases ; indeed, in the report issued by the Army Medical Commissioners of the Spanish-American 
War, it is emphatically stated that flies played an important part in the dissemination of typhoid fever.

There is no question as to the capability of certain micro-organisms to reside for considerable periods of time within the bodies of flies, and during this sojourn to abate no jot of their virulence. Indeed, it has been shown that the bodies of these insects may constitute incubators of a most successful type, for some varieties of bacteria grow luxuriantly and multiply abundantly within them.

In the hot days of summer, when flies abound, it would be well to banish these insects, as far as lies in our power, not only from our sick-rooms in particular, but from our general surroundings. The catholic taste of flies for garbage of all kinds is too well known to require entering into, but the consequences which may follow from their visits to dustbins and centres of disease, and then alighting upon our food or persons, has received too little attention in the past.

In regard to the subject of insects as disease disseminators, it may be mentioned that $\mathrm{Mr}$. Hankin, when studying plague conditions in India, expressed his belief that ants in Bombay also assisted in spreading the scourge, for he found that when he inoculated mice with the excreta of 


\section{IN THE VICTORIAN ERA}

ants, such insects having previously fed on plaguestricken rats, the mice succumbed to plague in a few hours. Fleas have also been conclusively proved to be carriers of plague germs.

There is no doubt that the revelations of hygienic science have aroused the vigilance and zeal of public authorities in various new directions to try and cope with the spread of zymotic disease.

In no direction, perhaps, is the fruit of this energy so apparent as in the increasing supervision which it has incited over two of the greatest menaces to public health which hang over society -i.e. our water and dairy supplies. Now that it has been proven beyond doubt that the germs of consumption, typhoid fever, and cholera can be and are distributed through the consumption of contaminated milk or water, not to mention other diseases such as diphtheria and scarlet fever, an ever-increasing demand is being made that these all-important articles of diet shall be protected from pollution, and that public authorities shall be made responsible for their distribution in a pure and wholesome condition.

It is, however, undoubtedly in the matter of water that the greatest service has been rendered by bacteriology to sanitary science, and for the important advance in this department we are 
indebted to the beautifully simple and ingenious methods devised by Robert Koch.

Not yet twenty years have passed since the new bacterial examination of water was introduced and systematically employed, and the use which has been made of the opportunities thus opened up of investigating water problems on an entirely new basis is shown by the voluminous dimensions which the literature on this one branch of bacteriology alone has reached. Considerably upwards of two hundred different water bacteria have been isolated, studied, and their distinctive characters chronicled. The behaviour of typhoid, cholera, and other disease-producing microbes in waters of various kinds has been made the subject of exhaustive experiments; the purification power of time-honoured processes in operation at waterworks and elsewhere has been for the first time accurately estimated. Water engineers have through these bacteriological researches been provided with a code of conduct drawn up by the light of erudite scientific inquiries, which has now rendered possible the removal of the process of water purification from the rule of empiricism guided by tradition, and to raise it to the level of an intelligent and scientific undertaking.

The above short sketch may serve to convey some idea of the rise and phenomenal develop- 
ment of bacteriology during the past sixty years. To record, even in outline, the individual triumphs of the various branches of this science would require volumes, whilst the astounding mass of work already accumulated by its devotees is but the earnest, the guarantee of yet greater achievements in the future.

The progress which has been made in this brief period of time must not necessarily be expected to continue at this rapid rate; it may be that generations to come have yet the hardest and the longest tasks to accomplish; for in science, as in other walks of life, it is, as a rule, the easiest problems which are first disposed of, and the farther we advance the more complicated, the more intricate become the questions to be attacked, the difficulties to be overcome.

The late Queen's reign has bestowed a splendid legacy of bacteriological discoveries upon those who, in the future as in the present, must inevitably follow in the footsteps of those great and brilliant leaders of bacteriological science belonging to this auspicious era, Louis Pasteur and Robert Koch. 


\section{WHA'T WE BREATHE}

EEW people realise that, with the advent of autumn, the great majority of the swarms of bacteria which have been circulating in the air during the hot summer months take their leave of us and disappear.

Practically, however, we are all conscious of this fact, for we know what greater difficulties attend the keeping of food sweet and wholesome in the summer than are met with in the winter; bacteria, not unlike some other armies of occupation, securing a footing rather by their numbers at this season of the year, than by virtue of the superior strategy or, in other words, special attributes of their units. Bacterial operations are, however, distinctly favoured by the accident of temperature, the warmth of the summer encouraging their vitality and multiplication.

When Pasteur first announced his conviction that the familiar phenomena of putrefaction and decay were due to minute living particles present in our surroundings, his sceptical critics sought to 
ridicule his conclusions by declaring that, were this the case, the air must of necessity be so heavily laden with living forms that we should be surrounded by a thick fog-"dense comme du fer." We do not now, forty years later, require to recite the exquisitely simple experiments which, whilst sufficiently establishing his theories, served to effectually suppress those of his opponents.

Since Pasteur's pioneering work was carried out, a vast number of investigations have been made in all parts of the world by scientists of almost every nationality on the subject of the distribution of bacteria in air, and not only on their distribution, but on their functions or the place they occupy in the economy of nature. With our increased knowledge concerning their distribution has come our ability to differentiate between individuals, and to adequately assess the value and importance of their work from various points of view.

In the bacterial treatment of sewage we have not only one of the latest, but perhaps also one of the most successful examples of that system of division of labour, or specialisation of energy, which forms such a characteristic feature of work of all kinds at the present time Other familiar instances of the applications of individual and special bacterial labourers to the solution of in- 
dustrial problems are to be found in the conduct of commercial undertakings of such national magnitude and importance as brewing and agriculture. But it is not with these beneficent or great industrial classes of bacteria that we are now more immediately concerned, but rather with the malevolent varieties, or the so-called "submerged tenth," for which no labour colony has at present been created to direct their energies into useful and profitable channels.

We know that as regards mere numbers the bacteria in air may vary from 0 to millions in a couple of gallons, these extremes being dependent upon the surrounding conditions or relative purity of the atmosphere.

Out at sea, beyond the reach of land breezes, it is no uncommon thing to find none whatever; on mountains and even hills of humble elevation the paucity of bacteria is very marked if there are no abnormal or untoward circumstances contributing to their distribution. In illustration of this the recent investigations of the air on the summit of Mont Blanc by M. Jean Binot are of especial interest, inasmuch as the altitude at which they were carried out is the highest at which the search after bacteria has so far been pursued. This intrepid investigator spent no less than five days in the observatory, which is situated on the 
top of the mountain. As was to be anticipated, frequently no bacteria at all were found, and it was only when such comparatively large volumes of air as one thousand litres (about 200 gallons) were explored that microbes in numbers varying from four to eleven were discovered. The air of the country is far freer from microbial life than that of cities; whilst open spaces, such as those afforded by the London parks, are paradises of purity compared with the streets with their attendant bacterial slums.

That it is no exaggeration to describe streets from the bacterial point of view as slums is to be gathered from the fact that much less than a thimbleful of that dust which is associated with the blustering days of March and the scorching pavements of summer may contain from nine hundred to one hundred and sixty millions of bacteria. But investigators have not been content to merely quantitatively examine street dust; in addition to estimating the numerical strength of these bacterial dust-battalions, the individual characteristics of their units have been exhaustively studied, and the capacity for work, beneficent or otherwise, possessed by them has been carefully recorded. The qualitative discrimination of the bacteria present in dust has resulted in the discovery of, amongst other disease germs, the 
consumption bacillus, the lock-jaw or tetanus bacillus, bacteria associated with diphtheria, typhoid fever, pulmonary affections, and various septic processes. Such is the appetising menu which dust furnishes for our delectation.

There can be no doubt, therefore, that dust forms a very important distributing agent for micro-organisms, dust particles, aided by the wind, being to bacteria what the modern motor-car, with its benzine or electric current, is to the ambitious itinerant of the present day. Attached to dust, bacteria get transmitted with the greatest facility from place to place, and hence the significance of their presence in dust.

Mention has been made of the fact that the germs of typhoid fever have been discovered in dust, and the belief in the possibility of this disease being spread by dust is gaining ground.

An interesting case in point is afforded by an outbreak of typhoid fever which occurred in Athens a few years ago, and in which the startingpoint or nucleus was discovered to be a group of labourers who were engaged upon excavating the soil in a street through which a sewer had once been taken. The epidemic subsequently spread to those districts of the city swept by the prevailing wind, which passed over the place where the soil had been turned up and exposed. 
M. Bambas, who brought his observations before the International Congress of Hygiene at BudaPesth, was convinced from the inquiries he made that this outbreak of typhoid was due to the disturbance of the soil and the dissemination by means of the wind of typhoid-dust-particles to certain parts of the city.

That this hypothesis is by no means without experimental justification is shown by the properties possessed by the typhoid bacillus in regard to its vitality in soil which have been discovered. Thus numerous investigators have studied the important question of the behaviour of this microorganism in soil, and have found that it can exist over periods extending from three to twelve or more months in the ground. This property of the typhoid bacillus may possibly explain the appearance over and over again of typhoid fever in particular localities, suggesting that the bacteria had become indigenous in the soil.

Dr. Mewius, of Heligoland, describes an epidemic of typhoid fever in the island, concerning which he made a most searching and elaborate inquiry. It appears that a case of typhoid occurred and was concealed from the medical authorities, so that no steps for disinfection could be taken in the first instance; and, following the primitive custom which prevails on the island, the dejecta 
was thrown over and upon the cliffs, this being the usual method of disposing of sewage. Ample opportunity was thus given for its desiccation and subsequent distribution as dust. That this typhoidal matter did subsequently become pulverised and spread the infection Dr. Mewius has no doubt, the germs having been conveyed to the open rain-water cisterns which constitute the water-supply of the majority of the inhabitants. His theory is again supported by the coincidence between the prevailing direction of the wind and the quarter where the outbreak occurred.

That diphtheria germs can remain for a long time in a living and, what is more, virulent condition in dust has been clearly demonstrated by Germano, amongst other investigators, this organism being specially endowed with the capacity for resisting the, to other microbes, lethal effect of getting dried up.

Bacteria, however, survive this desiccation process much better when they are herded together in large numbers than when they have to face such untoward conditions as isolated individuals. This has been well illustrated in the case of diphtheria bacilli, and the difference in their powers of endurance under these respective conditions is very striking. Thus when a few only were exposed to a very dry atmosphere on 
silken threads they disappeared after eight days; but when somewhat larger numbers were taken they contrived to exist for eighteen days, whilst when great multitudes of them were herded together even one hundred and forty days' starvation in these desert-like surroundings could not entirely stamp out their vitality.

This dangerous property possessed by the germs of diphtheria should, if possible, increase the vigilance with which the outbreaks of this disease are watched and dealt with. Abel cites an instance in which a wooden toy in the sickroom of a child suffering from diphtheria was found six months later to have virulent diphtheria bacilli upon it.

This reminds me of a case in which tetanus or lock-jaw ensued from the use of some old cobwebs in stopping the bleeding of a cut. The wound was a perfectly clean one, and nothing need have resulted from this obedience to a superstitious prejudice had not the cobwebs unfortunately arrested some tetanus germs, and these getting access to the wound set up the typical symptoms of lock-jaw. That this implication of the cobweb was no idle accusation was subsequently proved by portions of the same web, on being inoculated into animals, inducing in the latter well-defined symptoms of tetanus. 
That cobwebs readily catch dust is familiar to everyone who has the mortification of seeing them adorn ceilings and corners; that they also arrest bacteria follows as a natural consequence of the presence of dust, and hence these delicate filaments may become veritable bacterial storehouses, more especially as it is usually in the dark and remote corners that they best succeed in eluding the vigilance of the domestic eye, and are thus also out of reach of the lethal action of sunbeams; and hence their unwelcome lodgers may manage to maintain a very comfortable existence over long periods of time.

That the bacillus of consumption should have been very frequently found in dust by different investigators is hardly surprising when it is realised that the sputum of phthisical persons may contain the tubercle germ in large numbers, and that until recently no efforts have been made in this country to suppress that highly objectionable and most reprehensible practice of indiscriminate expectoration. Considering that the certified deaths from phthisis in I90I, in England and Wales only, reached the enormous total of 42,408 , and bearing in mind the hardy character of the bacillus tuberculosis when present in sputum, it having been found alive in the latter even when kept in a dry condition after ten months, it is 
not too much to demand that vigorous measures should be taken by the legislature to cope with what is now regarded as one of the most fruitful means of spreading consumption. We know that in some of the states of America public opinion has permitted the enactment of laws penalising this practice. Local rules to the same effect exist in our Australian colonies. On the Continent the trend of public opinion is evident by the prohibition found in the railway carriages and the notices to that effect conspicuously posted in public places. In this country public opinion moves so slowly that we are not yet ripe for any such strong step, and so far one of the few attempts at official activity in this respect is to be found in a circular issued by the Local Government Board of Ireland to the various local authorities stating that "tuberculous sputum is the main agent for the conveyance of the virus of tuberculosis from man to man, and that indiscriminate spitting should therefore be suppressed." The public exhibition of notices calling attention to the danger accruing from expectoration in public resorts is, as already pointed out, one means of educating the people, and it has been stated that such a notice is posted in every beerhouse in Manchester. The question has also been raised of the inspection of beerhouses and the 


\section{4}

suggestion made that licences should be withdrawn in the case of those holders who did not wash the floors of their public rooms and keep them in a sanitary state. At the present time, in this country, it is perhaps more to the private conscience of the individual and the pressure of public opinion than to penal enactments that we must look for effective reform in this direction, for the objection of the English to official sanitary control is deeply rooted. It is to be hoped, however, that with the spread and popularisation of the knowledge acquired through the arduous labours of so many scientific authorities, it may come to be regarded as a matter for both public and private morality that every step should be taken which lies in the power of each member of society to minimise the opportunities for the spread of a disease which by its very familiarity we have until the last few years accepted as incurable and the ravages of which as inevitable.*

* Since the above was written, the first international conference of the Central Committee for the Prevention of Consumption has been held in Berlin. The official report of the English National Association for the Prevention of Tuberculosis was presented to the Congress, and the encouraging announcement was made that the Corporations of Glasgow, Manchester, and Liverpool had made expectoration in tramcars a punishable offence; and that the Glamorganshire County Council had passed a bye-law providing as penalty for expectoration in public buildings a fine of $£ 5$, which enactment had been sanctioned by the Secretary for the Home Department. 


\section{WHAT WE BREATHE}

Now that we are considering the status of street dust in bacterial circles, it will not perhaps be out of place to inquire into the character of another waste product of streets, i.e. the discarded ends of cigars and cigarettes. That what is carelessly tossed away on the one hand may be as carefully collected on the other is well known, as is also the fact that such material may subsequently be raised once more to the dignity of a marketable commodity. Under these circumstances, it is of hygienic interest and importance to ascertain whether disease germs, should they have obtained access to this tobacco refuse, are in a virulent or quiescent condition.

Some experiments to decide this question in connection with the tubercle bacillus have been recently carried out in Padua by Dr. Peserico, who, whilst extending our knowledge on the subject of bacteria and tobacco, has also confirmed the earlier results obtained by Kerez.

Portions of cigar-stumps smoked by phthisical persons in whose saliva the tubercle bacillus was known to be abundantly present were inoculated into guinea-pigs, with the result that fifty per cent. of the animals thus treated succumbed to tuberculosis. Thus neither the fumes nor juice of the tobacco had destroyed the consumption bacillus. In these experiments the cigar ends were used 
directly they were discarded, in another series of investigations they were collected and kept in a dry place for from fifteen to twenty days before being tested; but even storage for this length of time did not prevent the animals inoculated with them from contracting tuberculosis. In another series of experiments Dr. Peserico kept the infected cigar-ends in damp surroundings, and it was satisfactory to find that under these conditions the tubercle bacillus at the end of ten days was entirely deprived of its virulence. Encouraged by these results, inoculations were made with cigar-ends which had been left in the open and exposed to normal atmospheric conditions, which included falls of rain and snow, and in this case also no symptoms of tuberculosis followed their introduction into the guinea-pigs. These experiments show that the tubercle bacillus is prejudicially affected by contact with tobacco when the latter is kept in a moist condition, but that in a dry condition the properties in tobacco inimical to its vitality are not liberated and the bacillus can retain its virulent properties for a period of over twenty days.

In view of the importance of this discovery on the destruction of the toxic character of the tubercle bacillus by contact with moist tobacco, further experiments were made in which emulsions 
of tobacco were infected with tuberculous sputum. It was found that the bacilli steadily declined in virulence as the length of time they were kept in the emulsion was prolonged. Thus whereas after a few hours they were still armed with all their virulent properties, after three days, out of the four animals inoculated with the emulsion three succumbed to tuberculosis, after five days two out of four succumbed, whilst after eight days only one animal out of the four was infected, and after a period of ten days' immersion in the tobacco emulsion the tubercle bacillus failed to kill a single animal.

Cigar-and cigarette-ends were collected from the streets and cafés of Padua by Peserico, but in spite of consumption being stated to be very prevalent in this city, in no single case could the presence of the tubercle bacillus be discovered, although, as in the other investigations, the surest method for its detection, i.e. animal inoculations, was employed.

Brief reference may be made also to the experiments conducted to ascertain if cigars and cigarettes, as sold, contain the tubercle bacillus. The more interest attaches to this investigation because it is well known that the operators employed in tobacco factories are, as a rule, an unhealthy class, diseases of the respiratory organs, and especially tuberculosis, being very prevalent 
amongst them. A German official report on this subject states that the average duration of life of such factory hands only reaches thirty-eight years. Doubtless the lightness of the occupation encourages many to seek employment in these factories whose state of health would debar them from obtaining work under more trying circumstances. Some of the conditions under which cigars and cigarettes are made, such as the workers using their saliva to facilitate the rolling of them and fixing of the leaves, and the testing of the "drawing" properties of a cigar by placing it in the mouth, with the facilities offered for the dissemination of dried tuberculous sputum as dust, contribute to make it highly probable that tobacco as it leaves the factory may contain the germs of consumption.

Before leaving the subject of tobacco and disease germs it may be of interest to inquire what justification in fact there is for the practice adopted by anxious mothers, when travelling in times of epidemics of zymotic disease, of thrusting themselves and their children into the sanctum of the other sex-the smoking compartment of a railway carriage. I have frequently seen this done, despite the voluble protests of its legitimate occupants. Tassinari has made some very interesting experiments on the effect of tobacco smoke on the vitality 
of various descriptions of disease germs. He constructed an apparatus in which he suspended pieces of linen soaked in broth infected with the particular micro-organism to be tested. Tobacco smoke was then admitted, and the microbes were retained in this stifling atmosphere for half an hour. In these surroundings cholera and typhoid germs were destroyed, and other bacteria, such as the anthrax bacillus and the pneumonia bacillus, were so prejudicially affected, that when subsequently transferred to their normal surroundings it was only with extreme difficulty that they could be revived. When, however, the tobacco smoke was made to pass through water before reaching the bacteria, its pernicious influence was entirely removed, and the latter suffered no detriment. Hence the practice, so often seen in the East, of passing tobacco smoke through rose or other perfumed water before inhaling it, whilst doubtless rendering it less noxious to the smoker, deprives the exhaled tobacco fumes of all their bactericidal or disinfecting properties.

To return, however, after this somewhat lengthy digression, to the question of dust and its bacterial properties, we have learnt enough to enable us to realise that the movement for the migration of the working-classes from crowded streets to rural districts, in which Mr. George Cadbury has played so practical and important a part in the creation of 
his model village, with its gardens and open spaces, some five miles from the city of Birmingham, is, if only bacterially considered, a very real barrier against the dissemination of disease, for the denser the population, the greater will be the crowd of bacteria, and the greater the chance of pathogenic varieties being present amongst them. Again, we know that sunshine is one of the most potent germicides with which nature has provided us; ${ }^{*}$ and it requires no effort of the imagination to realise how, in the gloomy back courts and crowded tenements of our great smoke-laden cities, bacteria succeed in obtaining a firm hold on their surroundings, and, in the shape of spores, attaining an undesirable and hoary old age, in which they are in some cases almost indestructible. Fräulein Dr. E. Concornotti has shown that this is no figment of fancy only, for she has recently made a special and very elaborate study of the distribution of pathogenic or disease bacteria in air, searching for them in the most varied surroundings, such as prisons, schools, casual wards, etc., with the result that, out of forty-six experiments in which the character of the bacteria found was tested by inoculation into animals, thirtytwo yielded organisms which were pathogenic. Dr. Concornotti concludes her valuable memoir by stating that her investigations proved con-

* See "Sunshine and Life." 
clusively that the dirtier or more slumlike the surroundings, the greater was the frequency with which she found bacteria associated with disease in the air.

Messrs. Valenti and Terrari-Lelli have quite recently been able fully to endorse these statements in the results they have obtained in their systematic study of the bacterial contents of the air in the city of Modena. In their report they state that the narrower and more crowded the streets, the greater was the number of bacteria present in the air, and the more frequently did they meet with varieties associated with septic disease.

Numerous detailed investigations have also been made of the bacterial contents of the dust in hospitals. That cases of infection arising within hospital precincts are of no uncommon occurrence may be gathered from the observations made by Lutand and Hogg, who report no fewer than 2,294 such cases having arisen in the space of six years in certain Paris hospitals, whilst Solowjew records $I, 880$ cases as occurring in the space of four and a half months in the St. Petersburg city hospital. Solowjew made a special study of the bacterial contents of dust collected in hospitals, and states that $4 \mathrm{I}^{\circ} 8$ per cent. of the samples examined contained disease germs. The 
degree of infection possessed by dust in such surroundings must, of course, depend upon the degree of cleanliness which characterises the management of any particular institution; and such investigations as the above can only help to emphasise the immense importance of common cleanliness and the reasonableness of taking every precaution possible in the disinfection of utensils, etc.

Some years ago Messrs. Carnelley, Haldane, and Anderson carried out an elaborate series of investigations on the air of dwelling-houses in some of the poorest parts of Dundee. The samples were taken during the night, between I 2.30 a.m. and 4.30 a.m., and in their report the authors state that the one-roomed tenements were mostly those of the very poor; "sometimes as many as six or even eight persons occupied the one bed," whilst in other cases there was no bed at all. As regards the number of bacteria present in the air in these one-roomed houses, an average of several examinations amounted to sixty per quart; in two-roomed houses it was reduced to forty-six, and in houses of four rooms and upwards only nine micro-organisms in the same volume of air were discovered.

On comparing the mortality statistics with the composition of the air of dwelling-houses of different dimensions, the authors arrive at the 
following conclusions: "That, as we pass from four-roomed to three-, two-, and one-roomed houses, not only does the air become more and more impure, as indicated by the increase in the carbonic acid and organic matter, and more especially of the micro-organisms, but there is a corresponding and similar increase in the deathrate, together with a marked lowering of the mean age at death."*

Mention may also here be made of the investigations made by these gentlemen on the air of Board schools, which showed that in those buildings where mechanical ventilation was used the carbonic acid gas was three-fifths, the organic matter one-seventh, and the micro-organisms less than one-ninth of what was found in schools ventilated by the ordinary methods. In commenting upon this series of investigations, the authors write: "When we come to consider that

* It is, of course, obvious that other circumstances besides overcrowding have to be reckoned with in considering these statistics. In the one-roomed houses the wages earned by the occupants must have been small, and the amount available for even the bare necessaries of life very limited, that, in fact, they were to be reckoned amongst the class defined by Mr. Rowntree as living in "primary poverty," whose earnings are insufficient to keep the body in a properly nourished condition. Mr. Rowntree has shown by statistics that the height, weight, and general condition of the poor are very much below those of the well-to-do labouring classes. 


\section{BACTERIA IN DAILY LIFE}

the children who attend average Board schools for six hours a day are during that time subjected to an atmosphere containing on an average nearly nineteen volumes of carbonic acid per 10,000, and a very large proportion of organic matter, and no less than 155 micro-organisms at least per quart, we need not be surprised at the unhealthy appearance of very many of the children. It must also be borne in mind that many of them are exposed for nine hours more to an atmosphere which is about five times as impure as that of an ordinary bedroom in a middle-class house. They are thus breathing for at least fifteen hours out of the twenty-four a highly impure atmosphere. The effects of this are often intensified, as is well known, by insufficient food and clothing, both of which must render them less capable of resisting the impure air. The fact that these schools become, after a time, habitually infected by bacteria renders it probable that they also become "permanent foci of infection for various diseases, and particularly, perhaps, for tubercular disease in its various forms."

Further practical evidence of the manner in which the general death-rate for certain diseases is influenced by the conditions under which the poor are housed is afforded by statistics which have been collected at Glasgow. In the case of zymotic 
diseases, whereas the death-rate in tenements consisting of one or two rooms was 4.78 per 1,000 , it fell to 2.46 in those of three or four rooms, and to $\mathrm{I} \cdot \mathrm{I} 4$ per I,O0O in those of five rooms and upwards. Again, in the case of acute diseases of the lungs, the death-rate was as high as 9.85 in the smallest tenements, and but 3.28 in the largest.

Of great interest are the certified mortality statistics of phthisis in the British Army in the period $1830-46$ and $1859-66$ respectively; in the former it was 7.86 per 1,000 , whilst in the latter period it had fallen to $3 \cdot I$, this important difference being coincident with an increased cubic space per head in the barracks.

Such facts as these, if only fully realised, should surely serve to stimulate municipal and other local authorities to provide decent and wholesome accommodation for the poor. It has been recently estimated that in London the total number of persons living in tenements of one to four rooms is $2,333, \mathrm{I} 52$, and of these nearly half a million live the life of the one-room tenement of three to a room and upwards. In the stirring words of $\mathrm{Mr}$. John Burns, M.P.: "At least a million of people who live thus on wages that barely sustain decent life, are but prisoners of poverty, whose lot in life is but a funeral procession from the cradle to the grave ... for these, as soon as practicable, better 
homes should be provided at once in the interest of physique, of morals, of industrial efficiency, and municipal health."

Yet, despite all these facts and the overwhelming evidence which has been collected on the dire results which follow in the wake of overcrowding and insanitary dwellings, we find a prominent magistrate in one of our great industrial cities publicly expressing himself as follows at a municipal banquet: "The Town Council sometimes attempted too much. For instance, they had been far too anxious to get quit of the slums. Now slums, in his opinion, were one of the necessities of all large towns, and it was impossible in the present state of civilisation to dispense with slums unless they could take the people living in them, who were not fit to live anywhere else, and drown them wholesale, as would have been done in the time of the French Revolution."

We have seen how bacteria may be distributed by dust, how they may linger in crowded tenements and badly ventilated buildings, that insanitary surroundings provide, in fact, for the scientist a well-stocked bacterial covert, where he may with ease bag his thousands of germs of various descriptions. The fact already referred to, that the bacteria of consumption may be released in the sputum of phthisical persons, has 
perhaps already suggested the possibility of other bacteria being likewise discharged into the surrounding air, but it is no doubt difficult to realise that the utterance of even a few words may liberate a variety of bacteria, the mischievous or harmless character of which depends upon the condition of the speaker's health. But even the health of a speaker if satisfactory is not necessarily a safeguard against his dissemination of disease germs, for it is well known that the mouth secretions of healthy people may frequently contain the staphylococcus pyogenes aureus, and also, though less frequently, the diplococcus lanceolatus, both virulent microbes; whilst that diphtheria bacilli may be present in the mouths of people who are not suffering from the disease has been demonstrated repeatedly. What a capacity, then, for spreading evil does the public orator possess! It makes one tremble to think of the aerrial condition of the House of Commons when a big debate is on, for it has been found that the sharper the enunciation of the consonants, and the louder the voice, the larger is the number of organisms discharged and the farther they reach!

If this danger attends the speaking of healthy people, what must be the risk accompanying the listening to speeches from persons suffering from consumption, influenza, or any other disease which 
specially affects the air passages! What applies to speaking applies to a still greater degree to the act of coughing or sneezing.

To Schäffer we owe the discovery that leprosy bacilli may be disseminated in immense numbers by the coughing of leprosy patients, whilst it has been estimated that a tuberculous invalid may discharge a billion tubercle bacilli in the space of twenty-four hours, whilst the dried sputum of consumptive persons has actually engendered tuberculous symptoms in the lungs of animals which were made to inhale it. Plague bacilli have been found in masses in the mouths of plague patients, and were found, moreover, before any symptoms of the disease had declared themselves; and the sputum of infected persons is regarded by some authorities as one of the most important vehicles by which plague is spread. The culpability of air in the dissemination of tuberculosis amongst animals has been made the subject of some very exhaustive and valuable investigations by Kasselmann. In as many as $7 \mathrm{I}$ per cent. of bovine tuberculosis cases the respiratory organs, Kasselmann found, were the seat of the disease. The undoubted contamination of the air which takes place in the surroundings of tuberculous animals is not, however, due to the bacilli being exhaled by such cattle in the mere process of 
respiration, for it has been repeatedly found by various investigators that the air expired by infected animals is free from the dreaded tubercle bacteria. As in man, so in animals-it is by the act of coughing that tuberculous secretions are discharged through the mouth and nasal passages, some of which in the form of spray may enable the bacilli to remain suspended in the air for periods of five hours or more, whilst other portions of such secretions fall on the ground or in the feeding troughs, and later on, as dust, may again relentlessly claim their toll of victims.

In other cases of tuberculosis the excrementitious matter becomes, of course, a fertile source of infection to the surroundings. The dire results which may follow the introduction of a single tuberculous animal into a healthy stall of cows may be realised from the fact that in one instance a whole herd of twenty-eight animals became in the course of one year infected in consequence of the admission of one diseased cow, the cow-house having previously had a perfectly clean bill of health in this respect.

On the Continent the risk of wholesale infection by such means is greater than in this country; for abroad the animals are to a much greater extent stall-fed, and kept shut up both winter and summer. A case is mentioned by the well-known veterinary authority, M. Nocard, of a whole stall 
of animals becoming infected through the cowman who tended them being consumptive. $\mathrm{He}$ slept in a loft over the cows, and his tuberculous sputum in the form of dust was conveyed to the stalls beneath and so spread the infection.

It has been stated on high authority that domestic pets such as parrots may contract consumption from their masters, and that no less than thirty-six per cent. of these birds brought to the veterinary college in Berlin are found to be suffering from tuberculosis.

In that much-dreaded South African cattle disease, rinderpest, the infection, contrary to what is found in the case of tuberculous animals, is principally spread by the materies morbi being liberated in the air expired by afflicted cattle, the contagious area surrounding an infected animal extending to as much as a hundred yards and more. Again, as regards pleuro-pneumonia in cattle, the contagion is given off in the air expired, and owing to the length of time which elapses before the lung becomes completely healed and healthy, even after a period of from six to nine months, the expired air may still prove a source of infection.

In an official report on the open-air treatment of consumption in Germany a case is mentioned in which the patient, a farmer by occupation, had 
contracted the disease from some tuberculous cattle which he had on his farm. The writer goes on to say, "This case is worthy of special attention, inasmuch as it indicates that in addition to the danger of contracting the disease from the use of milk or meat derived from tuberculous animals, the tending of such animals may serve to convey the infection to man possibly much more frequently than has hitherto been supposed."

In addition to the above instances of the responsible part played by air in the dissemination of consumption many others might be cited, but perhaps the most striking is that in which a scientific assistant of Tappeiner contracted the disease, and succumbed to it, in the course of some experiments which were being made to ascertain whether consumption could be communicated to animals by spraying them with an emulsion of the sputum of consumptive patients.

It is of historical interest to note that these experiments were being conducted by Tappeiner three years before Robert Koch made the now classical announcement to the scientific world that he had succeeded in identifying, isolating, and in cultivating outside the human body the specific cause of consumption in the shape of the now familiar bacillus tuberculosis. The opinion expressed by Koch at the Congress on Tuberculosis 
recently held in London, that human and bovine tuberculosis are distinct diseases, is still the subject of contention and experimental investigation. Even if the opinion of this great authority is correct, and in this connection it is interesting to note that already in 1896 this opinion was brought forward by Smith in the Medical Record at a time when Koch was maintaining the identity of human and bovine tuberculosis-granted that Koch is correct, it should not, as so many fear, cause any relaxation in the efforts which have been at last made to safeguard our dairy produce by reasonable hygienic precautions ; for even if tuberculosis is not transmissible from the cow to man, we know that in the hygienic supervision of our dairy industry we place a great barrier between us and the bacillus tuberculosis and those numerous other disease germs which can and do gain access to milk from the personnel of a dairy and so spread infection. With the alarming prevalence of consumption is it not justifiable to regard as certain that a definite proportion of the people engaged in milking, for example, are consumptive? And knowing, as we now do, how such persons can give off the germs of the disease in the simple act of speaking, the contamination of our milk with human tubercle bacilli must be regarded almost as a certainty. Would it not be reasonable that a code of simple 
precautions to be taken, coupled with a few of the more cogent facts concerning consumption and its distribution, should be drawn up and circulated amongst all engaged in the dairy industry? The National Health Society has done much for the prevention of disease by disseminating, through leaflets and lectures, simple facts concerning health and its preservation; might it not make itself the vehicle for the transmission of some such code which, whilst instructing, should impress upon its readers the responsibility which rests upon each and every individual member of society, by his or her own personal efforts, to assist in the great task of combating disease?

A fact which urgently needs the widest recognition is the possible dissemination of disease germs by individuals not themselves suffering from the disease in question, but who have resided in the immediate surroundings of infected persons.

Dr. Koch was the first to call attention to this danger when he discovered, during the Hamburg cholera epidemic, that perfectly healthy persons were infected with cholera vibrios, and were the unconscious means of spreading the disease. Still more recently it has been found that true typhoid germs may similarly be present in persons not suffering from typhoid fever but sharing the same living-rooms. 
Huxley has said "science is nothing but trained and organised common sense," and it is in this spirit that we must endeavour to make use of the discoveries which have been made in the prevention of disease, in which the science of bacteriology has played so great and important a part. 


\section{SUNSHINE AND LIFE}

T $\mathrm{T}$ was nearly a century ago that a German 1 physician incidentally wrote, "Our houses, hospitals, and infirmaries will, without doubt, some day be like hot-houses, so arranged that the light, even that of the moon and stars, is permitted to penetrate without let or hindrance." This was spoken long before the world of microorganisms had been discovered, but curiously has found an echo in the writings of a distinguished bacteriological chemist in recent years. "Laissons donc entrer largement partout l'air et le soleil," writes M. Duclaux; "c'est là une maxime bien ancienne, mais si les mots sont vieux l'idée qu'ils revêtent est nouvelle." The interpretation of this ancient maxim is indeed very modern, and we must turn to the investigations made within the past few years to learn with what justification M. Duclaux thus expresses himself, for it is only comparatively recently that we have learnt the novel fact that sunshine, whilst essential to green plant life, is by no means indispensable to the most 
primitive forms of vegetable existence with which we are acquainted, i.e. bacteria. In fact, we have found out that if we wish to keep our microbial nursery in a healthy, flourishing condition, we must carefully banish all sources of light from our cultivations, and that a dark cupboard is one of the essential requisites of a bacteriological laboratory.

That light had a deleterious effect upon microorganisms was first discovered in this country by Messrs. Downes and Blunt, and their investigations led Professor Tyndall to carry out some experiments on the Alps, in which he showed that flasks containing nutritive solutions and infected with bacteria when exposed in the sunshine for twentyfour hours remained unaltered, whilst similar vessels kept in the shade became turbid, showing that in these the growth of bacteria had not been arrested. In these experiments mixtures of micro-organisms were employed, and the interest of the French investigations which followed lies in the use of particular microbes-notably the anthrax bacillus and its spores, * Roux demonstrating very conclusively that the bacillar form was far more sensitive

* In the interior of some bacilli there appears a round or oval body, having a very bright and shining lustre, which is known as a spore, and plays a most important part in the propagation of many kinds of bacilli. These spores are capable of resisting many hardships, which would be immediately fatal to the parent bacilli from which they have sprung. 
to light than the spore form, while Momont, in a classical series of experiments, not only fully confirmed these observations, but showed also that the intensity of the action of light depends to a very large extent on the environment of the organism. Thus, if broth containing anthrax bacilli is placed in the sunshine, the latter are destroyed in from two to two and a half hours, whilst if blood containing these organisms is similarly exposed, their destruction is only effected after from twelve to fourteen hours of sunshine. This difference in resistance to insolation was also observed in the case of dried blood and broth respectively-eight hours' exposure killing the bacilli in the former, whilst five hours sufficed in the latter.

This is an instance of the apparent idiosyncrasies possessed by micro-organisms, which render their study at once so fascinating and so difficult, and it is through being thus constantly confronted with what, in our ignorance, we mentally designate as "whims," that we can hardly resist the impression of these tiny forms of life being endowed with individual powers of discernment and discrimination. Indeed, these powers of selection and judgment are in certain cases so delicately adjusted that in some of the modern chemical laboratories micro-organisms have become indis. 
pensable adjuncts, and by their means new substances have been prepared and fresh contributions made to the science of chemistry.

Momont is not able to give any satisfactory explanation of this different behaviour of the anthrax bacilli in these two media, but goes on to show that yet another factor plays an important part during insolation.

In the above experiments air was allowed to gain access to the vessels containing the broth, but if the precaution be taken of first removing the air and then exposing them to the sunshine, a very different result was obtained, for instead of the anthrax bacilli dying in from two to two and a half hours, they were found to be still alive after fifty hours' insolation. There appears, therefore, to be no doubt that sunshine in some way or other endows atmospheric oxygen with destructive power over the living protoplasm of the bacterial cells; indeed, there is considerable reason to believe that the bactericidal effect is due to the generation of peroxide of hydrogen, which is well known to possess powerfully antiseptic properties.

Numerous investigations have been also made to determine whether all the rays of the spectrum are equally responsible for the bactericidal action of light. 


\section{SUNSHINE AND LIFE}

Geisler's work in St. Petersburg is especially instructive in this respect, for by decomposing with a prism the sun's light, as well as that emitted by a I,OOO-candle-power electric lamp into their constituent rays, he was able to compare the different effects produced by the separate individual rays of both these sources of light.

The organism selected was the typhoid bacillus, and it was found that its growth was retarded in all parts of the two spectra excepting in the red, and that the intensity of the retardation was increased in passing from the red towards the ultraviolet end of the spectrum, where it was most pronounced of all.

But whereas from two to three hours of sunshine were sufficient to produce a most markedly deleterious effect upon the typhoid bacillus, a similar result was only obtained by six hours' exposure to the electric light.

Dr. Kirstein, of the University of Giessen, in the course of some experiments he made to ascertain how long different varieties of bacteria can exist when they obtain access to the air in the form of fine spray, and subsequently, as happens under ordinary circumstances, get dried up, noted also the effect upon their vitality of exposure in daylight and darkness respectively. For this purpose the apparatus in which the experiments 
were carried out was in some cases kept in a dark cellar, whilst in others it was left standing in the laboratory in ordinary daylight.

Delicate bacteria, such as the fowl-cholera bacillus, it was found, could not survive exposure to daylight in this dried-up condition for more than ten hours, but when they were put in the dark their lease of life was prolonged for more than twice that length of time; whilst as regards varieties of tougher constitution, such as diphtheria and tubercle bacilli, whose initial vitality was very considerably greater under these adverse circumstances, confinement in the cellar enabled them to exist more than four times as long as they were able to in the healthy atmosphere of the well-lighted laboratory.

Dr. Onorato, of the University of Genoa, has recently shown, also, that influenza bacilli are entirely destroyed after the sun has been shining on them continuously for three and a half hours.

Such facts indicate how essential to health is plenty of light in our dwelling-rooms, and how important it is that in the designing of houses the trapping of the maximum amount of sunshine should be very carefully considered. Architects might indeed with advantage be compelled to include in their qualifications a knowledge of the fundamental facts of sanitary science. The 
fashion of shutting the sunshine out by barriers of blinds and curtains drawn across the windows, a practice which seems to be almost entirely independent of the habitual gloom of the surroundings or general scarcity of sunshine, might possibly be modified were it but known that by thus excluding light we are conferring an inestimable benefit upon the members of the microbial community, which may at any moment comprise some of the subtlest and most dangerous antagonists with which we have to reckon in the struggle for existence.

From a hygienic point of view, also, the question of the potency of sunshine in regard to the bacteria present in water is both important and interesting, for it is to water at the present time that we look for the dissemination of some of the most dreaded zymotic diseases.

Comparatively little has been done in this direction, but those results which have been obtained are exceedingly suggestive. Professor Buchner has published some preliminary experiments which he made with particular micro-organisms. In these investigations boiled tap-water was used to ensure the absence of all bacteria except those which were subsequently introduced, and, whilst some of the vessels were exposed to the sunshine, others were simultaneously preserved 
in the dark. It was found that typhoid, cholera, and various other bacilli were most deleteriously affected by insolation. Perhaps an example will best serve to illustrate the nature of the results obtained. Some boiled water contained in a flask was inoculated with an immense number of a bacillus, closely resembling the typhoid organism, normally present in the body and frequently found in water, the bacillus coli communis. So many were introduced that nearly one hundred thousand individuals were present in every twenty drops of the water. This flask then, containing water so densely sown with microbes, was placed in the sunshine for one hour, whilst another and similar flask was kept during the same time in the dark. On being subsequently examined it was ascertained that whereas a slight increase in the number of bacilli had taken place in the "dark" flask, in the insolated flask absolutely no living organisms whatever were present.

Professor Percy Frankland has also investigated the action of sunshine on micro-organisms in water, and in one of his reports to the Water Research Committee of the Royal Society an account is given of the effect of insolation on the vitality of the spores of anthrax in Thames water. These experiments show again what an important influence the surroundings of the organism 
have on the bactericidal potency of the sun's rays, for the remarkable fact was established that when immersed in water anthrax spores are far less prejudicially affected by sunlight than when exposed in ordinary culture materials such as broth or gelatine. Thus it was only after one hundred and fifty-one hours' insolation in Thames water that these spores were entirely destroyed, whilst a few hours' exposure in the usual culture media is generally sufficient for their annihilation. In water not subjected to insolation anthrax spores were found to retain their vitality for several months.

In case the reader should be tempted to compare these results with those obtained by Buchner, it must be borne in mind that whereas those experiments were made with bacilli, these were directed to determine the behaviour of spores in water, which are some of the hardiest forms of living matter with which we are acquainted. This alone would sufficiently explain the results obtained, whilst each variety of microbe may be, and doubtless is, differently affected during insolation.

We know now that a remarkable improvement takes place in the bacterial condition of water during its prolonged storage in reservoirs, and although, no doubt, the processes of sedimenta- 
tion which have been shown to take place during this period of repose are to a large extent responsible for the diminution in the number of bacteria present, yet it is also highly probable that insolation assists considerably in this improvement, at any rate, in the upper layers of the water. As the depth of the water increases the action of light is necessarily diminished. Indeed, exact experiments conducted in the Lake of Geneva to ascertain by means of photographic plates the depth to which the sun's rays penetrate showed that they did not reach beyond five hundred and fifty-three feet, at which depth the intensity of the light is equal to that which is ordinarily observed on a clear but moonless night, so that long before that their bactericidal potency would cease.

It is the more important that this limit to the powers of sunshine in water should be duly recognised, inasmuch as solar enthusiasts, when first the fact became known, rashly jumped at the convenient hypothesis, based on very slender experimental evidence, that the sun's rays were possessed of such omniscient power to slay microbes, that they might safely be relied upon to banish all noxious organisms from our streams, and that local authorities might therefore comfortably and without any qualms of conscience 
turn sewage into our rivers and so dispense with the cost and labour of its treatment and purification.

This was actually suggested in a proposal made for dealing with the sewage of the city of Cologne. Fortunately further investigations have removed these most erroneous and dangerous ideas; and whilst all due credit may be given to sunshine for what it really does accomplish in the destruction of bacteria in water, there is now no doubt as to its potency being confined to the superficial layers of water.

Perhaps Dr. Procacci's experiments will most clearly convey some idea of this limitation, for he made a special study of this particular phenomenon. Some drain water, containing, of course, an abundance of microbial life, was placed in cylindrical glass vessels, and only the perpendicular rays of the sun were allowed to play upon it. The column of water was about two feet high, and whilst a bacteriological examination at the commencement of the research showed that about two thousand microbes were present in every twenty drops of water taken from the surface, centre, and bottom of the vessel respectively, after three hours' sunshine only nine and ten were found in the surface and centre portions of the water, whilst at the bottom 
the numbers remained practically unchanged. Professor Buchner, of Munich, demonstrated the same impotence of the sun's rays to destroy bacteria much beneath the surface of water, in some ingenious experiments he made in the Starnberger See, near Munich. He lowered glass dishes containing jelly thickly sown with typhoid bacilli to different depths in the water during bright sunshine; those kept at a depth of about five feet subsequently showed no sign of life, whilst those immersed about ten feet developed abundant growths; in both cases the exposure was prolonged over four and a half hours.

In our own rivers Thames and Lea frequently about twenty times more microbes have been found in the winter than in the summer months, but it would be extremely rash to therefore infer that the comparative poverty of bacterial life was due to the greater potency of the sun's rays in the summer than in the winter. Doubtless it may contribute to this beneficial result; but we know as a matter of fact that, in the summer, these rivers receive a large proportion of spring water, which is comparatively poor in microbes, and that this factor also must not be ignored in discussing the improved bacterial quality of these waters at this season of the year.

Another point which must be taken into con- 
sideration in regard to the effective insolation of water is its chemical composition, for it has been shown* that the action of sunshine in destroying germs in water is very considerably increased when common salt is added to the water, and this opens up a wide field for experimental inquiry before we can accept sunshine as a reliable agent in the purification of water.

Again, we must remember that a great deal depends upon the condition of the microbe itself. If it is present in the spore or hardy form, then considerably longer will be required for its annihilation. This fact has been abundantly shown in the case of anthrax, which in the condition of spores will retain its vitality in water flooded with sunshine for considerably upwards of a hundred hours, the bacilli being far more easily destroyed. We must also bear in mind that the individual vitality of the microbe is an important factor in determining its chance of survival; if it is in a healthy, vigorous condition, it will resist the lethal action of sunshine for considerably longer than when its vitality has been already reduced by adverse surroundings.

It is, therefore, sufficiently obvious that the power of insolation to bacterially purify water

* Percy Frankland, Our Secret Friends and Foes, 4th edition, p. I88. 
is by no means easy of estimation, and that numerous and very varied factors have to be taken into account when we attempt to endow it with any measure of practical hygienic importance.

In connection with the vitality of anthrax germs in water, which has afforded material for so "many laboratory investigations, it is of interest to consider what chance exists of anthrax being communicated by water. Until a few years ago, as far as I am aware, no instance had been recorded of anthrax having been actually communicated by water, until an outbreak of anthrax on a farm in the south of Russia was distinctly traced by a skilled bacteriologist to the use of water from a particular well, in the sediment of which the bacillus of anthrax was discovered.

Anthrax bacilli have also been detected in the water of the River Illinois in the vicinity of Chicago, one of the chief sources of pollution of which is the slaughtering of cattle and the discharge of their offal into the river.

The likelihood of such contamination taking place through the drainage of soil makes it of importance to ascertain what may become of the bacilli of anthrax derived from the bodies of animals which have died of this disease, and whose carcasses have been buried and not burnt. 
The anthrax bacillus cannot produce the hardy spore form within the bodies of animals, but it does outside. Now it has been shown that the bacilli of anthrax taken from the blood of an animal dead of anthrax are destroyed rapidly in ordinary River Thames water, for example, but that if the temperature of the water to which they gain access is somewhat higher than usual, such bacilli are able to sporulate or produce spores in the water, and in that hardy form can retain their vitality and virulence for several months.

That anthrax bacilli can produce spores in water under certain conditions has not hitherto been dwelt upon in discussing the question of their vitality in water, and it is of obvious importance in connection with the action of sunshine on anthrax germs in water, knowing as we now do the very different manner in which the spores and bacilli respectively behave when under the influence of the sun's rays.

It was not, perhaps, unnatural that rash assumptions as to the efficacy of sunshine should have been readily accepted when such remarkable feats performed on microbes by sunshine were being continually put forward.

Thus it has been found that insolation, even when it does not destroy, may effect profound 
changes in the physiological character of certain micro-organisms.

Dr. Lohmann, of Rostock, discovered that some hours' exposure to bright sunshine entirely destroys yeast cells, whilst even feeble and intermittent sunshine is capable of paralysing them, and that they only recover their vitality when removed from this obnoxious influence. This recuperative power is not, however, shared equally by all varieties of yeast, some possessing it in a far greater degree than others. Dr. Lohmann also found that yeast cells, after being exposed to sunshine, assumed a shrunken and distorted appearance, showing that insolation had produced a striking physiological effect upon the structure of these cells.

Professor Hansen published some years ago a most interesting memoir on some of the characteristic features of the moulds which are to be found on manure heaps, in which he records how light exerts a very important influence on the manner in which the spore or fruit of these lowly vegetables is set free or distributed. All the various phases in the fructification process of some of these moulds were carefully watched by Dr. Hansen. He kept his caged specimens near a window with an eastern aspect, and he states that in the first instance the stalks inclined towards the light, but that afterwards they 
assumed an upright position. Darkness was nearly always chosen for the liberation of the spores, but in a few instances a small number were released during the daytime, and it was noticed that when this did occur they were invariably discharged on the side away from the source of light. In various other ways he confirmed this interesting observation, and found that the fruit of the mould was invariably discharged in the opposite direction to that in which the stalk had previously inclined under the influence of light. The force with which the spores were discharged varied very considerably, sometimes being cast to a distance of four inches or more from the stalk, and sometimes being found close to and even on the stalk.

The manner in which sunshine may also modify the pigment-producing powers of micro-organisms is remarkable.

Many microbes are able to elaborate when grown on various culture media, such as gelatine or slices of potato, most brilliant and beautiful pigments ranging from intense blood-red to the most delicate shades of pink, and embracing every gradation of yellow, as well as browns, greens, and violets. Now it has been found that some of these pigment-producing bacteria, when exposed to sunshine on these nutritive materials, fail to exhibit their characteristic colour, although the duration 
of insolation may not have sufficed to destroy their actual vitality. One of these organisms originally obtained from water has been specially studied in this respect by M. Laurent. If slices of potato are streaked with a small number of this particular bacillus (bacille rouge de Kiel) a magnificent patch of blood-red colour makes its appearance in the course of a day or two, but if, on the other hand, similar slices of potato are exposed to three hours' sunshine, a colourless growth subsequently develops, except where here and there a few isolated spots of pale pink are visible. When the insolation is prolonged for five hours nothing whatever appears on the potato, the bacilli having been entirely destroyed. But this is not all. M. Laurent found that if he took some of the colourless growth and inoculated it on to potatoes he obtained again, but without insolation, a colourless vegetation-in fact, three hours' insolation had so modified the physiological character of the bacillus that a new race had been generated, a race deprived of its power of producing this red pigment. In what numerous directions the character of microbes may be and are being modified, even by simple exposure to sunshine, opens up a wide field for speculation and research, whilst the tractability of these minute and most primitive forms of life, if we only approach their 
education with sufficient insight and patience, may enable us to make them serve where they now are masters.

The remarkable discoveries on the modification of the disease-producing properties of certain bacteria by sunshine may perhaps encourage the idea that we are making some progress towards the attainment of this desirable millennium. That diminution of the virulence or disease-producing power of such deadly microbes as those of cholera, anthrax, and tuberculosis can be brought about through simple exposure to the sun's rays seems almost inconceivable, yet it has been discovered that by placing the cholera bacillus, for example, in the sunshine its virulent character undergoes such a profound modification that it is actually reduced to the condition of a vaccine, and may be employed to protect animals from infection with its still virulent brethren. Yet this is what has been undoubtedly shown by Dr. Palermo in very carefully conducted investigations. He was, moreover, able to indicate, within a very narrow margin, the precise amount of insolation necessary to bring about this result: for if the cholera cultures were only exposed for three hours, their toxic properties were not reduced to the condition of vaccine; but if the insolation was continued for three and a half hours up to four and a half hours, they became 
endowed with the requisite immunising properties, and animals treated first with the so-called sunshinecholera-vaccine were able subsequently to withstand otherwise fatal doses of virulent cholera cultures. Dr. Palermo also found that, besides producing this subtle modification in the character of cholera bacilli, sunshine exerted a remarkable physiological change in these organisms, for when examined under the microscope they no longer exhibited their typical activity, having been deprived of all powers of movement, whilst those kept during the same length of time in the dark had not abated one jot of their customary mobility.

But sunshine not only controls in this wonderful manner the action of the living bacillus, but it also operates upon the products elaborated by disease organisms. Thus the microbe producing lock-jaw or tetanus may be grown in broth, and the latter may be subsequently passed through a porcelain or a Berkefeld filter, so that the resulting liquid is entirely deprived of all germ life. This tetanus-filtrate, as it is called, is endowed with very powerful toxic properties, and it will retain its lethal action even when kept for upwards of three hundred days, providing it is screened from all light; but place such filtrates in diffused light, and they lose their poisonous 
properties, requiring, however, upwards of ten weeks to become entirely harmless; if, on the other hand, they be exposed to sunshine, they are completely deprived of their toxic character in from fifteen to eighteen hours. Again, as little as five hours' sunshine is sufficient to greatly modify the toxic action of diphtheria cultures. It is of interest also to note that even the venom of the rattlesnake, that most potent of all poisons, cannot emerge unscathed from an exposure to sunshine maintained during a fortnight.

Interesting as all these isolated observations are, they indicate what an immense amount yet remains to be done before we can hope to have any connected conception of the mechanism, so to speak, of insolation. At present there is too large an allowance, which we are compelled to make, for the unknown to permit of our adequately manipulating this marvellous agency in relation to bacteriological problems. But who shall say what part has been, and is being still, played by sunshine in determining the individual character of microbes, operating as it has done from time immemorial upon countless generations of these minute germs of life?

The problem of insolation has been attacked from an entirely novel point of view by Dr. Masella, who has endeavoured to find out whether 
sunshine plays any part in the predisposition of animal life to infection.

Now sunshine has long been credited with possessing therapeutic powers, and, indeed, traditions of cures effected by the ancients by means of insolation have been treasured up and handed down to the present day. Even as late as the beginning of the present century we may read of a French physician seriously recording his claim to have cured a dropsical patient within two weeks by placing him daily for several hours in the sunshine, and many medical journals of recent years contain communications on the beneficial results derived from the use of sunshine in the treatment of various diseases. It seems curious, therefore, that whilst so much has been done to test the action of light on disease microbes in artificial surroundings, such as are to be found in laboratory experiments, hardly any investigations have been made to try and define more precisely how sunshine may affect their pathogenic action within the animal system. Dr. Masella's researches, undertaken with the express object of, if possible, elucidating this question, are therefore of special interest and importance.

The first series of experiments was carried out to ascertain whether exposure to sunshine 
increases or reduces an animal's susceptibility to particular diseases, those selected for investigation being typhoid fever and cholera. For this purpose guinea-pigs were exposed to the full rays of the sun during a period of from nine to fifteen hours for two days, whilst other guinea-pigs, for the sake of comparison, were not permitted to have more light than that obtainable in a stable where only diffused light was admitted. Both these sets of animals were subsequently infected with virulent cultures of cholera and typhoid germs respectively, and were in neither case exposed to sunshine. The results which Dr. Masella obtained were remarkable, for he found that those animals which previous to infection had been placed in the sunshine died more rapidly than those which had been kept in the stable, and that the exposure to the sun's rays had so increased their susceptibility to these diseases that they succumbed to smaller doses, and doses, moreover, which did not prove fatal to the other guinea-pigs. Still more striking was the part played by insolation in the course of these diseases in animals exposed to sunshine after inoculation, for instead of dying in from fifteen to twenty-four hours, they succumbed in from three to five hours.

Here, then, we find sunshine, in some mysteri- 
ous manner not yet understood, far from benefiting the animal and assisting it in combating these diseases, actually contributing to the lethal action of these bacteria. It has been asserted on the authority of some medical men that in cases of small-pox recovery is rendered more easy and rapid when light is excluded from the patient's room; whether Dr. Masella's experiments will permit of any such interpretation being placed upon them remains to be seen; they are, at any rate, extremely suggestive.

That it is possible for temperature to have some determining influence upon the course of certain diseases has been shown by O. Voges, who, experimenting with a minute bacillus which he isolated from tumours characteristic of a cattle disease very prevalent in South America, found that although this bacillus was the undoubted fons et origo of the disease, he could not produce fatal results in animals if he kept them in cold surroundings; only when the temperature was raised to from 35-45 degrees Centigrade did the infected animals succumb. The dependence of the activity and virulence of this micro-organism upon temperature is also borne out in actual experience, the disease being the more prevalent and the more fatal the hotter the climate of the country. 
It may be mentioned in passing that this bacillus has the distinction of being the smallest yet discovered; the influenza bacillus hitherto held the palm in this respect, but it must yield its position to its more successful rival, for Voges states that when magnified about fifteen hundred times it is only just discernible in the microscopic field.

Even the smoke-laden atmosphere of our great cities, our leaden skies and dreary fogs and mists, may after all, then, if we can only learn to look at them from Dr. Masella's point of view, become a source of benefit and a subject for congratulation; yet our inherent love of light and sunshine would cause us willingly to hand over our murky climate had we but the chance of obtaining in exchange that of any of the sunny cities of the south. Moreover, in the case of tubercular disease experience is daily impressing upon us the wisdom, and indeed necessity, of absorbing as much sunshine as possible, and hence the pilgrimage which is now recommended to Davos and other resorts where invalids can get the maximum amount of bright sunshine. And not only is this the outcome of practical experience, but De Renzi has shown by actual experiment that sunshine acts beneficially in cases of tuberculosis in animals. Thus, guinea-pigs were infected with tuberculous 
material and exposed in glass boxes to the sun for five or six hours daily, others being similarly infected but protected from sunshine. The animals which had received the sunshine died in $24,39,52$, and 89 days respectively, whilst those which had not been sunned succumbed in from 29, 25, 26, and 4I days; or, in other words, De Renzi found that insolation had very materially increased the infected animals' power of coping with tuberculosis.

The part which sunshine plays, or may be made to play, in disease is very obscure, but it would appear at least justifiable to assume that it is an agent which further investigation may show we cannot afford to disregard, contributing as it may to the production of a healthy tone in the system, and thereby materially assisting the body to defy the insidious attacks made upon it from without.

The so-called open-air treatment of consumption which has made such giant strides in the last few years is an example of how, by contributing to the general health of an individual, the powers for resisting a localised disease may be so increased that the latter can, in many cases, be thrown off altogether. In no country has more progress been made in the establishment of institutions for the cure of consumption on these lines than in Germany. At the end of the year I899 
there were forty-nine such institutions in Germany, with four thousand beds; in a little more than twelve months later there were no less than sixty such, with accommodation for altogether five thousand patients. It is of interest to note that amongst the earliest of these institutions to be founded was that erected and endowed by the famous Badischen Anilin and Soda Fabrik Company, for the exclusive benefit of those of their workpeople who were suffering from tuberculous disease.

We have learnt that sunshine is endowed with distinctly lethal action as regards particular bacteria, that it can modify the subtle properties of toxic solutions, and we are asked to believe that it may exercise an important influence on the animal system in determining the power of the latter to deal with the agents of disease; but, as we have seen, the mechanism of it all is shrouded in mystery, and we are at a loss to divine how it works. Might not some fresh light be thrown upon this problem if we could ascertain the effect of sunshine on some of these natural fluids of the body, which recent brilliant research has shown to be endowed with such wonderful protective or immunising properties? So far as I am aware, the action of sunshine on these antitoxins or protective fluids has not yet been in- 
vestigated. Can sunshine interfere with the therapeutic effect of diphtheria-serum, for example? If simple insolation can so profoundly modify the character of toxic fluids, it is not unreasonable to anticipate some action on these anti-toxins, and their study in this connection would appear to offer an important step in the direction of unravelling the mystery attending the action of light on life. 


\section{BACTERIOLOGY AND WATER}

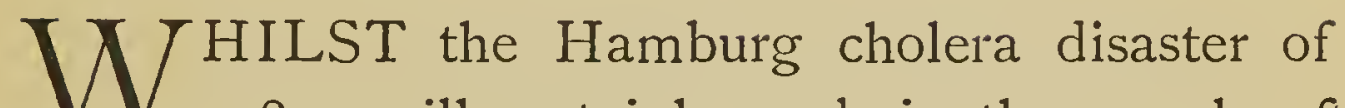
I 892 will certainly rank in the annals of epidemiology as one of the great catastrophes of recent times, it will also be memorable as one of the most instructive which has ever taken place.

It is perhaps not unnatural that this should be the case, for since the last European epidemic of importance our study of the principles of sanitation has received a new impetus, and this impetus must be in great part ascribed to the science of bacteriology, which has sprung into existence within the past two decades. We have now no longer to confront mysterious and unknown morbific material, but have been brought face to face with some of the most dreaded foes of the human race. We are no longer groping, as it were, in the dark, but have a definite object, in the shape of well-recognised micro-organisms associated with specific zymotic diseases, for our common crusade.

But it is the light which has been thrown for 
the first time upon numerous intricate problems connected with the sanitary aspects of public water-supplies which constitutes not the least important of the many services rendered by bacteriology to the public. Perhaps one of the most striking of these may be considered the insight which it has afforded into the value of various processes of water-purification, furnishing us with the most subtle and searching tests, surpassing in delicacy those of the most refined chemical methods.

Thus for years the processes of sand-filtration, as practised at waterworks in dealing with river and other surface waters, were regarded by chemical experts as of but little or no value, because, on chemical analysis, but little or no difference was found to exist between the filtered and unfiltered samples respectively. Water engineers started this method of water treatment in London as far back as the year I839, with no other object than the distribution of a water bright and clear on delivery, but, unknown to themselves, they were carrying out a system of water-purification the nature and extent of which has been left to the infant science of bacteriology to unravel and reveal.

It was in the year I885 that Dr. Koch's new bacteriological water-tests were introduced, and 
systematically applied for the first time to the London water-supply by Professor Percy Frankland, and the entirely unexpected result obtained, that whereas the River Thames water at Hampton contained as many as 1,644 micro-organisms in about twenty drops, this water, after passing through the sand-filters, possessed as few as thirteen in the same number of drops. The remarkable purification effected in the treatment of the water was thus very clearly shown, and an entirely new aspect was given to the processes of sand-filtration.

The importance of these results was quickly appreciated by the official water-examiner, the late Sir Francis Bolton, and at the request of the Local Government Board regular monthly bacteriological examinations of the London watersupply were conducted.

It is amusing to recall that, at the time when these results were first published, the public, instead of being reassured by these facts, were greatly alarmed, and it is a matter of history that the mere demonstration of the presence of micro-organisms in drinking-water caused a fall in the price of several of the water companies' stocks!

These investigations, which have since been confirmed by others both in this country and 
on the Continent, have clearly shown, then, that sand-filtration, when carefully carried out, offers a most remarkable and obstinate barrier to the passage of microbes, and there was every justification in presuming that if disease organisms should at any time be present in the raw untreated water, they would also undergo a similar fate, as there was no reasonable ground for supposing that they would behave any differently from the ordinary harmless water bacteria.

But this was a hypothesis only, and, however satisfactory experiments in this direction made in the laboratory might prove, there was always the uncertainty attaching to a fact which had not passed through the ordeal of practical experience.

The answer to this searching and all-important question has been furnished in the most conclusive manner by the history of the cholera epidemic in Hamburg and Altona respectively in the year I 892 .

These two cities are both dependent upon the River Elbe for their water-supply, but whereas in the case of Hamburg the intake is situated above the city, the supply for Altona is abstracted below Hamburg after it has received the sewage of a population of close upon 800,000 persons. The Hamburg water was, therefore, to start with, relatively pure when compared with that des- 
tined for the use of Altona. But what was the fate of these two towns as regards cholera? Situated side by side, absolutely contiguous, in fact, with nothing in their surroundings or in the nature of their population to especially distinguish them, in the one cholera swept away thousands, whilst in the other the scourge was scarcely felt; in Hamburg the deaths from cholera amounted to $\mathrm{I}, 250$ per I00,000, and in Altona to but 22 I per I00,000 of the population. So clearly defined, moreover, was the path pursued by the cholera, that although it pushed from the Hamburg side right up to the boundary line between the two cities, it there stopped, this being so striking that in one street, which for some distance marks the division between these cities, the Hamburg side was stricken down with cholera, whilst that belonging to Altona remained free. The remarkable fact was brought to light that in those houses supplied with the Hamburg water cholera was rampant, whilst in those on the Altona side and furnished with the Altona water not one case occurred.

We have seen that the Hamburg water, to start with, was comparatively pure when compared with the foul liquid abstracted from the Elbe by Altona, but whereas in the one case the water was submitted to exhaustive and careful 
filtration through sand before delivery, in Hamburg the Elbe water was distributed in its raw condition as drawn from the river.

But further testimony was afforded later to the truth of these results, for during the winter, whilst the cases of cholera had almost completely died out in Hamburg, suddenly a most unexpected and unaccountable recrudescence of the epidemic occurred, and this time in Altona. This outbreak could not be traced to any direct infection from Hamburg, but must have arisen in Altona itself. In all about forty-seven cases were recorded between December 23rd, I892, and February I2th, I893. A searching inquiry was instituted, and it was ascertained that the number of bacteria found in the filtered water, usually about fifty, had during these months risen to as many as $I, 000$ and more in about twenty drops of water, clearly indicating that the filtration of the water was not being efficiently carried out. That this was actually the case was proved by the fact that one of the sand-filters which had been cleaned during the frost had become frozen over, and was not able to retain the bacteria. That the outbreak did not become more serious Koch ascribes to the fact that this, to all intents and purposes raw untreated water, was largely diluted with efficiently filtered water before de. 
livery. Dr. Koch, who personally superintended this inquiry in Altona, traced another local outbreak of cholera in the city to the use of a well-water obviously open to pollution, which was used by about 270 persons. In one of the houses employing this water, and in the immediate vicinity of the well, a boy died of cholera on January $23 \mathrm{rd}$, and during the week following a number of cases occurred amongst persons using this source. On discovering the cholera bacilli in this polluted water, its contamination was placed beyond doubt, and five days after the well was closed all cases ceased in the locality.

There cannot be any longer a doubt as to the value of sand-filtration as a means of waterpurification, but the responsibility which we have seen attaches to this treatment of water cannot be exaggerated, for whilst when efficiently pursued it forms a most important barrier to the dissemination of disease germs, the slightest imperfection in its manipulation is a constant menace during any epidemic.

It is, as a rule, during the winter months that the largest number of bacteria are present in the filtered water, and it is therefore of especial importance that during this season, when the raw river water is generally richest in bacterial life, and when, therefore, the filters are most taxed 
and the consequences of frost are most to be apprehended, that those entrusted with this responsible task should be unremitting in their endeavours to obtain a good filtrate.

That waters submitted to exhaustive natural filtration, such as those derived from deep wells sunk into the chalk, and usually almost entirely devoid of bacterial life, may at times become the carriers of disease has been proved by the disastrous outbreak of typhoid fever which occurred some years ago at Worthing.

This town has long been supplied with water of the very finest quality for dietetic purposes, and nothing could have been more unexpected than this most fatal epidemic. It must, however, be borne in mind that such deep-well waters are not necessarily immaculate, for in the event of any fault in the water-bearing strata occurring, the filtration becomes inefficient, and the water may then, as in the case of Worthing, be the bearer and disseminator of zymotic disease.

The bacteriological methods for the examination of water, although when first introduced but a few years ago were lightly looked upon, and by many opposed, have now become of paramount importance in all questions of waterpurification. The immense mass of evidence of a purely bacteriological character' which was 


\section{BACTERIOLOGY AND WATER IOI}

taken, and indeed required by the Royal Commissioners of 1893 on the London water-supply, indicates clearly enough the change which has taken place in the public estimation of the value of these methods; and it is highly significant that in their report the Commissioners lay stress upon the importance of extensive storage and efficient filtration, two factors the meaning and worth of which rest almost entirely on the results of bacteriological research.

Cholera is not, however, the only water-carried disease which has borne eloquent testimony to the services rendered by the efficient purification of public water-supplies. The experience of the State of Massachusetts in America, in regard to typhoid fever and drinking-water, is also exceedingly instructive.

Massachusetts has, by creating a Board of Health, and affording the same every facility for the prosecution of hygienic investigations of the greatest importance, laid the whole scientific world under a deep obligation. The reports issued have a very wide circulation, and embrace a variety of subjects, but second to none in interest and importance is the account of the experimental work carried out by the officials of the Board on the purification of water and sewage. These experiments have become classical, and 
have been conducted with a zeal and thoroughness which deserve the highest praise. It is in looking at the results achieved by the city of Lawrence in regard to its water-supply that some conception can be obtained of the immense importance to the community of the scientific experiments conducted in the State Laboratory. No expense has been spared, and for years past elaborate and costly experiments on a large scale have been carried out to determine the most efficient manner in which water may be rendered fit and safe for drinking.

Now the death-rate in a community from typhoid fever may be taken as an index of the general sanitary conditions prevailing in such a community, the character of the public watersupply, not without justification, being regarded as a prime factor in its determination. One of the most significant points in the sanitary history of the State of Massachusetts is the almost uniform decline in the mortality from typhoid fever in proportion as measures have been taken to introduce better water-supplies and to improve those which already exist. Thus in the twenty years, from 1856 to 1876 , the death-rate from this disease was 8.6 per 10,000 of population, whilst in the period from 1876 to 1895 it had fallen to $4^{1} \mathrm{I}$ per 10,000 , the improvement in 
respect of typhoid-mortality being coincident with the improvement made during the last twenty years in providing public water-supplies. In the words of one of the State reports, "The death-rate from typhoid fever has generally fallen as the per cent. of the population supplied with public water has risen, for the reason that the majority of the deaths from this disease have occurred among communities and portions of communities not supplied with public water."

That this improvement is being maintained is seen from the fact that in the four-year period I 896-99 the deaths from typhoid fever in Massachusetts were further reduced to $2 \cdot 6$ per 10,000 .

It is, however, in the city of Lawrence that the most striking insight is obtained as to the manner in which typhoid fever may be controlled by conditions surrounding the water-supply to the community. Thus, whereas the death-rate from typhoid fever reached a mean of II'2 per 10,000 in $1886-90$, it fell to 7.7 in $189 \mathrm{I}-95$ and to 2.5 in 1896-99. It was in the autumn of the year I893 that the raw river-water supplied to the city from the Merrimac River was first begun to be filtered, and since that time the sandfilters have been subjected to systematic and most elaborate bacterial supervision, and improvements have been constantly introduced so as 
to secure the most efficient purification possible of the water before distribution, and the results are reflected in the marked diminution in typhoid fever which has followed these strenuous efforts to obtain the best water-supply available.

The splendid example set by the State of Massachusetts, in promoting the welfare of the people by the encouragement of original researches in practical hygiene, has stimulated other American States to create Boards of Health and enact laws for the protection of their rivers and streams. In view of all that has been done to promote sanitary science in the United States, it is surprising to learn that Lake Michigan, which receives the untreated sewage of municipalities and small towns aggregating over two million people, still furnishes Chicago with its drinking water, and undergoes no preliminary purification before distribution. The city of Chicago, by constructing the Chicago Drainage and Ship Canal, opened in January, I900, has diverted its own sewage from Lake Michigan, but this great sewer has only been made possible because of its advantages as a commercial waterway; and it has been stated, on high authority, that every project for the drainage of Chicago into the Illinois which has not recognised the waterway features has been predestined to failure. Dr. Egan, of the Illinois State Board 
of Health, however, points out that "with the present increase in population the Great Lakes, if they continue to be used as common sewers, will soon become totally unfit for use as drinking water, .... and one of two alternatives must be followed - either every source of water-supply must be filtered, or the sewage of the towns must be efficiently purified before it is allowed to flow in to the lakes."

Doubtless this seeming inertia of the citizens of Chicago in the matter of filtering their water is attributable to the fact that already the authorities have expended eighty-five million dollars in their waterworks and sewerage systems, which represents an investment of something over fifty dollars per head of population, and that plans in connection with the great canal which has been described as "the greatest feat of sanitary engineering in the world," and to which reference has already been made, will, when carried out, involve an expenditure of thirty or forty million dollars more. In the face of such burdens even so prosperous a community as Chicago does not care to contemplate further capital charges, at any rate until the unsatisfactory conditions shadowed by Dr. Egan become more pressing in regard to the source of their water-supply.

The systematic investigations carried out in the 
great Institutes of Health on the Continent and elsewhere should surely make the sporadic work, as by comparison it must be designated, produced in this country an eloquent argument for the creation of a British Imperial Board of Health adequately endowed by the State, manned by the ablest investigators, and forming a centre for the prosecution of researches which in other countries, as in our own, have contributed so greatly to the health and welfare of mankind.

Why should England for ever have to knock at the door of foreign institutes for information and guidance in matters in which once she was the leader and enlightened example to every civilised country?

The question of how far polluted water-supplies, besides possessing the potentiality for spreading cholera and typhoid, may disseminate consumption, has been approached in a very instructive manner by Dr. Musehold, of the German Imperial Board of Health.

Some ten years ago the discovery of the tubercle bacillus in water for the first time was announced by a Spanish investigator, Fernandez. The water containing the bacillus tuberculosis was derived from an open ditch, and hence had been doubtless exposed to contamination of divers kinds.

In the course of the elaborate experiments on 
London sewage and its treatment, carried out by Professor Frank Clowes, Chief Chemist to the London County Council, an instance was recently met with in which a guinea-pig, inoculated with a portion of coke-deposit derived from a bacterial sewage bed, died from typical tuberculosis, and sections of its organs showed the presence of numerous tubercle bacilli. Dr. Musehold has now submitted the whole question of the vitality of virulent tubercle bacilli present in the expectorations of consumptive persons in sewage, in river water, and on cultivated land respectively, to an exhaustive examination, and the novelty as well as importance of these researches merit their being carefully considered.

In the first instance tuberculous sputum was introduced into river water in its natural condition, and as this water was abstracted from the River Spree, in Berlin, it was exposed at any rate to a certain degree of surface contamination. In this water, kept in ordinary daylight, the tubercle bacilli remained alive and in a virulent condition for over five months; in ordinary sewage for six and a half months. Some of the sewage-infected samples were left in the open air and exposed to ordinary meteorological conditions, but even the ordeal of getting frozen up in their surroundings did not in the slightest shorten the lease of 
virulence possessed by the tubercle bacilli. Some of this tubercle-infected sewage was poured over garden soil in which radishes were growing, and after the bacilli had spent eighty-eight days in these surroundings, during which time they had experienced frost, snow, rain, and sunshine, they still retained their virulence. Of special interest are the investigations Dr. Musehold made to ascertain if tubercle bacilli could be detected on the fields attached to a hospital for consumption and irrigated with the sewage from the same. Not only were tubercle bacilli found, but they were also, as was to be expected from the laboratory experiments cited above, discovered in a highly virulent condition.

That disease germs may be distributed with the vegetables grown on municipal sewage farms is not a mere whim or fancy of the faddist, but is a very real danger, and must be regarded as a menace to the health of all who consume such articles as lettuces, radishes, celery, and other vegetables which are not first cooked before being placed on the table.

This forcibly suggests the desirability of all expectorations from consumptive patients being thoroughly disinfected, or, in other words, deprived of their virulence before being admitted to sewage. The importance of such precautions being taken 
is borne out by the examinations of the clear effluent derived from the treatment of the sewage of a consumptive hospital which revealed the presence of virulent tubercle bacilli, whilst they were also discovered in the bottom of a ditch conducting the effluent away.

Such facts as these deserve the earnest attention of all public authorities, and it is to be hoped that the overwhelming evidence which is now available regarding the distribution and Spartan character of the tubercle bacillus will lead to serious efforts being made to bestow upon it that measure of consideration which in the case of recognised zymotic diseases leads to the enactment of rules and regulations for the restriction at least of the fateful activities of these malignant foes of mankind.

Before leaving the subject of bacteria in relation to water, it will be interesting to glance at what is known regarding the attitude taken up by these minute forms of life towards that large and everincreasing class of waters vaguely grouped together under the synonym of mineral waters. The fortunes made in manufacturing artificially aerrated waters and the mine of wealth contained in a new mineral spring are sufficient evidence of the popularity enjoyed by this description of beverage. The beer and spirit statistics of the 
country and their contributions to the national revenue do not, however, permit us to indulge in the belief that this large consumption of harmless drinks is due to their displacing the use of intoxicants-the increasing sale of non-alcoholic beverages cannot in fact be taken as an index of the growing sobriety of a nation; far more must the greater demand be attributed to the improvements in manufacture which have cheapened production and placed what was formerly an article of luxury almost prohibitive in price, and hence reserved for the few, within comparatively easy reach of the many. Perhaps also an increased sale may be assisted by a prevailing impression that by substituting carbonated for ordinary potable water, the risk of contracting zymotic disease is, if not altogether removed, at any rate very materially diminished.

It will be therefore instructive to see how far this assumption is justified by actual facts.

The first fact to be recognised is that the number of bacteria present may and does fluctuate between such wide limits as is represented by as few as three, and as many as 100,000 being found in about twenty drops of artificially aërated waters. Seltzer water, manufactured from well water, was found by Sohnke to contain numbers varying from 200 to 6,000 , whilst when only distilled water 


\section{BACTERIOLOGY AND WATER III}

was used, i.e. water previously deprived of all bacterial life, only from ten to thirty microbes were present. But an important and far too little recognised factor in the manufacture of aërated waters is the contamination which so frequently takes place subsequent to the initial purification of the water by sterilisation. In some instances this contamination is due to the storing of water before use in reservoirs, where an excellent opportunity is offered for microbial multiplication.

Merkel found water which originally only boasted of from four to five bacteria per cubic centimetre, subsequently, when ready for distribution as seltzer water, contained considerably over 3,000 . In this case storage had been resorted to. Again, insufficient importance is attached to the efficient cleansing of the syphons on their return to the factory. The experiments made by Slater in this country and Abba in Italy have conclusively shown that the gaseous aëration of water exerts an inhibitory action on the growth of at least some varieties of water bacteria, for both these investigators found that in proportion as the amount of gas present was diminished by being allowed to escape, so was the multiplication of the bacteria present promoted and their numbers increased. Unsavoury as may be the idea of swallowing down myriads of even harmless 
microbes, yet the real significance of the whole question from a hygienic point of view lies in the evidence as to the fate of disease germs in aërated waters.

On this important matter there fortunately exists some precise and conclusive information in regard to the bacteria associated with two essentially water-borne diseases, i.e. typhoid fever and cholera. The investigations made to test the vitality of the anthrax bacillus are of significance as again emphasising the superior degree of vitality possessed by the spore over the bacillar form of this micro-organism, but the chances of this disease being disseminated by water are usually regarded as too remote to excite much interest in the fate of the $b$. anthracis in seltzer water. It may, however, be mentioned that whereas the bacilli succumbed after being in the seltzer water from fifteen minutes to an hour, the spores were still living after one hundred and fifty-four days. Investigations on the vitality of cholera bacilli in aërated waters have been made by Hochstetter in Germany, by Slater in England, and by Abba in Italy, and these various authorities all agree that the lease of life of these micro-organisms is a very short one in ordinary unsterilised carbonated waters, and that they are in fact destroyed in from half an hour 
to three hours. As regards typhoid bacilli the case is different, for the same investigators found that in ordinary unsterilised aërated water these bacteria can live as long as eleven days. In seltzer water their vitality is not so marked, but even then it greatly exceeds that of the accommodating cholera microbes, extending to five days.

Thus supposing typhoid bacilli to be present in the water employed for the manufacture of aërated waters-and we cannot afford to disregard such a possibility-we have no guarantee that such waters will be safe for drinking purposes unless a considerable period has been allowed to elapse between their production and consumption.

It was considerations of this kind which led M. Duclaux, the accomplished director of the Paris Pasteur Institute, to write now some years ago: "Contentons-nous de conclure que l'usage de l'eau de seltz, recommandé en temps d'épidémie peut en effet être recommandable, surtout si on laisse vieillir l'eau quelques jours. On a chance d'y voir diminuer ou même périr les germes nuisibles."

On the whole, therefore, the scientific report on bacteria and artificially aërated waters may be regarded as a reassuring one. It is to be regretted, however, that in England we do not 


\section{II4 BACTERIA IN DAILY LIFE}

follow the example set by Italy, where the aërated water manufacturers are closely looked after by the State, and no factory may be opened unless a satisfactory guarantee can be given of the chemical and bacteriological purity of the water which is intended to be used, whilst the authorities must also be assured that the methods employed are satisfactory from a hygienic point of view. The sale of all aërated waters prepared from insanitary water-supplies is strictly prohibited by the State.

It will now be of interest to ascertain what is the result of the endeavours which have been made to explore the bacterial flora of those highly prized and largely circulated natural mineral waters, which abound in so many parts of the world and are practically the making of so many health resorts.

Perhaps the most exhaustive examinations of mineral water which have been so far made are those published by Dr. Eugenio Fazio, who studied the bacterial condition of some of the celebrated springs situated near Naples at Castellamare, Telese, Acetosella, and Muraglione, care being taken to select examples of different types of water, samples being collected from chalybeate, carbonated sulphur, and alkaline springs respectively. All these various mineral waters were character- 
ised by a remarkable paucity of bacteria; in the chalybeate and alkaline springs sometimes as few as two microbes only in a cubic centimetre were found, and the largest number recorded only amounted to forty-five. The satisfactory significance of such figures will be appreciated when we realise that they rival very closely the numbers which characterise the purest spring and the deepest well water, and which are usually regarded as the aristocracy among drinking-waters. Of special interest is Dr. Fazio's discovery that the variety of bacteria present in these waters is extremely restricted, as a rule only three, or at most four, different kinds of bacteria being detected.

This is also characteristic of the pure water derived from deep wells sunk into the chalk, usually but very few different kinds of bacteria being found amongst the limited number of their Lilliputian inhabitants, whilst in samples collected from rivers or other surface sources, especially those which have been polluted with sewage or similar refuse matters, the bacterial population is frequently as diverse as it is unwieldy.

From the exacting point of view of the uncompromising bacteriologist the most satisfactory waters in existence for drinking purposes should be those derived from sulphur springs. Dr. Fazio 
and other investigators have frequently found absolutely no bacteria whatever in these waters, and often only four in a cubic centimetre. When we remember the high temperature of so-called thermal sulphur waters, which in many cases reaches more than fifty degrees Centigrade, it is perhaps surprising that even four individuals can be found in a cubic centimetre capable of withstanding the nauseous atmosphere of sulphuretted hydrogen in addition to such hot environment. Perhaps in the bacterial community these hot sulphur springs provide that place of punishment which figured so largely in the imagination of the early Christian fathers ; certain it is that in this bacterial hell, in the picturing of which so many of the old masters seem to have revelled, but very few individuals are to be found, and those which are there are almost entirely derived from one family.

In giving weight to the highly satisfactory results of these bacterial examinations in forming an estimate of the microbial quality of natural mineral waters, it must be borne in mind that these investigations were all made of the said waters in a state of nature straight from the source, and before they had undergone the barbarous ordeal of commercial manipulation such as the process of bottling. 


\section{BACTERIOLOGY AND WATER II7}

We are all of us sufficiently acquainted with the first principles of germ life to realise how deftly and how directly any inattention to hygienic details is reflected in the larder or the store-room; and it requires but little stretch of the imagination to picture the bacterial armaments which would at once invade these peaceful waters on the first suggestion of relaxed vigilance, or removal of that rigid surveillance so essential for their protection and preservation. 


\section{MILK DANGERS AND REMEDIES}

T T may with justice be said that in no depart1 ment of applied bacteriology is more activity apparent than in that which has for its object the building up of a scientific basis for dairy practice. Although this is undoubtedly true, yet, unfortunately, unlike its continental neighbours, the British public, with whom practically rests the control of our dairy industries, has hitherto held itself strangely aloof, evincing little or no sympathy in researches which, even if they fail to interest, should surely impress with a sense of the great hygienic importance attaching to them. But this apathy is not only to be deprecated in the interests of health, but also on economic grounds.

We have only to turn to the reports issued by the Board of Agriculture to realise what this characteristic British apathy has brought about in the dairy industry of this country. Thus in the year 1898 we are officially informed that we imported $359,425, \mathrm{I} 36$ pounds of butter, the little country of Denmark alone sending over to us 
$163,883,360$ pounds! Our cheese imports reached the enormous total of $262,018,624$ pounds, whilst 8I7,274 cwts. of condensed milk and I0,69I of milk and cream were supplied to us from without.

If we glance at the energy and enthusiasm displayed by other countries, and notably Denmark, in the prosecution and scientific development of the dairy industry, we shall not wonder at the high standard of excellence achieved, or at the readiness displayed by Great Britain to absorb their produce. Thus, whilst in England it may be questioned whether in a single dairy the artificial souring of cream by pure cultures of bacteria is carried out, in Denmark the use of so-called special bacterial butter-starters is rapidly gaining ground. Thus, whereas in 1888 at the Odense Exhibition not a single sample of butter was exhibited in which pure bacterial cultures had been employed, in $1894,46.7$ per cent. of the samples shown were thus produced, in $1896,89.2$ per cent., in 1897 , 94.4 per cent., $1898,95.9$ per cent., and in 1899 , every sample, and since this year nearly every dairy of importance in the country employs special bacterial butter-starters.

The Danes are enlightened and shrewd enough to realise that in order to retain their existing markets and acquire fresh ones, it is necessary to take advantage of every improvement in methods 
of manufacture which scientific research has placed at their disposal, and their reward is justly reaped in the prosperity of their dairy industry and the high reputation enjoyed by their produce. If we contrast the adaptability and elasticity of the continental mind in regard to new discoveries with the crude conservatism of the British manufacturer, then, indeed, is the success of our rivals and corresponding decline of our own prosperity most perfectly intelligible.

Again, we are informed that the recent visit to London of a deputation representing Russian agricultural interests is already bearing fruit, and contracts have been signed for the regular importation of large quantities of Russian dairy produce. The English market is already well supplied with Russian eggs, but an opening has now been found here for the disposal of Russian butter and cheese.

Finland, again, the total population of which is less than half that of London, exports to this country no less than 12 million marks' worth of butter annually.

As a writer recently put it: "Foreigners and colonists have captured our butter markets; if the consumption of milk sterilised in bottles becomes the fashion, they will likewise capture our milk markets." And this is no fanciful suggestion, for whilst the production of Pasteurised milk does not 
involve any considerable outlay in apparatus, its transport may be effected with the greatest ease. Indeed, frozen milk has been introduced into England from Norway and Sweden. It is first Pasteurised, then frozen in large wooden boxes, and shipped in the congealed condition, in which state it remains unchanged for a long period of time.

But it is undoubtedly with the public that the responsibility really rests, for as long as it does not care to create the demand for Pasteurised dairy products all the efforts of enlightened agricultural authorities in this country must inevitably end in failure.

On the Continent and in America dairybacteriology, as already pointed out, has made enormous strides, and has practically revolutionised the conduct of dairy work; and if we could but rouse ourselves from our lethargy we likewise should be able not only to boast of progress, but also to better hold our own ground in this important branch of agriculture; and one result would be that dairy troubles, which for so long have been accepted as more or less necessary evils, would yield here, as they have done elsewhere, to a more rigid attention to details, the significance of which scientific research has so successfully shown. 
Some of the most easily preventable, but at the same time most aggressively assertive, dairy troubles are undoubtedly directly dependent upon the conduct of milking operations.

In the first place, the cow itself is only too frequently in an uncleanly condition, and as its coat offers exceptional facilities for the harbouring of dust and dirt, the danger of foreign particles falling into the milk is always present unless precautions are taken to negative, or at least minimise, all such chances of contamination.

Professor H. L. Russell, of the Wisconsin Agricultural Experiment Station, cites in his little volume on Dairy Bacternology an instructive experiment which brings home very forcibly the importance of such precautions. A cow pastured in a meadow was selected for the experiment, and the milking was done out of doors, so as to eliminate as far as possible any intrusion of disturbing foreign factors into the experiment, such as the access of microbes from the air in the milkingshed. The cow was first partially milked without any precautions whatever being taken, and during the process a small glass dish containing a layer of sterile nutrient gelatine was exposed for one minute beneath the animal's body, in close proximity to the milk-pail. The milking was then interrupted, and before being resumed the 
udder, flank, and legs of the animal were thoroughly cleansed with water; a second gelatine surface was then exposed in the same place and for the same length of time. The results of these two experiments are very instructive. When the cow was milked without any special precautions being taken, 3,250 bacteria were deposited per minute on an area equal to the surface of a teninch milk-pail; after, however, the animal had been cleansed, only II 5 bacteria were deposited per minute on the same area.

Thus a large number of organisms can, by very simple precautions and very little extra trouble, be effectually prevented from obtaining access to milk. Even in the event of the milk being subsequently Pasteurised, clean milking is of very great importance; but still more imperative is it when it is destined for consumption in its raw, uncooked condition. If we consider how cows become covered with dirt and slime, that obstinately adhere to them when they wade through stagnant ponds and mud, and realise the chance thus afforded for malevolent microbes to exchange their unsavoury surroundings for so satisfactory and nourishing a material as milk, then indeed precautions of cleanliness, however troublesome, will not appear superfluous.

That a very real relationship does exist between 


\section{I24 BACTERIA IN DAILY LIFE}

the bacterial and dirt contents of milk has been clearly shown by actual investigation. A German scientist has made a special study of the subject, and has determined in a large number of milk samples the amount of foreign impurities present per litre, and the accompanying bacterial population per cubic centimetre.

The following results may be taken as typical of those obtained: in milk containing 36.8 milligrammes of dirt per quart as many as I $2,897,600$ bacteria were present per cubic centimetre; in cleaner samples, with $20^{\circ} 7$ milligrammes of dirt per quart, the number of bacteria fell to $7,079,820$; whilst in a still more satisfactory sample, containing 5.2 milligrammes of dirt per quart, there were $3,338,775$ bacteria per cubic centimetre.

Such results indicate how important a factor is scrupulous cleanliness in milking operations in determining the initial purity of milk, for there is no doubt that bacterial impurities in milk are in the first instance, to a very great extent, controlled by the solid impurities present.

I do not know of any determinations which have been made of the actual amount of such solid impurities present in our public milk-supplies, but such estimations have been made in many of those belonging to large cities in Germany. Thus, Professor Renk found in a litre of milk supplied to 
Halle about 75 milligrammes, whilst in another sample as much as 0.362 grammes per litre were detected. In Berlin Io milligrammes, and in Munich 9 milligrammes per litre, were found. Dr. Backhaus has estimated that the city of Berlin alone consumes daily with its milk no less than $300 \mathrm{cwt}$. of cow-dung. If we associate these amounts of solid impurities with their consequent bacterial impurities, then we shall obtain some idea of what the microbial population of these milksupplies may amount to.

These impurities are almost wholly preventable, but, unfortunately, but little importance is apparently attached to their presence in milk as a rule by dairymen.

In a letter published in the Sussex Daily Nezes a correspondent and well-known authority on dairy matters sounds a timely note of warning to our dairy managers :-

"I happen to know," he writes, "for a fact that Americans who visited one of our Dairy Shows at Islington were so disgusted at the method - or rather lack of cleanly method-exhibited there as our ordinary way of milking cows, that these visitors stated that nothing would induce them to drink milk while in England. I mention this circumstance so as to bring home to the minds of English dairy-farmers who may read this letter how very backward we are in this country as compared 


\section{I26 BACTERIA IN DAILY LIFE}

with more studious and careful foreign competitors. It is insisted upon by our foreign teachers that our cow-stalls are too short and not roomy enough, and our cow-houses badly constructed; that we do not (I) groom our cows or (2) clean the teats, nor (3) sponge their udders, bellies, and sides before milking with clean, tepid water; (4) that the milkers do not tie up the cow's tail nor clean their own hands and persons, nor (5) cover their clothes with a clean, well-aired blouse during milking; that (6) they generally milk in a foul atmosphere (bacterially), tainted with the odour of dung, brewer's grains, or farmyard refuse. I am sorry to state that there is too much solid fact about the contentions which, based upon bacteriology, are given as causes of injury to quality. . . Cleanliness is now a matter requiring the primary attention of English dairy-farmers. The study of bacteria proves that such inattention is greatly the cause of foreign butters beating ours."

It follows as a natural sequence that all the cans and vessels used for dairy purposes should be absolutely beyond suspicion of contamination. Professor Russell has shown by actual experiment that, even where the vessels are in good condition and fairly well cleaned, the milk has a very different bacterial population when collected in them and in vessels sterilised by steam.

Two covered cans were taken, one of which had been cleaned in the ordinary way, and the other sterilised by steam for half an hour. Previous to milking the animal was carefully cleaned, and 
special precautions were taken to avoid raising dust, whilst the first milk, always rife with bacteria, was rejected. Directly after milking bacterial gelatine-plates were respectively prepared from the milk in these two pails, with the following results: In one cubic centimetre of milk taken from the sterilised pail there were 165 bacteria; in that taken from the ordinary pail as many as 4,265 were found.

Another experiment illustrates perhaps even more strikingly the effect of cleanly operations in milking upon the initial bacterial contents of milk. The preliminary precautionary measures were carried out by an ordinary workman, and are in no sense so refined as to be beyond the reach of ordinary daily practice. "The milk was received in steamed pails, the udder of the animal, before milking, was thoroughly carded, and then moistened with water, so as to prevent dislodgment of dirt. Care was taken that the barn air was free from dust, and in milking the first few streams of milk were rejected. The milk from a cow treated in this way contained 330 bacteria per cubic centimetre, while that of the mixed herd, taken under the usual conditions, contained I 5,500 in the same volume. The experiment was repeated under winter conditions, at which time the mixed 
milk showed 7,600 bacteria per cubic centimetre, while the carefully secured milk only had 2 Io in the same volume. In each of these instances the milk secured with greater care remained sweet over twenty-four hours longer than the ordinary milk."

An organism which has exceptional opportunities for finding its way into cows' milk is the Bacillus coli communis, normally present in the fæces of all animals. This microbe is a very undesirable adjunct to milk, and may greatly interfere with the souring process, by multiplying extensively, and so producing a change in the milk which renders it impossible for the particular souring bacteria to carry on their work, resulting in their collapse and ultimate extinction. But this is not the only injurious effect which these Coli bacilli can produce in milk, for there is a growing conviction that their presence is responsible for many intestinal disturbances with which young children are specially troubled. Quite recently determinations of the bacterial contents of cow-dung have been made, and it has been ascertained that $a$ single gramme, ${ }^{*}$ freshly collected, of this material may contain as many as $375,000,000$ bacteria, of which the majority were found to be the above undesirable organism, the $B$. coli communis.

* One gramme $=15$ grains. 
Milk may also contain bacteria characterised by their remarkable resistance to heat, which is due to their possessing what is known as the hardy spore in addition to the ordinary rod form. The numbers in which they are present in milk varies with different samples; but they may be taken as a sort of index as to the care observed in milking, for they are always present in great quantity in uncleanly-collected milk. Careful studies have been made of this class of milk bacteria by Professor Flügge and others, and it has been found that when added to milk upon which puppies were subsequently fed the latter succumbed under symptoms of violent diarrhøea.

The danger of even a few bacteria gaining access to milk is serious, on account of the fabulous rapidity with which they multiply when they find themselves in such congenial surroundings. Professor Freudenreich has made very exhaustive investigations to show how milk microbes may multiply in the time which elapses between milking and the receipt of the milk by the consumer. The following example will convey some notion of what bacterial propagation under these circumstances is capable of.

The sample of milk in question was found to possess on reaching the laboratory, two and a half 
hours after milking, a little over 9,000 bacteria in a cubic centimetre. The sample was divided into three portions, which were kept at different temperatures, and after definite intervals of time they were examined. The following table shows at a glance the results obtained:-

Number of Bacteria in about Twenty Drops of Milk.

\begin{tabular}{|l|r|r|r|}
\hline & \multicolumn{3}{|c|}{ Temperature. } \\
\cline { 2 - 4 } When Examined. & \multicolumn{1}{|c|}{${ }^{\circ} 5^{\circ} \mathrm{C}}$. & \multicolumn{1}{|c|}{$25^{\circ} \mathrm{C}}$. & \multicolumn{1}{c|}{$35^{\circ} \mathrm{C}}$. \\
\hline After 3 hours & 10,000 & 18,000 & 30,000 \\
After 6 hours & 25,000 & 172,000 & $12,000,000$ \\
After 9 hours & 46,000 & $1,000,000$ & $35,280,000$ \\
After 24 hours & $5,700,000$ & $577,500,000$ & $50,000,000$ \\
\hline
\end{tabular}

Thus, after being kept in the laboratory for three hours the original 9,000 bacteria had in one case doubled, and in another more than trebled themselves. It will be seen that the temperature most favourable to the multiplication of these bacteria was 25 degrees Centigrade.

If a sample of milk containing originally such a comparatively small number of bacteria-for a figure under 10,000 per cubic centimetre sinks into utter insignificance when we read of samples containing 2,500,000_if such relatively bacterially pure samples may support such prodigious numbers 
of these Lilliputians, what the microbial population of less satisfactory samples may amount to well-nigh baffles our powers of calculation. Professor Russell writes: "If we compare the bacterial flora of milk with that of sewage, a fluid that is popularly, and rightly, supposed to be teeming with germ life, it will almost always be observed that milk when it is consumed is richer in bacteria by far than the sewage of our large cities. Sedgwick, in his Report to the Massachusetts Board of Health for I890, found that the sewage of the city of Lawrence contained at the lowest 100,000 germs, whilst the maximum number was less than 4,000,000 per cubic centimetre.* This range in numbers is much less than is usually found in the milk-supply of our large cities."

Numerous researches have been carried out during the last half-dozen years to try and localise the origin of some of the principal dairy troubles, with a view to their possible extinction, or at least control. In the course of these investigations quite a number of the bacteria found in milk have been successfully hunted down, and their offences brought home to them.

Thus, from so-called "bitter" milk a bacillus

* American sewage, it must be noted, is usually weaker and poorer in bacterial life than that of our country, by reason of the greater amount of water with which it is diluted. 
has been isolated by Professor Weigmann, and found responsible for this particular change. Another microbe was discovered in bitter cream whose office apparently consisted in rendering milk strongly acid and extremely bitter. Again, that objectionable condition of milk known as slimy, ropy, or stringy, is brought about by certain bacteria which render it viscous; whilst another crop of microbes are occupied in conferring upon it the power of sticking to everything that touches it, making it capable of being drawn out into threads from several inches to several feet in length.

Although we object in this country to slimy milk, in Holland it is in special request for the production of a certain cheese known under the name of Edam. In Norway this kind of milk forms a popular drink called Taettemjolk, and to produce it artificially they put the leaves of the common butter-wort (Pinguicula vulgaris) into milk. Professor Weigmann has discovered a micro-organism which frequents the leaves of this plant endowed with particular powers of producing slimy milk, and doubtless the credit of furnishing Taettemjolk is really due to this microbe, and not to the innocent butter-wort. "Soapy" milk, again, has been traced to a specific germ discovered in large numbers in straw used for bedding, whilst it was also detected in the hay that served for fodder. During 
milking these sources had supplied the infection, and the peculiar fermentation was distinctly shown to be microbial in origin. So-called red and blue milk, and those various hues ranging from bright lemon to orange and amber, are also now known to be directly attributable to bacterial activity.

But of even greater significance than all these bacterial dairy troubles is the risk of spreading disease which is furnished by milk contaminated with pathogenic micro-organisms.

"There can be no shadow of doubt," said the Lancet now many years ago, "that the contagia of typhoid and scarlet fever are disseminated by milk, and that boiled milk enjoys a much greater immunity from the chance of conveying disease."

This was written at a time when the study of bacteria was yet in its infancy, and before any direct experimental evidence had been obtained on the behaviour of microbes in milk or concerning the part played by them in the dissemination of disease. The writer evidently did not venture to cast further aspersions on the character of milk, or he might have included diphtheria amongst the diseases which can be spread by its means; but there is another omission which still more conclusively indicates the remote age in the history of bacterial science at which this correspondent to the Lancet wrote, and that is the absence of 
all reference to the tubercle bacillus in relation to milk. At the present day hardly a bacteriological journal is published which does not contain some reference to the question of tuberculosis and milk, and the transmissibility of this disease when present in cattle to man.

As regards the dissemination of various zymotic diseases by milk, the evidence which has been collected points very conclusively to the responsible part which may be played by milk in this connection. Many instances have been cited, also, of the culpability of milk in distributing typhoid germs. A striking case which occurs to me, and which may be mentioned in passing, is one which occurred in a city in America a few years ago, in which an outbreak of this disease was traced to a dairy in which the vessels had been washed out with typhoidal-polluted water. No less than 386 cases of typhoid declared themselves in six weeks, and of this number over 97 per cent. occurred amongst families obtaining their milk from the same dairy. A careful inspection revealed the fact that the milk-cans had been rinsed out with water from a shallow well contaminated with typhoid dejecta.

Diphtheria is also justly associated with infected milk, and if we take into consideration the now established fact that diphtheria bacilli thrive and 
multiply with particular facility in milk, even more so than in ordinary broth cultures; that they have been found in air in a vital and virulent condition, and may be scattered far and wide attached to dust particles; and if we remember the numerous opportunities offered for the infection of milk by persons handling it, who either themselves are suffering from this disease or are in diphtheria surroundings - then indeed we can readily understand how milk becomes a diphtheria-carrier of the first order.

Tuberculosis in cattle, and how this disease may affect the character of dairy produce, is, as already pointed out, a subject which is attracting the attention of a large number of investigators.

The general public is perhaps hardly aware of how widespread this disease is amongst cattle, and it is only of late years that very careful inquiries have elicited the fact that it is not only very extensively distributed, but may be present in animals to all outward appearance in perfect health.

In Germany it was asserted a few years ago that every fifth cow was tuberculous, and even this was regarded as a moderate estimate. The distinguished Danish pathologist, Professor Bang, is responsible for the announcement that during the years 189I-3 17.7 per cent. of the animals slaughtered in Copenhagen were infected with 
tuberculosis. In Paris we have been told that, of every thirteen samples of milk sold, one was infected with tubercle bacilli, whilst in Washington one in every nineteen samples of milk was stated to be similarly tainted.

The existence of tubercular disease in cows, and its transmission to other animals fed with their milk, has been brought out in a striking manner in investigations published by the Massachusetts Society for the Promotion of Agriculture. In one case as many as over 33 per cent. of the calves fed with milk from tuberculous cows succumbed to the same disease. According to Hirschberger, Io per cent. of the cows living in the neighbourhood of towns where the conditions of their environment are not generally the most satisfactory or conducive to health suffer from tuberculosis, and 50 per cent. of these animals yield milk containing tubercle bacilli.

The demand which is being made by municipal authorities to be invested with the power of inspecting the country farms from whence their cities are supplied with milk and other argricultural produce could not have received stronger support than was recently supplied by a case tried in Edinburgh, and as this is only a sample of what is doubtless a daily, although undetected occurrence in many municipalities, it will not be 


\section{MILK DANGERS AND REMEDIES}

out of place to quote the following from the published report of the proceedings :-

"A cow was brought into the city for sale as food, and the evidence showed it to be in the last stages of tubercular disease. 'Its head was hanging down; it breathed with difficulty, and it had frequent fits of coughing; while its udder was swollen with the disease.' All the organs were diseased, and the milk teemed with bacilli. Yet, it seemed, the milk from this animal had been regularly sent into Edinburgh for sale. In face of facts like these, it is difficult to see on what grounds the claim of towns to inspect country dairies doing a town business can be resisted. At least the towns should have the power to refuse admission to milk from sources not open to inspection. It is not enough for the county authorities to say that they inspect the dairies in their own areas. In this case the condition of the animal was only found out when it was brought into the town to be sold for food."

\section{Further comment is unnecessary!}

Some German investigators have discovered the interesting fact that the centrifugal method of separating milk not only has a remarkable effect upon its bacterial contents, but also upon tubercle bacilli when present. On examining the so-called "separator slime," it is found to contain not only large quantities of solid matters, but also masses of bacteria which have been thrown out during the operation. This method of treating milk has, 
curiously, a particular effect upon tubercle bacilli present, for Professor Scheurlen has found that they are nearly all left in the slime. Naturally his observation was not slow in being tested by other investigators; but Professor Bang has quite independently confirmed Scheurlen's discovery, and, still more recently, Moore purposely infected milk with these bacilli, and found that they were deposited in the slime to a most remarkable extent. Coupled, however, with this peculiar behaviour of tubercle bacilli in separated milk is the fact called attention to by Ostertag, that tuberculosis is much more prevalent among swine in Denmark and North Germany, where the centrifugal process in creaming is extensively used, and where, until recently, this slime was given to the animals in its raw, uncooked condition.

Before leaving this subject of separated milk, reference may be made to a danger, which has recently been publicly called attention to, surrounding the use which is made of skim milk. By an arrangement with the farmers who supply the milk, those clients who principally use it for producing butter return the skim milk to them after it has been through the separator, when it is employed for stock-feeding purposes. The milk in large dairies derived from different farmers is mixed, and hence the skim milk which is re- 
turned is also mixed. Thus, in the event of the milk from one farm being infected, not only is the whole milk-supply of a particular dairy infected, but, in returning the mixed skim milk likewise infected in its proper proportion to the different farmers, the virus is distributed over several farms. So real is this danger, and such unfortunate results have followed this practice of returning mixed infected skim milk, that since I 894 the Prussian Government has issued special orders for its disinfection by means of heat, in the hope of coping with this difficulty.

The longevity of the tubercle bacillus and its remarkable vitality under all kinds of untoward circumstances have not unnaturally added fresh significance to this frequent discovery of its presence in milk; moreover, laboratory experiments have shown that these germs can live for upwards of one hundred and twenty days in butter, and from sixty to seventy days in cheese. It is not surprising, therefore, to find a Royal Commission appointed in 1890 with the express object of inquiring and reporting upon "What is the effect, if any, of food derived from tuberculous animals on human health?"

In the summary appended to the report we read: "Tuberculous matter in milk is exceptionally active in its operation upon animals fed either 


\section{I4O BACTERIA IN DAILY LIFE}

with milk or with dairy produce derived from it. No doubt the largest part of the tuberculosis which man obtains through his food is by means of milk containing tuberculous matter."

That the Commissioners were alive to the great importance of this means of spreading disease is further shown by the following significant paragraph: "In regard to milk, we are aware of the preference by English people for drinking cow's milk raw, a practice attended by danger on account of possible contamination by pathogenic organisms."

The Commissioners spared no pains in endeavouring to throw light upon the important question they were appointed to report upon, and five years elapsed before they published the results of their inquiries. A decade ago the opinions expressed by them represented the current opinions of the leading bacteriological authorities in scientific circles at home and abroad, and these opinions were gradually filtering down to the general public, which is so conservative in clinging to traditions and popular delusions, when, like a flash out of the blue, the bacteriological Jove, Professor Robert Koch, hurled his thunderbolt into the arena, and at the British Congress on Consumption, held in London in the summer of I90I, declared his belief that bovine and human tuberculosis were distinct 
diseases. The significance of such a challenge to current scientific opinion, and its far-reaching influence if proved to be correct, was quickly appreciated by the distinguished audience who had gathered to hear what so great an authority as Dr. Robert Koch had to say on consumption and its distribution. The vital question raised by the original discoverer of the tubercle bacillus is still the subject of discussion, experimental inquiry, and much controversy, and we cannot here attempt to discuss the pros and cons for the acceptance or rejection of this new theory concerning the character of tuberculosis. It would, however, be regrettable in the extreme if the publication of this opinion were to encourage dairy authorities to relax in the slightest the efforts now so tardily being made by them to protect their dairy produce and ensure its safety for food-supply.

Before leaving this branch of the subject reference must be made to some very important researches recently published by Professor Ostertag, of Berlin, on the presence of tubercle bacilli in the milk derived from cows which, whilst reacting to the tuberculin test, exhibit no clinical symptoms of tuberculosis. The importance of this investigation to farmers and all breeders of stock is evident, for it has not infrequently been urged that all the milk from such tuberculin-reacting cows should 
be discarded for dietetic purposes. Professor Ostertag, at the request of the German Government, has carried out a most elaborate and very extensive series of investigations to determine the question as to whether such milk is dangerous to health. I cannot do better than quote the conclusions appended to the original memoir, in which Professor Ostertag expresses himself as follows: "The milk of cows which only react to tuberculin does not contain tubercle bacilli; calves and pigs can be fed during weeks and months with milk derived from such cows without contracting tuberculosis."

A very important rider, however, is added, in which it is pointed out that inasmuch as no doubt exists as to the highly infectious character of the milk derived from cows the udders of which are tuberculous, and from animals in which the disease is clinically recognisable, the weeding out of all such animals must be regarded as the most important measure for the prevention of the dissemination of tuberculosis through milk.

We must now pass on to a consideration of some of the methods which are available for obtaining germ-free milk, some of which are, however, attended with too great labour and inconvenience to admit of practical application. Thus, wishing to prepare some sterile milk without 
altering its chemical composition to feed certain microbes with, I had to patiently heat it for from one to two hours on five successive days, watching the while that the temperature remained between $58^{\circ}$ and $65^{\circ}$ centigrade. The milk was sterile, and I kept it for months, but such a process, of course, is impossible for domestic purposes.

The addition of chemicals to milk is both undesirable and ineffectual; amongst such substances boracic acid, borax, and salicylic acid are employed, but whilst the two former have been found to produce but little effect upon disease germs present in milk, salicylic acid hinders curdling more than other substances, and even if added in the small proportion of twelve grains per quart is said to impart a taste to the milk, and is, moreover, incapable of destroying typhoid bacilli if present.

Authorities are, moreover, not agreed as to the harmlessness of this ingredient, and in France the employment of salicylic acid in the preservation of food is strenuously opposed by doctors, who consider its habitual use injurious to health.

\section{A Departmental Committee of the Local} Government Board was appointed in this country to inquire into the use of preservatives in foods. In their report they state that from 42 up to 126 grains of boracic acid were detected in milk offered for sale, and that on one occasion no less than 
80 grains of this material were present in a pint of milk sold to their inspector. It is pointed out that as long as preservatives are permitted there is no guarantee against the addition of excessive amounts to milk, and that evidence has been obtained pointing to an injurious effect of boracised milk upon the health of young children. The Committee report that in Denmark the use of preservatives is strictly prohibited, and the prohibition is strongly enforced; neither are preservatives permitted in Belgium.

The application of heat to milk is, in fact, the only advisable and reliable method for rendering it free from germs, but a great deal depends upon the manner in which the heat is applied and the cleanly condition or otherwise of the milk employed.

The difficulties which have to be overcome in producing efficiently sterilised milk are due, in the first place, to the remarkable power of resisting heat which characterises not only some disease germs, but also some of the microbes which are particularly partial to milk; secondly, to the sensitiveness of milk to heat, as exhibited by its alteration in taste and other respects through exposure to high temperatures.

To overcome these difficulties many ingenious pieces of apparatus have been devised, based upon a process originally introduced by Pasteur for pre- 
venting certain defects in wine and beer, and which consists in the application of a temperature of about $60^{\circ}$ Centigrade. This process is known as Pasteurisation, after its renowned initiator.

So-called "Pasteurised" milk has become during the last year or so increasingly popular in this country, whilst on the Continent it has been largely dealt in for several years past, and has commercially proved a great success. Indeed, so strong is the prejudice amongst our neighbours across the Channel against using unboiled milk that in Leipzig and other cities in Germany endeavours have been made by charitable and other societies to encourage the use of sterile milk amongst the poorer classes, whilst it has been stated that the introduction of Pasteurised milk among the poor of New York City, through the philanthropic efforts of $\mathrm{Mr}$. Nathan Straus, has done much to reduce the high rate of mortality amongst infants during the hot summer months. In France, i.e. in Paris and Grenoble, in order to reduce if possible the lamentable mortality amongst infants from diarrhoea in the summer months, which was largely attributed to the use of unboiled milk, sterilised milk was distributed to the poor at the cost of the community in general. In Grenoble, according to statistics collected by Berlioz during the years I894-6, the death-rate of infants under a year old 
in the months of July, August, and September fed on raw milk reached $69^{\circ} 3$ per 1,000 , whilst amongst those supplied with sterilised milk it was reduced to $27^{\circ} 9$ per $\mathrm{I}, 000$.

Just, however, as all is not gold that glitters, so all sterilised milk so-called is not necessarily free from bacteria. Indeed, according to a recent German authority, "the complete and certain sterilisation of milk is not yet to hand."

Dr. Weber examined the sterilised milk as supplied by various companies in the city of Berlin. As many as I 50 bottles were tested from eight different sources, with the result that not one of these eight companies was found to be supplying milk free from bacteria, or, in other words, what it professed to be-sterile. True, the percentage of sterile bottles varied from 5 per cent. in some of the supplies to 86 per cent. in others.

Thus it may be realised how, as has been already pointed out, difficult a matter it is to devise an efficient apparatus for the reliable sterilisation of milk. So far it appears that the best results have been obtained with an apparatus devised by Flaack, a director of the Brunswick Sterilising Milk Company, and known as the Flaack apparatus. Exhaustive examinations made during the course of a whole year in the Hygienic Institute at 
Würzburg never once showed a failure, all the samples tested being germ-free.

Some supervision is, therefore, necessary in the case of these milk-sterilising companies to ensure that the public is obtaining what it is paying for, as it has been shown by Professor Flügge, a worldrenowned authority on the subject of milk and its sterilisation, that the bacteria left over in these so-called sterilised milk samples are by no means invariably a harmless residue, but, on the contrary, may consist of individuals which he has gathered together in a class under the heading of poisonous peptonising bacteria, and which owe this unfortunate designation to the rapidity and energy with which they can engender the putrefaction of albumen. As indicating how essential it is that every detail in the sterilisation of milk should be adequately assessed, I may mention a paper recently published by $\mathrm{H}$. L. Russell and E. G. Hastings, of the Wisconsin Agricultural Experiment Station in the United States, on the importance of Pasteurising milk in closed rather than in open vessels, bacteria having been found more resistant in milk when heated in contact with the air than in closed vessels, this variation being attributed to the formation of a surface pellicle, which readily forms on milk when heated in open vessels to a temperature of about $60^{\circ}$ Centigrade 
or above. Experiments showed that organisms present in this pellicle or skin were capable of retaining their vitality when exposed to a temperature six degrees higher than that of the milk beneath the membrane in which they were destroyed.

Objections to the use of boiled milk have been frequently made on the grounds of its being more difficult of digestion, and hence less wholesome than the raw article. I may only point out that in this, as in most other matters where opinions may be made or unmade, and in consequence of the facts available being scanty must be more or less arbitrary in character, Dr. Duclaux, the successor to Pasteur as Director of the Pasteur Institute in Paris, has expressed himself as follows in an article on "La digestibilité du lait stérilisé." After reviewing the various special researches which have been made on the subject, he says:-

"Ceci nous amène á une conclusion qu'il faut bien avoir le courage de tirer, c'est que ces études chimiques sur la digestibilité du lait ne sont pas adéquates à la question à résoudre. . . . En attendant, tenons-nous-en à cette conclusion générale, que le lait pasteurisé, chauffé ou stérilisé, est encore du lait, devant la science comme devant la pratique, et que si son emploi présente parfois des inconvénients, ceux-ci sont légers et amplement compensés par les avantages." 


\section{BACTERIA AND ICE}

THE fate of bacteria when frozen excited the 1 curiosity of investigators already in the early years of bacteriology, for in I87 I we find Burdon Sanderson recording the fact that water which he had obtained from the purest ice contained microzymes, or, as we now prefer to call them, micro-organisms.

It is quite possible that at the time this announcement was made it may have been received with some scepticism, for it was undoubtedly difficult to believe that such minute and primitive forms of vegetable life, seemingly so scantily equipped for the struggle for existence, should be able to withstand conditions to which vegetable life in more exalted circles so frequently and lamentably succumbs.

The tormented agriculturist realises only too well what havoc is followed by a return in May to that season

"When icicles hang by the wall,

And Dick the shepherd blows his nail And Tom bears logs into the hall,

And milk comes frozen home in pail." 
Again, with what solicitude those of us who have gardens wait to see what will have survived the iron grip of winter in our favourite flower borders, and how frequently we have to face blanks in the ranks of some of its most cherished occupants! Numerous bacteriologists, however, have now confirmed this fact, the fields of ice and snow have been repeatedly explored for microorganisms, and it has been shown how even the ice on the summit of Mont Blanc has its complement of bacterial flora, that hailstones as they descend upon the earth contain bacteria, that snow, the emblem of purity, is but a whited sepulchre, and will on demand deliver up its bacterial hosts. Quite apart from its general scientific interest, the bacterial occupation of ice is of importance from a hygienic point of view, and a large number of examinations of ice as supplied for consumption have been made. Thus, Professor Fraenkl and also Dr. Heyroth have submitted the ice-supply of the city of Berlin to an exhaustive bacteriological examination. These investigations showed that the bacterial population of ice as supplied to Berlin is a very variable one, and fluctuates between great extremes, rising to as many as 25,000 bacteria in a cubic centimetre (about twenty drops) of ice-water, and falling to as few as two in the same measure. 
There are numerous circumstanccs which come into play in determining the density of the bacterial population in ice. First, of course, the initial quality of the water from which the ice is derived is a factor of great importance, for the purer the water the fewer will be the bacteria found in the resulting ice.

Again, if the ice field is wind-swept by air bearing an unduly rich complement of bacteria, as may be expected in the vicinity of populous cities, for example, then the ice will reflect in its bacterial contents the undesirable neighbourhood in which it was produced. Water in repose, again, yields purer ice than water in movement during freezing, for during rest opportunity is given for the bacteria present in suspension to subside, the process of sedimentation or deposition of bacteria which takes place under these conditions playing an important part in water-purification; when, however, the water is disturbed by swift currents, or agitated by storms, this process is interrupted, and the bacteria become entangled in the ice and frozen in situ.

The importance attaching to the physical conditions under which ice is produced in enabling an estimate to be formed of the safety or otherwise of the same for consumption may be gathered 
from the following extract from an American report on the subject:-

"On the whole it is evident that the conditions surrounding water when it freezes are very important factors in determining the purity of the ice formed. If there is a considerable depth of water in portions of a somewhat polluted pond or river, and the ice is formed in these portions in comparatively quiet water with but little matter in suspension, this ice will probably be entirely satisfactory for domestic use. On the other hand, ice formed in shallow portions of such ponds or rivers, even during still weather, or in any portion if there is a considerable movement of the water by currents or wind while it is forming, may be rendered by these conditions entirely unfit for domestic use."

We have learnt that ice contains bacteria, that its bacterial contents are to a certain extent dependent upon the bacterial quality of the water before crystallisation, and that an important factor in determining its purity is afforded by the physical conditions prevailing at the time of freezing.

It will be of interest to ascertain in more detail what effect the process of freezing has upon the number of bacteria present in the water-what is the degree of bacterial purification effected during the conversion of water into ice.

Now Professor Uffreduzzi, in his investigations 
on the ice-supply of Turin, part of which is derived from a much-polluted portion of the River Dora, found that about 90 per cent. less bacteria were present in the ice than were present in the water from which it was produced. In the making of ice, therefore, a remarkable removal of bacteria may be effected which approaches very nearly the degree of bacterial purification which is achieved during the best-conducted sandfiltration of water.

Uffreduzzi's results have been repeatedly confirmed by other researches. Thus, in regard to ice obtained from the River Merrimac, water which contained originally about 38,600 bacteria per cubic centimetre, on its conversion into ice had only from three to six. Sewage, again, containing about a million and a half bacteria per cubic centimetre after being frozen only contained under 74,000 . It should be mentioned that this last figure represented the number of bacteria obtained by thawing the outside of the sewage ice-cake; inside the cake there were more found-about I 21,000 . The difference in these figures is due to the fact that, whereas the outer layers of ice looked quite clear, towards the centre the ice contained sewage sludge and hence more bacteria had become arrested; but in spite of this the bacterial purification effected is very striking, 
although not sufficient to render the use of ice from such a polluted source either palatable or desirable.

It is, of course, a well-known fact that water possesses the power of purifying itself during its transformation into ice, and that the process of crystallisation not only prevents a considerable proportion of the matters in suspension from becoming embodied in the ice, but also eliminates a large percentage of the matters in solution, the latter being driven from the water which is being frozen into the water beneath. If, therefore, ice in the act of forming can get rid of matters in solution, it is not difficult to understand how it can eject bacteria, which though so minute are yet bodies of appreciable dimension and in suspension. But that there are limits to this power of excluding bacteria, and that, as in the case of other mechanical processes, an overtaxing of the available resources is at once reflected in the inferiority of the product, is shown by the frozen sewage experiment, in which the ice, having had too large a supply of bacteria in the first instance to deal with, was unable to get rid of more than a certain proportion, and was obliged to retain a very considerable number. Hence great as is the degree of purification achieved by ice in forming, yet it must be recognised that its powers in this 


\section{BACTERIA AND ICE}

direction are limited, and that the fact of water being frozen does not necessarily convert a bad water into immaculate ice.

It is worthy of note that the city of Lawrence, in Massachusetts, obtains the greater portion of its ice from a river which in its raw, unpurified condition was rejected for purposes of water-supply in consequence of the numerous and severe epidemics of typhoid fever which accompanied its use. Since the application of sand-filtration to this water, however, the death-rate from typhoid in this city, instead of being abnormally high, has fallen abnormally low, and this improvement is attributed to the excellent quality of the water supplied to the city, and has taken place despite the use which still continues of ice from the polluted river. The authorities consider the city's immunity from typhoid amply justifies their sanctioning the distribution of this river-ice, the freezing of the water having rendered it sufficiently pure to remove all danger to health from its consumption.

So far we have been considering the effect on bacteria of freezing carried on under more or less natural conditions; but much interesting work of a more detailed character has been carried out with reference to the behaviour of particular varieties of micro-organisms when frozen under more or less artificial conditions. 


\section{I56 BACTERIA IN DAILY LIFE}

Thus Dr. Prudden froze various bacteria in water at temperatures ranging from $-\mathrm{I}^{\circ} \mathrm{C}$. to $-10^{\circ} \mathrm{C}$., and he found that different varieties were very differently affected by this treatment; that, for example, a bacillus originally obtained from water, and introduced in such numbers as represented by 800,000 individuals being present in every twenty drops, after four days' freezing had entirely disappeared, not one having survived. On the other hand, similar experiments in which the typhoid bacillus was used resulted in the latter not only enduring a freezing of four days' duration, but emerging triumphant after it had been carried on for more than IO3 days!

In these experiments it should be borne in mind that, as the ice was frozen to a solid block or lump, there was no opportunity for the mechanical committal of the bacteria during freezing to the water beneath; all the bacteria present were imprisoned in the ice, and the fact that the typhoid bacteria were not destroyed by being frozen shows that they can withstand exposure to such low temperatures, although, as we have seen, the other variety of bacillus employed was destroyed.

Dr. Prudden, however, discovered an ingenious method by which even typhoid bacilli were compelled to succumb when frozen. In the course of his investigations he found that bacteria which had 
offered the stoutest resistance under freezing were extremely sensitive to this treatment if the process was carried on intermittently, or, in order words, if the temperature surrounding them was alternately lowered and raised.

In this manner the bacteria may be said to be subjected to a succession of cold shocks, instead of being permitted to remain in a continuously benumbed condition. The vitality of typhoid bacilli was put to the test under these circumstances, the freezing process being carried on over twenty-four hours, during which time, however, it was three times interrupted by the ice being thawed. The effect on the typhoid bacteria was striking in the extreme; from there being about 40,000 present in every twenty drops, representing the number originally put into the water, there were only ninety at the end of the twenty-four hours; and after a further period of three days, during which this treatment was repeated, not a single bacillus could be found. This signal surrender to scientific tactics forms a marked contrast to the stout resistance maintained for over IO3 days under the ordinary methods of attack.

But, although the typhoid bacillus appears to submit and meekly succumb to this plan of campaign, yet the conclusion must not be rashly 
drawn that all descriptions of bacteria will be equally feeble and helpless in these circumstances.

Doctors Percy Frankland and Templeman have shown that the spore form of the anthrax bacillus is able to successfully challenge all such attempts upon its vitality. Thus when put into water and frozen at a temperature of $-20^{\circ} \mathrm{C}$, the process being extended over a period of three months and interrupted no fewer than twenty-nine times by thawings, when examined even after this severe series of shocks, it showed no signs of submission and clung to life as tenaciously as ever.

The more sensitive form of anthrax, however, the bacillus, was readily destroyed; for after one freezing its numbers were already so much reduced that it was only with difficulty that even one or two could be found, and after the second freezing every one out of the large number originally present had died.

Renewed interest has been of late revived in the question of the behaviour of bacteria at low temperatures, in consequence of the possibility of obtaining, by means of liquid air and liquid hydrogen, degrees of cold which were undreamt of by the scientific philosophers of fifty years ago. Public interest has also been quickened in such inquiries on account of the important part which low temperatures play in many great commercial 


\section{BACTERIA AND ICE}

developments, their application rendering possible the transport from and to all parts of the world of valuable but perishable foodstuffs, thus encouraging local industries by opening up markets, and bringing prosperity to countries and communities which before were seeking in vain an outlet for their surplus produce.

The application of cold storage for preservation purposes is, however, no novelty; for nature ages ago set us the example, and of this we have been lately reminded afresh by the discovery announced by Dr. Herz of a mammoth in Siberia, which, despite the thousands of years which have elapsed since it was originally overwhelmed and frozen, is described as being in a marvellous state of preservation.

Thus we are told that "most of the hair on the body had been scraped away by ice, but its mane and near foreleg were in perfect preservation and covered with long hair. The hair of the mane was from four to five inches long, and of a yellowish brown colour, while its left leg was covered with black hair. In its stomach was found a quantity of undigested food, and on its tongue was the herbage which it had been eating when it died. This was quite green."

Considering that certainly more than eight thousand years had elapsed since this creature 
was peacefully consuming what proved to be its last meal, nature's method of cold storage must indeed be regarded as unsurpassable in the excellence of its results.

I believe it was in the year I 884 that the first attempts were made to follow more closely and in greater detail the precise effect upon different bacteria of submitting them to temperatures of such a low degree as - $130^{\circ} \mathrm{C}$., obtained by means of solid carbonic acid. These experiments were carried out by Pictet and Young, and are recorded in the Comptes Rendus of the Paris Acádemy of Sciences.

They differ from those which we have so far been considering, inasmuch as the bacteria were not frozen in water, but in culture-material, or, in other words, like the mammoth, whilst enjoying a midday meal!

One of the micro-organisms experimented with was a bacillus known at that time as the rinderpest bacillus, capable of producing disease in animals when inoculated into them and existing both in the spore and bacillar form. Pictet and Young specially state that the spore form was present in the specimens employed by them, and hence the fact that this micro-organism was alive after being frozen and exposed to this low temperature of $-130^{\circ} \mathrm{C}$. for the space of twenty hours is not, 
perhaps, so surprising when we bear in mind the remarkable feats of endurance exhibited by spores which have with justification obtained for them a prominent place amongst the so-called curiosities of bacteriology. But of more interest than their mere survival in these circumstances is the fact that, on being restored to animation-or, in other words, released from their ice-prison-these bacteria were discovered to have retained all their pathogenic properties, this period of enforced rigidity having in no way affected their disease-producing powers.

Such results naturally only served to whet the scientific appetite for more, and the liquefaction of air and of hydrogen placing much lower temperatures at the disposal of investigators, those bacteriologists who were fortunate enough to command a supply were not long in availing themselves of the opportunity thus given them of further testing the vitality of micro-organisms.

Botanists had already shown that exposure to liquid air, which means a temperature of about $-190^{\circ} \mathrm{C}$., and to liquid hydrogen, which means a temperature of about $-250^{\circ} \mathrm{C}$, did not impair the germination powers of various descriptions of seeds, such as those of musk, wheat, barley, peas, vegetable marrow, and mustard, and that their actual immersion in liquid hydrogen for the 
space of six hours did not prevent them coming up when sown just as well as ordinary seeds which had not undergone this unique experience; hence the opportunity of submitting other members of the vegetable kingdom to these low temperatures was eagerly sought for by bacteriologists. Dr. Macfadyen found this opportunity in the laboratories of the Royal Institution, and, Professor Dewar having placed a generous supply of liquid air and liquid hydrogen at his disposal, he submitted specimens growing in various culturematerials, such as gelatin, broth, potatoes, etc., of typhoid, diphtheria, cholera, anthrax with spores, and other bacteria, for twenty hours and seven days respectively, to a temperature of about $-190^{\circ} \mathrm{C}$. In no instance, however, whether exposed when growing in fluid or solid media, could any impairment of their vitality or the slightest alteration in their structure be observed. Similar results were obtained when liquid hydrogen, or a temperature of about $-250^{\circ}$ C., was applied. The question of the retention or otherwise of the disease-producing powers of these bacteria was not investigated, and in this connection much interest attaches to Mr. Swithinbank's investigations on the vitality and virulent properties of that notorious malefactor amongst micro-organisms, the bacillus tuberculosis, when exposed to the tempera- 
ture of liquid air. The specimens of the consumption bacillus employed were originally obtained from the human subject, and they were exposed for periods varying from six hours to six weeks to $-190^{\circ} \mathrm{C}$. In each case the malignant properties of the tubercle bacillus after exposure were tested by their direct inoculation into animals, and the results compared with those which followed similar inoculations made with bacilli which had not been frozen in this manner, but had been grown in ordinary circumstances. In no single case, Mr. Swithinbank tells us, were these frozen tubercle bacilli deprived of their virulence, and the length of exposure, at any rate as far as could be judged after six weeks, appeared to make no difference in this respect. It is true that the pathogenic action of the frozen bacilli appeared to be somewhat retarded-that is, they took rather longer to kill animals than the ordinary unfrozen bacilli-but in every case their inoculation produced the typical tuberculous lesions associated with them.

Of particular interest, however, in view of what has been already discovered about the lethal effect upon bacteria of violent alternations of temperature, are Mr. Swithinbank's observations on the vitality of the tubercle bacillus when exposed to such extreme variations of temperature as are 
represented by a passage from $-190^{\circ} \mathrm{C}$. to that of I $5^{\circ} \mathrm{C}$.

The bacillus tuberculosis is admittedly a tough antagonist to deal with, and enjoys an unenviable notoriety for its robust constitution amongst the pathogenic members of the microbial world; hence a knowledge of its behaviour in these trying circumstances, as we now know them to be to bacterial life, becomes of special interest. Great must have been the investigator's satisfaction, then, when he discovered that the vitality of the consumption bacillus had been so seriously impaired by this treatment that its pathogenic properties collapsed, and the animals which were inoculated with these specimens, instead of with the continuously frozen bacilli, suffered no inconvenience, and remained in good health.

But although no appreciable change either in the structure, vitality, or malignant properties of the particular bacteria investigated have been noted as resulting from their exposure to extremely low temperatures, yet there is no doubt that a certain proportion of the individual micro-organisms present-those probably whose constitution is less robust than their more fortunate associates-do succumb under these trying conditions.

This fact has been well brought out by Dr. Belli, of the University of Padua, in the experi- 
ments which he made with the fowl-cholera bacillus and the anthrax bacillus in the presence of very low temperatures. Thus he exposed a large number of fowl-cholera bacilli in broth to the temperature of liquid air, as many as 396,000 bacilli being present in every twenty drops of the liquid. After exposing them continuously for nine hours to $-190^{\circ} \mathrm{C}$., he had the curiosity, after thawing them, to count how many were left alive, and he found that an enormous mortality had taken place amongst them; for, instead of nearly 400,000 bacilli being present in one cubic centimetre, there were only about 9,000. On the other hand, in the broth tubes kept during that time in ordinary surroundings, the bacilli had flourished remarkably, and had greatly increased in numbers. Thus not only had no multiplication amongst these bacilli taken place, which circumstance is always regarded as indicative of their vital conditionnot only, then, had their vitality been arrestedbut a very large number of them had been actually destroyed in consequence of this severe treatment; but that the residue were not only alive, but unimpaired in their energies on being restored to animation, was proved by their being able to destroy animals, not having parted with any of their malicious propensities. Dr. Belli carried out similar experiments with the bacilli of anthrax 
and obtained very similar results. With regard to both these varieties of pathogenic bacteria, he mentions that their action upon animals was not quite so rapid as is characteristic of normal specimens of these micro-organisms, thus confirming the experiments in this direction made with frozen tubercle bacilli.

Not content with the exhibition of their powers of endurance, Dr. Belli determined to make yet another demand upon the vitality of these bacilli. For this purpose he immersed them in the liquid air itself, thus bringing them into direct contact with it, effecting this by lowering into the liquid strips of filter-paper soaked in broth containing these bacilli. But, in spite of remaining for the space of eight hours in these surroundings, they emerged triumphant, exhibiting no modification whatever either in their structure or pathogenic properties.

There are doubtless many other trials yet awaiting bacteria, to which they will most certainly be submitted before the limits of their powers of endurance have been adequately tested, but it is difficult to conceive of a severer strain upon their vital resources than the imposition of the conditions of which the above is but a brief sketch.

The triumphs achieved in this direction by micro-organisms are, however, closely approximated by the remarkable record established, according to 
the recent researches of Dr. Krause, by typhoid, anthrax, tubercle, and some other bacteria of preserving unimpaired not only their vitality but their virulence after having undergone for a period of twenty hours a pressure of no less than that of 500 atmospheres. When we reflect that a pressure of 500 atmospheres is equal to a pressure of about 7,500 pounds to the square inch, and that the normal pressure under which life is maintained upon this planet is approximately that of fifteen pounds to the square inch, this bacterial victory over physical conditions will be more readily appreciated.

The more intimate becomes our knowledge of bacteria, the more must we marvel at the equipment with which they have been provided for enabling them to maintain themselves in the struggle for existence-a struggle which is as severe and as remorseless in this lowly region as it is in those domains the inhabitants of which have risen to far loftier heights on the great ladder of life. 


\section{SOME POISONS AND THEIR PREVENTION}

ITTLE did the learned Dutchman Leeuwen1 hoek dream when, more than two hundred years ago, he recorded, in his Arcana Naturce, that he had found "viva animalcula" in his saliva, that this, the first beginning of bacteriology, would lead, a couple of centuries later, to the inauguration of a new era in the treatment of disease, in which these so-called animalcula, from being considered as curiosities, would come to be regarded as powers for good and evil of the first importance. Protective inoculation or serum theraphy, of which the public have lately heard so much in connection with diphtheria, is the direct outcome of bacterial investigations which during the last two decades have been pursued with such zeal in every part of the globe.

The vast domain of immunity, which until recently was an undiscovered country, is now being bit by bit annexed, and in all directions workers 


\section{POISONS AND THEIR PREVENTION I69}

are engaged upon opening up new tracts, in overcoming difficulties, in changing chaos into order.

The problems which surround immunity are of so complex and subtle a character that their mastery is by no means either easy or rapid, and many recondite researches appear at frequent intervals on this subject in foreign and other scientific journals, rendering it a difficult matter to keep pace with the new discoveries and the latest theories.

The interest in this country in toxins and antitoxins not unnaturally centres round that branch of the subject which deals with diphtheria, this disease having of late years figured so prominently in our mortality tables, whilst the production of diphtheria and other anti-toxic serums has been so finely elaborated abroad that it already constitutes an article of commerce, and doubtless helps to swell the exports of our great continental commercial rival.

In this connection the following statistics, published by Dr. Jalzer, of the Mülhaus Hospital, are of interest regarding the mortality from diphtheria before and after the introduction and application of diphtheria anti-toxin. The deathrate from this disease, writes Dr. Jalzer, which in 1892 and 1893 was fully 50 per cent., fell in 1895 
to 38.5 per cent., in 1896 to 28.8 per cent., in 1897 to 16 per cent., to 20 per cent. in 1898 , 15.15 per cent. in 1899 , and 18.75 per cent. in 1900.

So far the efforts which have been made to mitigate human suffering have attracted most attention; but it will be remembered that Pasteur, before he commenced the study of hydrophobia, had already won his laurels in combating disease in the victory he gained over anthrax, the ravages of which so frequently decimated the herds of the French farmer and robbed him of his well-earned return on his capital and labour.

In summoning the brilliant Director of the German Imperial Board of Health to South Africa to investigate the nature of rinderpest, and, if possible, discover a means of protecting cattle from its onslaught, the Cape Government afforded another opportunity for the scientific study of a disease associated with animals, upon the successful mastery and limitation of which the agricultural prosperity of South Africa is so largely dependent, being as it is one of the most fatal and contagious maladies to which cattle are subject. Apart from the great commercial importance attending Dr. Koch's discovery of a device whereby cattle can be immunised or protected from contracting rinderpest when exposed to its contagion, this discovery is of great scientific interest, inasmuch 
as it has inaugurated a new departure in methods of immunisation.

The previous methods in vogue for inducing immunity in animals from a particular disease consisted in converting the virus itself into a vaccine, as was done by Pasteur in his classical investigations on anthrax and its prevention; and secondly, the employment of anti-toxic serums, in which the virus is not directly inoculated into the animal to be protected, but in which an intermediary is employed between the virus and its victim. This intermediary, or living machine for the generation of the anti-toxin, is usually a horse, which is artificially trained by being given gradually increasing doses of the virus or toxin, until it ultimately withstands doses which in the first instance would infallibly have killed it. When the animal has arrived at this satisfactory stage or condition of complete immunity, some of its blood is from time to time drawn off, and the serum thus obtained constitutes the anti-toxin which now figures so prominently in modern therapeutics. Besides diphtheria-antitoxic serum there are also those of tetanus, or lock-jaw, plague, the famous anti-venene serum, about the discovery and preparation of which greater detail is given later on, and many others which are still the subject of experimental inquiry. 


\section{BACTERIA IN DAILY LIFE}

Now Koch's method for the compassing of rinderpest differed from both the systems above mentioned, inasmuch as he neither employed artificially weakened cultures of the virus, or an anti-toxic rinderpest-serum; instead he took one of the natural secretions of an animal infected with rinderpest, and by injecting this into a healthy animal it was discovered that the latter, as is the case with a vaccine, suffered only local and temporary discomfort, and acquired pronounced immunity from the active virus. The secretion selected by Dr. Koch and his assistant, Dr. Kolle, for this purpose was the gall, and it might be supposed, from the fact that its inoculation into healthy animals did not communicate the disease, that the rinderpest bacteria were absent from the gall. But this is not so, for Dr. Kolle has succeeded in isolating the latter from the gall of infected animals, and, moreover, has proved them on isolation to possess their full complement of virulence. Further investigations made by Koch and Kolle have shown that the explanation of this seeming anomaly is to be found in the fact that the gall of an animal suffering from rinderpest contains a substance which prevents the migration of the rinderpest bacteria, with which it is associated, from the point of inoculation. Hampered in their movements by the controlling 


\section{POISONS AND THEIR PREVENTION I73}

influence of this special substance which has been generated in the gall, the bacteria remain rooted to the spot where they are first situate, and only a passing and exceedingly slight local affection results, which on its departure leaves the animal with an immunity from rinderpest lasting some four months. A number of interesting investigations have not unnaturally been stimulated by this remarkable discovery, and researches on the properties inherent in the gall of healthy animals of various kinds have been recently carried out by Dr. Neufeld, of the Institute for Infectious Diseases in Berlin, which are, however, of a too technical nature to deal with here.

As an illustration of the practical use to which Koch's gall immunisation method may be put in dealing with outbreaks of rinderpest, reference to a recent report furnished by the Health Officer of Shanghai may be of interest. Dr. Arthur Stanley describes the outbreak as follows :-

"A large herd of cattle infected with cattle-plague was brought to Shanghai from the Tanyang district, around the Grand Canal, for export to the allied troops in the north of China. The disease spread to an adjacent dairy, most of the cattle dying. On this dairy becoming infected a police cordon was established round it to prevent ingress and egress of cattle and ingress of persons unconnected with the dairy, while 
the outside infected herd was removed to an isolated part of the settlement. Having been previously convinced of the futility of police cordons in the prevention of cattle-plague, I was not surprised to find, within a short time, that the disease had spread, by the meeting together of cattle-coolies at a common tea-house, to three other dairies at a distance of a quarter, a half, and two miles from the original source of infection.

"As the animals are not, as a rule, taken away from the immediate vicinity of the dairy, there being no grazing fields, and as neither fodder nor dung is taken from one dairy to another, it is practically certain the infection was carried by the dairy-coolies.

"Immediately on this second series of dairies becoming infected it was resolved to apply the gall immunisation method of Koch as being the means at hand. About I, 500 cubic centimetres were collected from the gallbladder of a rinderpest animal, and ro cubic centimetres were injected into the dewlap of each of the twenty remaining cattle in the dairy.

"The injection caused slight local swelling and tenderness, but no constitutional symptoms and no alteration in the milk-supply, an important matter in a dairy. In all sixty-eight cattle were injected with cattle-plague gall. Of these, seventeen were among isolated uninfected herds; the remaining fifty-one belonged to infected herds, and among the latter eleven died of cattle-plague subsequent to the injection."

Dr. Stanley points out that ten of these animals, judging by the time which elapsed after the injection, when they showed the first symptoms of 


\section{POISONS AND THEIR PREVENTION I75}

the disease, must have been already infected when the injections were made; the eleventh animal, however, undoubtedly contracted the disease after and in spite of the injection.

"Considering," continues Dr. Stanley, "the usual excessive mortality during an outbreak of this disease, the result may almost be compared to the success of vaccination against small-pox. Three young bullocks, each having received 20 cubic centimetres of cattleplague gall, were purposely exposed to severe infection. They remained well, while unprotected animals around them died of the disease."

In the domain of immunity there is, however, no more fascinating or interesting story than that which deals with the discovery and elaboration of a cure for snake-bites, a discovery which, while attracting but comparatively little attention in this country, should prove of paramount importance to our fellow-subjects in the great Indian Empire. The significance to India of Professor Calmette's discovery of a specific cure for snake-poison may be gathered, indeed, from the statistics which have been compiled of the number of deaths attributed by Indian officials to this cause alone, amounting, it is said, to some 22,000 annually.

The Pasteur Institute in Paris has despatched many pioneers of science to various quarters of the globe, but perhaps no scientific missionary has 


\section{I76 BACTERIA IN DAILY LIFE}

produced more fruitful results than has Dr. Calmette. It was while acting in the double official capacity of Médecin de Ist Classe du Corps de Santé des Colonies and Director of the Bacteriological Institute of Saigon, in Cochin China, in the autumn of I89I, that Calmette first commenced his experiments on the neutralisation of serpent venom in the animal system.

He had, indeed, exceptional opportunities in the matter of serpent venom wherewith to carry out his investigations, for during the rainy season a village in the neighbourhood of Bac-Lieu (Cochin China) had been attacked by a band of most venomous serpents.

These creatures, driven by the floods into the very huts of the natives for shelter, created a terrible panic, and no fewer than forty individuals were bitten by them. The panic was certainly not without justification, for these serpents belonged to the species known as naja tripudians, or cobra de capello, renowned for the deadly nature of their venom, and widely distributed over India, Burmah, Sumatra, Java, Malacca, and Cochin China; but until Calmette set to work to systematically study the nature of this reptile's venom but little precise or reliable information had been obtained as to its character.

The governor of the district gave orders that as 
many as possible of the reptiles were to be captured alive and forwarded to the Director of the Bacteriological Institute, and a plucky Annanite actually succeeded in securing ninety specimens, which were forwarded in a barrel to Dr. Calmette.

This formidable gift was received with enthusiasm by the director, who realised the importance and scope of the inquiry, which he at once set himself to systematically work out.

Forty of these reptiles arrived alive, and several were at once sacrificed to secure their venom glands. Each gland, resembling both in size and shape a shelled almond, contains about thirty drops of venom, and in this transparent limpid liquid is embodied a toxin of extraordinary strength. It was, of course, necessary in the first instance to ascertain, within as narrow a limit as possible, the exact degree of toxic power inherent in the venom, and to determine, if possible, the precise lethal dose in respect of each variety of animal experimented upon.

A correct calculation of the quantity of venom required in every case was, however, found to be quite impossible, for so virulent is the poison that a single drop of an emulsion produced by pounding up eight glands in 300 grammes of distilled water is sufficient, when introduced into the vein of a rabbit's ear, to kill it in five minutes. All the 
mammals to which Calmette administered this cobra venom, such as monkeys, dogs, rabbits, guinea-pigs, rats, succumbed more or less quickly, according to the size of the dose.

Small birds and pigeons die very rapidly, but the domestic fowl is more fortunate, being somewhat less susceptible. Frogs also fall a prey to the venom, but they are far more refractory than rabbits, for it takes thirty hours to kill a frog with a dose of venom which would infallibly destroy a rabbit in ten minutes. Toads, curiously, do not enjoy to the same extent this power of resisting its toxic action, for they die more quickly than frogs, whilst it makes short work of lizards and chameleons. Fish form no exception to the rule, and even invertebrates, such as leeches, are killed by minute traces of venom.

Whilst Calmette has found that the venom of different kinds of reptiles exhibits marked differences in its toxic character, he has also discovered that the venom secreted by one and the same serpent varies considerably, according to the length of time the animal has fasted. He describes how he kept a naja haje (Cleopatra's asp) in his laboratory, which during the whole eight months that it lived never took any food whatever, although it was offered the most diverse dainties. On its arrival it was made to bite on a watch-glass, 
this being one method adopted for collecting the venom; the liquid was at once dried, and 0.7 milligramme was found to kill a rabbit weighing nearly four pounds in four hours. Two months later on, when the venom was again collected, 0.25 milligramme proved a fatal dose. On the death of the animal, at the end of eight months, the venom extracted from the glands was so toxic that it only required O.I milligramme to kill a rabbit of about the same weight as the previous one. The same curious fact was noted in the case of a cobra's venom. Another circumstance which appears to control the degree of toxicity inherent in serpent venom is the interval of time which elapses between two successive bites. The longer the interval the more virulent is the venom; and Calmette points out that these observations are in accordance with what has for a long time been known in France with respect to indigenous vipers - that their bites are far more dangerous and far more fatal in the spring, after the winter period of torpor is over, than in the autumn.

Until quite recently it was thought that the only creatures which could resist the fatal action of this poison were serpents, both poisonous and nonpoisonous. Calmette was led to this conclusion because, although he inoculated large doses, as much as ten drops, into cobras, they suffered 
absolutely no inconvenience, and the same results were obtained with harmless snakes. On repeating these experiments, however, and using much larger quantities of venom, Calmette has found that they do ultimately succumb. That their susceptibility in comparison with other animals is very slight, may be gathered from the fact that a lethal dose of venom for reptiles is roughly estimated to amount to as much as three times the quantity of venom normally present in their respective poison glands. These animals, therefore, although very refractory, are not absolutely immune from the action of venom-toxin.

There are, however, other animals which enjoy a relative although not absolute immunity to snake poison, and amongst these may be mentioned swine, hedgehogs, and the mongoose. Swine, it is well known, will greedily devour reptiles, and in some countries they are specially trained up and employed for this purpose. Of particular interest, however, are some experiments which were carried out to test the traditional immunity towards this toxin ascribed to the mongoose. These animals are very useful in sugar plantations, and are largely employed to keep down the serpents and rats with which they abound, for the carnivorous little mongoose is extremely partial to such prey. Attempts have been made by sugar planters to introduce 


\section{POISONS AND THEIR PREVENTION I8I}

them into Martinique, where they are not found in the wild state, as in the island of Guadeloupe.

Six specimens of the mongoose were forwarded to Calmette from Martinique, and these particular animals, it was stated, had never been set at liberty since they were imported, so that they had had no previous experience of snakes or venom. On arriving at the laboratory, one of these little creatures was placed in a glass cage along with a large cobra. The cobra, at once rising up and dilating its neck, darted with fury upon the mongoose; but the latter, thanks to its extraordinary agility, escaped being caught, and took refuge, stupefied and terrified for the moment, in a corner of the cage. This stunned condition, however, did not last long, for just as the incensed cobra was preparing to make a fresh attack upon its insignificant little victim, the latter, with wide-open mouth, rushed and jumped upon the head of its enemy, viciously bit through its upper jaw, and broke its skull in a few seconds. Thus, although in size but a little larger than a squirrel, this tiny creature was more than a match for a cobra two yards long.

Artificial inoculations of cobra venom into the mongoose fully substantiated all the observed facts as to its remarkable immunity from this poison. A dose sufficient to kill a large rabbit in three 
hours was absolutely without effect; only when the venom was introduced in quantities amounting to as much as eight milligrammes was it followed by fatal results. Thanks, therefore, to their extraordinary agility and remarkable power of resisting the effects of this lethal toxin, these little animals are able to battle successfully with the most dangerous reptiles.

The rapidity with which serpent venom becomes absorbed by the system is almost incredible, and is well illustrated by the following experiment. A rat was inoculated with venom near the tip of its tail. One minute later the latter was cut off a short distance above the point of inoculation; but this operation was quite unable to save the animal's life, for even in that brief interval the poison had accomplished its fatal work, and a few hours later claimed its victim.

This rapid diffusion of the venom helps to explain the difficulty which is experienced in arresting the course of the poison by local treatment, for its passage is too rapid to permit of its being overtaken by superficial measures of even the most stringent character. But Calmette points out that local precautions are not to be neglected, for although they cannot nullify the action of the venom, they undoubtedly do delay its progress, and thus create a longer interval or respite, during 


\section{POISONS AND THEIR PREVENTION I83}

which an opportunity is afforded for administering the anti-toxin. Before, however, passing on to the investigations which have culminated in the production of a specific antidote for this terrible toxin, there are a few more details which Calmette has furnished as to its character which are of interest. Serpent venom is characterised not only by its intensely virulent properties, but also by the tenacity with which it retains them under diverse circumstances. Thus it may be stored up for a whole year, and yet at the end of that time be as active as ever; and even after several years, although its toxic powers are somewhat reduced, it still retains them to a very appreciable extent.

Unlike the bacterial toxins, this venom toxin can stand exposure to considerable temperatures without injury to its activity, and that of the cobra only suffers after it has been submitted to $98^{\circ}$ Centigrade for twenty minutes. Sensitiveness to temperature varies, however, with the snake from which the venom is derived. Thus the venom of the so-called "tiger-snake" of Australia will stand being exposed for ten minutes to from $100^{\circ}$ to $102^{\circ}$ degrees Centigrade, and its virulence only disappears when this temperature has been applied for twenty minutes. The venom of the "black snake," another Australian variety, loses its toxicity at a temperature of between $99^{\circ}$ and $100^{\circ}$ Centi- 
grade; whilst an exposure to only $80^{\circ}$ Centigrade for ten minutes is sufficient in the case of viper venom, according to Messrs. Phisalix and Bertrand, to profoundly modify its lethal action. A continuous exposure for a fortnight to a temperature of $38^{\circ}$ Centigrade does not affect cobra venom in the least; but if during that same time it has been placed in the sunshine, it entirely loses all its lethal properties. Thus, a pigeon was inoculated with about thirty drops of venom which had been exposed to the sun's rays for fourteen days, and it survived; whilst another pigeon was inoculated with a little over six drops of similar venom which had been kept during this time in the dark, and it died in a quarter of an hour.

All these elaborate researches as to the character of serpent venom were essential to enable the next step to be taken in the elaboration of the antidote. Before this great achievement could be accomplished it was. necessary to first succeed in artificially immunising animals against the effects of this powerful toxin, so that the serum of such animals could be applied for the protection and cure of other animals from the effects of snakebites.

It may be readily conceived that the task of artificially rendering animals immune from snake poison was not an easy one, for the process 


\section{POISONS AND THEIR PREVENTION I85}

depends upon training the animal to gradually withstand larger and larger doses of the venom; and considering the intensely toxic character of the substance which had to be handled, the danger was ever present of the animal succumbing to venom poison before its serum had acquired the requisite pitch of protective power to render it of service as an anti-toxin. Dr. Calmette tells us that he carried out a very large number of experiments before he met with success. But it is not necessary here to discuss his various efforts ; suffice it to say that at length his labours were rewarded, and the following extract from one of his memoirs describes the methods which he adopted for this purpose :-

"The best method of procedure for the purpose of vaccinating large animals destined to produce antivenomous serum consists in injecting them from the outset with gradually increasing quantities of the venom of the cobra mixed with diminishing quantities of a onein-sixty solution of hypochlorite of lime. * The condition and the variations in the weights of the animals are carefully followed, in order that the injections may be made less frequently if the animals do not thrive well. Quan-

* More recently the snake venom employed by Dr. Calmette for the immunisation of his horses consists of a mixture of colubrine and viperine poisons, the former making up about 80 per cent. of the mixture. A solution of this mixture is heated at about $73^{\circ} \mathrm{C}$. for half an hour and then filtered, and injected into horses. 
tities of stronger and stronger venom are in turn injected, first considerably diluted, and then more concentrated; and when the animals have already acquired a sufficiently perfect immunity, the venoms derived from as large a number of different species of snakes as possible are injected. The duration of the treatment is of considerable length-at least fifteen months-before the serum is sufficiently active to be used for the purposes of treatment."

An immense number of animals have been vaccinated by this method at the Pasteur Institute at Lille, where Dr. Calmette is now director; and in one of his memoirs we are told that they have horses there which have yielded during a period of eighteen months serum extremely active against venom. These horses receive in a single inoculation, without suffering the least inconvenience, doses of venom sufficient to kill fifty horses fresh to the treatment.

Large quantities of this serum have been forwarded from the Lille Institute to various parts of the world where venomous serpents are most frequently met with, and already important evidence has been collected as to its efficacy in cases of human beings bitten by dangerous reptiles. So impressed with its importance are Indian medical authorities, that its preparation has been included in the work which the new great bacteriological institute at Agra is carrying on. 


\section{POISONS AND THEIR PREVENTION I87}

The importance of the production in situ of this anti-venomous serum has been recently demonstrated by the experiments which have been conducted in the Plague Research Laboratory, Bombay, by Mr. Lamb and his colleagues, on the keeping properties of such serums in India. From the careful investigations which have been made on this subject, these gentlemen state that anti-venomous serum undergoes a progressive and fairly rapid deterioration when stored in hot climates, and that this deterioration is greater and more rapid the higher the mean temperature to which it is subjected.

The protective potency of this horse-serum may be gathered from the fact that it suffices to inject a rabbit, for example, with a quantity amounting to about one two-hundred-thousandth of its weight to ensure the latter acquiring complete immunity from a dose of venom capable of otherwise killing it in twelve hours.

The rapidity with which it acts is also extremely remarkable. Thus, if a rabbit receive two cubic centimetres (about fifty drops) of anti-venomous serum in the marginal vein of one of its ears, it will suffer with absolute impunity an injection of venom into the marginal vein of the other ear capable of killing it under ordinary circumstances in a quarter of an hour. Its curative powers are 


\section{88}

\section{BACTERIA IN DAILY LIFE}

not less remarkable, for it is possible to inject venom sufficient to kill an animal in two hours, and to let one hour and three-quarters elapse before administering the antidote, and yet at this late stage to save the victim's life, although it is necessary where such a long interval has occurred between the respective venom and serum injections to employ the latter in larger quantities than is usually required. Dr. Calmette believes that the anti-toxin may be applied at an even more advanced stage of the disease if it is employed in yet larger doses. Another novel and important feature about this anti-venomous serum is the fact that it not only protects animals from one species of very active venom, such as that of the cobra and other poisonous snakes, but it also affords protection from the dreaded venom of scorpions. This is a very remarkable and significant discovery, for hitherto the opinion has been stubbornly held that each toxin requires its specific anti-toxin for its correction. Dr. Calmette has, however, frequently indicated by his researches that this view cannot be considered so completely proven as is claimed by its supporters, and his latest investigations support the theory that particular toxins may be counteracted by several anti-toxins of different origin. Thus it has been shown by Calmette and Roux that rabbits hyper- 
POISONS AND THEIR PREVENTION I89

vaccinated against rabies acquire the power of resisting venom-poison, and that the serum of horses vaccinated against tetanus or lock-jaw also nullifies the action of serpent venom.

The practical bearing of this discovery is obvious, and the hope is justified that the at present cumbrous appliances required for the elaboration of anti-toxins of such varied origin will ultimately give way to simpler and less costly methods, which will admit of these new antidotes being more widely circulated and applied.

We have seen that although most animals fall an easy prey to serpent venom, yet there are a few notable exceptions, amongst which may be mentioned hedgehogs, swine, and the mongoose. Now the very natural question arises why, if these animals are already in such a high degree immune from this poison, should not they be employed to furnish forth protective serum, instead of laboriously training up susceptible animals to become artificially immune and supply this venom antitoxin?

This brings us face to face with one of the many problems connected with the subject of immunity which so far have successfully eluded all attempts made to solve them. Experience has shown repeatedly that although artificially acquired immunity from a particular poison can 
be handed on by means of an animal's serum, yet the natural immunity from a given poison enjoyed by one species of animal cannot be similarly transferred to less-favoured varieties.

This fact has long been recognised in the case of poisons of bacterial origin. Thus, white rats are absolutely immune from diphtheria, but Wassermann showed some years ago that the serum of these animals has no power whatever to counteract the action of diphtheria-toxin in other animals. Guinea-pigs were inoculated with fatal doses of diphtheria toxin along with white-rat serum; but although other guinea-pigs treated with the same toxin mixed with the ordinary artificially elaborated anti-diphtheritic serum survived, those which received the rat serum died in every case.

Now very similar results have been obtained by Calmette in respect to the serum of animals naturally immune from serpent venom. The serum of the refractory little mongoose, as well as that of the hedgehog, is wholly unable to save other animals from the lethal effect of venom poison, and similar results have been noted in respect to swine serum. But a very curious fact has also been discovered by Calmette-i.e. that these so-called naturally immune animals very frequently are quite incapable of being artificially trained to elaborate a serum possessing protec- 
tive powers which can be transferred to another animal.

How splendid a domain for beneficent research lies before the scientific investigator is apparent to all, and the important work already accomplished is but an augury of yet greater discoveries awaiting the labours of such leaders as Calmette. It is not surprising, therefore, that the scientific interest in toxins and anti-toxins shows no signs of abatement. On the contrary, the competition for obtaining and working the new "claims" which pioneer research enthusiasts are constantly engaged in "pegging out" remains as keen as ever.

Despite, however, the extraordinary interest which this subject has aroused in scientific circles all over the world, nearly ten years elapsed before any notice was taken of the curious discovery made by two brothers that the blood of eels contained a highly poisonous principle, and the memoir containing this remarkable announcement remained until comparatively recently buried in the Italian journals where it was first published.

Calmette was, we believe, the first to call attention to this discovery of the brothers Mosso and give it the prominence it deserves, and both he and other investigators have not only fully confirmed it, but have greatly added to our know- 
ledge concerning the character of the poison contained in eel serum.

Now the venerable Izaak Walton, in one of his quaint and most fascinating discourses, which although written more than two centuries ago have a freshness as if penned but yesterday, waxes enthusiastic over the eel, and supplies an elaborate recipe for its preparation for the table, telling us "it is agreed by most men that the eel is a most dainty fish; the Romans have esteemed her the Helena of their feasts, and some the queen of palate-pleasure." The announcement that the blood of eels is poisonous will hardly, despite its scientific interest, form a comfortable subject for reflection to the modern votaries of this novel Helena. Indeed, in the present timid temper of the public, this article of diet would not improbably share the ill-odour which befell the unfortunate oyster and be practically banished from our tables; but although the oyster is perhaps justifiably at present ostracised from our menus, taking the majority of its breeding-grounds into consideration, it would be the height of injustice to measure out similar drastic treatment to the eel.

That the oyster bred in sewage-contaminated beds may revenge itself upon its consumer by infecting him with the germs of typhoid has been repeatedly contended, but that the eel, although 


\section{POISONS AND THEIR PREVENTION I93}

its unsavoury surroundings are proverbial, can be held responsible for poisoning those who eat it has never, we believe, been seriously maintained, although there is an old Italian saying which bids us "give eels and no wine to our enemies."

Public confidence, however, in the eel as an article of food need not be shaken, for it is satisfactory to learn that researches which, on the one hand, condemn eels as living generators of a highly poisonous substance, on the other hand allay any alarm which they may have reasonably raised by showing that this toxic principle is entirely destroyed in the processes of digestion, and that, therefore, taken through the mouth it is rendered harmless, and only when introduced into the system by inoculation beneath the skin or injected into the peritoneum can it assert its dangerous properties. That the blood of eels is, however, justifiably to be in future classed amongst the toxins, the number of which has of late been so increased, is at once apparent when we learn that about a dozen drops inoculated into a dog weighing about fourteen pounds will destroy the latter in less than ten minutes, whilst pigeons, rabbits, and guineapigs similarly treated, only with smaller quantities, also invariably succumb to its lethal action.

Quite recently an endeavour has been made to determine precisely the degree of toxicity possessed 
by eel's blood, or, in other words, to standardise the poisonous principle contained in it, so as to afford a guide to those experimenting on the subject; and it has been asserted that one cubic centimetre, or about twenty drops, injected into the veins of a rabbit weighing four pounds, may be regarded as a fatal dose for such an animal. But many difficulties surround such an attempt to exactly define the degree of toxic action possessed by such a substance, for, in the first place, the blood varies in respect to this property in different eels, whilst it also differs widely in character at different stages of the life of the fish. This seasonable variation in toxic character has been noticed in the case of viper venom, which it will be remembered was shown to be far more lethal in action when collected from snakes in the spring of the year than in the winter months.

The toxic substance contained in eel serum was originally called by its discoverers, the Mosso brothers, ittio-tossina; and they record the fact that the blood of rabbits and frogs, which animals had succumbed to its action, did not coagulate after death, whilst, curiously, in the case of dogs this abnormal phenomenon was not observed.

There are various means which may be resorted to for destroying the poisonous principle contained in eel blood, and from a dietetic point of view it 
is satisfactory to know that heat-exposure for a quarter of an hour to a temperature of from $57.7^{\circ}$ to $77^{\circ} 7^{\circ} \mathrm{Cent}$. entirely removes it, whilst its virulence is greatly modified by submitting it for a longer period, twenty-four hours, to a much lower temperature, i.e. $37^{\circ}$ Cent. It also gradually loses its toxic properties eight days after it has been collected, even when carefully shielded from light, a feature which contrasts favourably with viper venom, which can be kept for more than a year and remains as active as when first derived from the snake. We have seen also that its toxic properties invariably succumb to the processes of digestion, so that even if fashion or fad or advertising speculators, backed by scientific names, were to decree that a wealth of nourishment and support was contained in raw eel "juice," and the edict went out that it was a desirable and highly important article of invalid diet, the general public may, according to its wont, innocently accept the edict and in this case suffer no evil consequences.

But another and very remarkable method of mitigating the virulence of eel blood, and one which so far has received no explanation, is mentioned by Dr. Wehrmann, of Moscow, who has been lately studying the character of this fish's blood in Dr. Calmette's laboratory at the Pasteur Institute at Lille. Dr. Wehrmann found that if 
blood serum be taken from animals previously rendered artificially immune to the action of serpent venom, and if some of this so-called anti-venomous serum be injected under the skin of eels some hours before they are killed, the lethal properties of their blood after death are considerably reduced. Thus, an eel weighing about six ounces received subcutaneous injections of five cubic centimetres of anti-venomous serum; after the lapse of four-and-twenty hours it was killed and bled, and its serum inoculated into animals in the usual way. But whereas two cubic centimetres of normal eel blood sufficed to kill a guinea-pig, this eel's blood had to be administered in twice that quantity to produce a fatal result, so that its toxic character had been reduced to a very appreciable extent. The readiness with which eel serum parts with its lethal properties, and the restricted conditions under which they can operate, sufficiently assure us that in the present state of our knowledge there is no danger to be apprehended from this fish, and in the absence of any experiments to show what is the effect on human beings of subcutaneous inoculations of such blood, there is no call for this substance to be scheduled under the Poisons Act. We have, however, by no means exhausted the extremely curious properties which characterise this material, and these pro- 
perties are brought to light in a remarkable manner in connection with the investigations which have been carried out to artificially protect animals from its lethal influence, and also in some interesting experiments which have been made to compare the toxicity of eel blood with that of vipers.

It is far from an easy matter to secure for experimental purposes an adequate supply of eel serum, for even a big fish weighing nearly five pounds is not capable of yielding more than about twenty-five cubic centimetres of blood, and from this only from ten to twelve cubic centimetres of serum are obtainable. Calmette has shown that not only the venom glands of reptiles contain toxic substances, but that the blood of such snakes also possesses lethal properties, only in a far less degree. Curiously, the serum of eels is no less than three times as toxic as the serum of the most vicious viper, and, moreover, produces far more discomfort and pain to the animals into which it is introduced than accompanies the injection of viper blood. In the case of viper blood its introduction is followed by no symptoms of discomfort, the animal remains quite quiet, growing more and more somnolent, a condition which is followed by an abnormal fall of temperature, ultimately ending in complete collapse, 
symptoms which in a much more modified degree characterise the injection of heated eel serum into animals. This heated eel serum, which we have seen is deprived of the objectionable characteristics of ordinary eel serum, produces but very transitory symptoms in animals, occasioning some degree of somnolence, and now and again a reduction in temperature, a condition from which, however, the animals rapidly recover in from two to three hours. Animals, however, treated with this heated eel serum acquire a power of resisting the lethal action of unheated or ordinary eel serum, and this artificially induced condition of immunity continues for about three days after the completion of the treatment.

The protective properties of this heated serum are not restricted to animals subsequently inoculated with eel serum, but are extended also to animals which afterwards receive injections of viper serum; but of much greater interest and importance is the remarkable fact that heated eel serum, as well as weak doses of the latter not heated but diluted with water, are capable of protecting animals from the fatal consequences of the far more potent viper venom.

It is interesting to note that, although diluted eel serum can protect an animal from so deadly a poison as viper venom, the serum of vipers is 


\section{POISONS AND THEIR PREVENTION}

quite unable to afford any such service in the case of animals inoculated with ordinary eel serum. The full complement of protective power obtainable from this treated eel serum is only able to slowly assert itself, for it is necessary for a period of as long as twenty-four hours to elapse after its introduction to ensure the animal's system being thoroughly impregnated with it and enable it to withstand a lethal dose of viper venom.

In this respect, what may be designated treated or protective eel serum differs very markedly from anti-venomous serum, which we have seen is serum derived from animals trained up to withstand fatal does of serpent venom, for antivenomous serum acts immediately, and at once confers immunity on an animal from the lethal effects of such venom.

The rapidity with which it acts is indeed one of the most astonishing properties of this particular anti-toxin. Thus if two cubic centimetres of antivenomous serum be inoculated into the marginal vein of a rabbit's ear, it at once confers upon the latter complete immunity from snake poison. Immediately after the injection of the serum, venom sufficient to destroy an ordinary rabbit in a quarter of an hour may be injected with impunity into the vein of the other ear. But not only are the protective powers of this serum so 
remarkable in their degree, but its curative powers, a much more difficult property to establish in a substance, are extraordinarily intense, as may be gathered from the following example. Four rabbits were inoculated with a quantity of venom calculated to destroy them in the space of two hours; one of these four animals was abandoned to its fate, but the other three received, practically at the eleventh hour, viz. just fifteen minutes before the expiration of the calculated two hours' respite, an intravenous injection of a small quantity of anti-venomous serum, only amounting to one fourhundredth part of the weight of each animal respectively. The rabbit which received only the venom died at the end of two hours, whilst the other three remained in perfect health.

But although eel serum can be persuaded to part with its poisonous character and even exercise protective powers over otherwise doomed victims, it is not able to stretch forth a healing hand to the afflicted, for, when once the poison has been introduced, whether it be eel or viper blood, or the venom of snakes, it is absolutely powerless to mitigate or stop in any way the deadly progress of the toxin. Thus whilst eel blood may acquire protective properties it cannot acquire curative properties, and, therefore, treated eel serum cannot be legitimately enrolled with 


\section{POISONS AND THEIR PREVENTION 2OI}

the anti-toxins which have been elaborated, as, for example, anti-venomous serum, for, to be worthy of such rank, a substance must be capable of wielding both protective and curative powers.

But, although eel serum may under certain conditions protect from the lethal action of serpent venom, eels are not themselves under ordinary circumstances endowed with any power to withstand the influence of this poison, for a good-sized eel will succumb to a dose of venom which is sufficient to kill a guinea-pig.

Considerable interest is attached to the fact that anti-venomous serum not only acts as an antitoxin towards serpent venom, but also towards a poison of quite a different character, such as that present in the normal blood of eels, for this fact tends to confirm the view upheld by some authorities, that specific toxins do not necessarily only yield to specific anti-toxins, and that a particular anti-toxin may act as such towards divers toxins of varied origin and character. Calmette has brought this point out very clearly in his later investigations on the vegetable poison abrine, a very powerful toxin, furnished by the active principle of the seeds or beans of a leguminous plant common in India and South America, and frequently used, as already mentioned, by the 
natives in India to revenge themselves on their enemies in poisoning their cattle. Immunising serums of various kinds were selected for testing their protective action on animals poisoned with abrine, and it was found that anti-tetanic, antidiphtheritic, anti-anthrax, and anti-cholera serums all individually exerted a decided immunising action with regard to this powerful vegetable poison. The hope is, therefore, perhaps not beyond the realm of possibility, that at some future time the complexity of drugs which now figure in the chemists' pharmacopœia may be replaced by a few substances the application of which will come within the means and understanding of all. So far we have not dealt with the artificial immunisation of an animal from the action of eel poison, but this apparently offers very little difficulty, and is accomplished by introducing very small and gradually increasing doses of eel serum into the system, care being taken to proportion the quantity given according to the weight and general condition of the animal to be immunised. A rabbit, for example, treated in the above manner, subsequently yielded a serum which was proved to possess both preventive and curative powers in respect to both eel poison, and viper venom and blood, entitling this so called anti-eel serum to take its place amongst 


\section{POISONS AND THEIR PREVENTION 203}

the anti-toxins, and furnishing yet another instance of a substance exercising its immunising influence over various toxins.

This process of gradually acclimatising, as it were, animals to a particular poison by repeated doses of the same poison, recalls the old proverb, "Seek your salve where you got your sore," and brings us to a consideration of some of the primitive antecedents of a practice which, at the present time, promises to bring about so profound a revolution in the art of medicine. The modern system of inoculation has, however, arisen quite without reference to such antecedents, which latter were not based upon any scientific laws or considerations, but owed their evolution to local customs and experience handed down from age to age by tradition, and in many cases preserved through a simple faith in the superstitions which surrounded them.

To such a category must be added the curious superstitions indulged in by the native population of Tunis regarding methods of preventing hydrophobia in persons bitten by rabid animals. Dr. Loir refers to these primitive ideas on the art of healing in a report of the work carried out at the Anti-rabic Institute at Tunis, one of the many centres for the prevention of rabies by Pasteur's method which have been established in every 


\section{BACTERIA IN DAILY LIFE}

quarter of the globe except Great Britain, the inhabitants of this "great conservative islandEmpire," as a renowned foreign scientist describes it, still preferring a trip to Paris to countenancing the establishment of an anti-rabic institute in their own country. The Arab physicians in Tunis have from time immemorial sought to specially identify themselves with cures for this disease, which is so prevalent as to be a veritable scourge to the country. A much-vaunted remedy advocated by the profession consists in pounding up the charred head of a rabid dog with vinegar, and administering an emulsion of the same to the patient. The dung of camels is also highly prized as a remedy, as also the water of certain wells which the simple faith of the natives has endowed with supernatural curative properties. But the strangest prescription of all consists in broth made from lambs a year old, to which is added a peculiar kind of beetle, but in such a small quantity that the latter ingredient only equals the weight of a grain of corn. This concoction is given to the unfortunate patient twenty-three days after he has been bitten. In the urine, according to the Arabian doctors, seven small worms should be found which represent the embryos of dogs engendered by the virus in the human body, and which when once got rid of the patient recovers! 


\section{POISONS AND THEIR PREVENTION 205}

In the face of such crude traditions upheld with so much tenacity by the native population, it is surprising that the Tunisian Anti-rabic Institute has met with such a large measure of support in the shape of applicants for admission, which, on an average, number over one hundred annually. The mortality amongst those treated closely approaches the satisfactory results obtained at the Paris Institute, where the death-rate amounts to about 0.38 per cent. of the persons treated.

There is perhaps no more interesting chapter in the history and literature of medicine than might be compiled by searching out the early uses of drugs and the primitive application of methods in the art of healing, and tracing their connection, if possible, with the practices which are in vogue at the present day. In the matter of toxins and anti-toxins, or in respect to the modern theories of preventive medicine, there would appear to be a curious link between the methods based upon elaborate scientific inquiries and those which arose through simple experience and expediency.

The idea of a poison, as the old proverb above tells us, being a corrective for itself is no new idea, for we read how in ancient times, for example, the Ophiogenes of the Hellespont were renowned for their immunity to snake poison, and one account of them states particularly that they fed upon 
serpents, and that to this diet they probably owed their reputed magical art in withstanding the action of serpent venom. Again, a traveller in Egypt, Hasselquist, tells us how the serpentcharmers there eat serpents, making them into a kind of broth, and that invariably before starting off to catch these reptiles they partake of some of it.

In a paper by Mr. T. R. Rao on the Yánádés tribe of the Nellore district, Madras Presidency, the author mentions that these strange people have, amongst other characteristics, absolutely no fear in catching cobras, which they draw out of their holes without any alarm as to their fangs, and that they appear to protect themselves against the effects of snake-bites by swallowing the poisonsacs of snakes.

Bruce describes how he saw a serpent-charmer in Cairo who allowed himself to be bitten by a viper between the forefinger and the thumb, and made no endeavour whatever to apply remedies, neither did he exhibit the slightest anxiety as to the consequences. That this was no trick, and that the viper was really possessed of all its deadly faculties at the time it bit the man, was proved by the fact that a pelican subsequently bitten by the same animal died in thirteen minutes. Bruce also tells of a man who "with his naked hand took a 
viper from a number of others lying at the bottom of a tub. He put it on his head, then in his breast, and tied it about his neck like a necklace. Next it was made to bite a hen, which died in a few minutes; and, to complete the experiment, the man took it by the neck, and, beginning at the tail, ate it as one does a carrot or a stick of celery, without any seeming repugnance."

A most interesting account of snake-charmers is given by Drummond Hay, in his book on Western Barbary, in which he relates his experiences with some of these wonderful individuals belonging to the sect called Eisowy. Members of this sect, he mentions, frequently handled scorpions and poisonous reptiles without fear or hesitation, and they were never attacked by them. $\mathrm{He}$ was present at one of their exhibitions of feats with snakes in which they both allowed themselves to be bitten and provoked the snake to bite them. The charmer thus bitten then in his turn ate or chewed the reptile, which, he remarks, writhing with pain, bit him in the neck and hands till it was actually destroyed by the Eisowy's teeth.

In South Africa snake poison is actually taken as a protection against snake-bites, and if we turn to the Lancet of the year I886, we shall find a letter from Mr. Alfred Bolton stating that his curiosity had been aroused by the fact that while in South 
Africa cattle and horses frequently died from the effect of snake-bites, the natives themselves seldom or never appeared to suffer any inconvenience from such injuries other than would follow any accident which would set up local inflammation. On inquiry he found that they were in the habit of extracting the poison gland from the snake immediately it is killed, squeezing it into their mouths and drinking the secretion, thereby apparently acquiring absolute immunity from snake-bites. So impressed was Mr. Bolton by what he observed that he adds: "I can no longer refuse to believe in the efficacy of the snake virus itself as a remedy against snake poison."

Savage tribes have learnt from bitter experience how to protect themselves from snake-bites, and it is well known that they have a method of inoculation which they employ with success. The Creoles of Surinam use an ointment as a protection against snake-bites, which is regarded as highly efficacious. It is reputed to consist principally of the pounded head of a rattlesnake, which concoction would therefore include the contents of the venom glands. This is then mixed with the juices of a certain plant, which addition probably mitigates the intensity of the venom by acting as a diluent. This substance is generally applied by making an incision in the wrist or forearm and rubbing it in, 


\section{POISONS AND THEIR PREVENTION 209}

after which individuals thus treated appear to enjoy security from the venom of snake-bites.

What applies to serpent venom would also appear to hold good in regard to other poisons, such as that contained in the sting of a bee. This poison is extraordinarily tenacious of its irritant properties, and, unlike eel poison, retains its virulence even when exposed to high temperatures.

An interesting memoir on the immunity of the bee-keeper from the effects of bee poison was published a short time ago by Dr. Langer in a German scientific journal. He issued a number of circulars with questions to be answered, and sent these to more than a hundred bee-keepers in different parts of the country, with the result that a hundred and forty-four stated that they were now immune to bee poison, nine having been fortunately endowed with a natural immunity to this irritant, whilst only twenty-six out of the whole number applied to stated that they were still susceptible.

This condition of immunity to bee poison is obtained after a varying number of stings have been inflicted; in some cases thirty, at the rate of from three to four a day, are sufficient to ensure freedom from further discomfort, but the inoculations may have to be prolonged up to one hundred stings to secure complete immunity. 
In experiments carried out on animals this immunity to bee poison has been also induced by repeated application of the irritant. It was formerly generally supposed that the irritant nature of a bee's sting was due to the presence of formic acid; but inasmuch as bee poison can retain its poisonous character in spite of being submitted to heat, which would effectually volatilise the formic acid present, this assumption must be abandoned, and opinion is more inclined now to regard this irritant substance as partaking of the nature of an alkaloid.

Before closing this brief review of some of the most recent discoveries which have been made in the domain of immunity, we must mention some extremely suggestive and important researches on the poison of tetanus, or lock-jaw, which have emanated from Dr. Roux's laboratory at the Institut Pasteur in Paris.

It will perhaps be remembered that Pasteur, when working at hydrophobia, experienced the greatest difficulty in exciting rabies in animals with certainty, and that it was only when the fact of its being a disease which essentially affects the nervous system of the animal was taken into account that it occurred to him to cultivate the virus in the medium for which it had seemingly the greatest affinity, viz. the nervous tissue of an animal; it was 
only on taking this step that he succeeded in invariably provoking rabies in the animals under experiment.

In the case of tetanus we have another disease affecting the nerve-centres of the body, and although many authentic cases have been cited in which the treatment with anti-tetanic serum has been entirely successful, a great many instances have occurred in which it has been of no avail at all, more especially when the disease has obtained a firm hold on its victim. Now Dr. Roux has not only been carrying out experiments to ascertain what is the result of directly attacking, as Pasteur did in the case of rabies, the nerve-centres of an animal with the tetanus toxin, but he has also taken another and very important step further, and has investigated, not only the action of the toxin, but also that of the anti-toxin on the nerve-centres of an animal suffering from tetanus.

In describing the cerebral inoculations which he has conducted on animals, Dr. Roux points out that the operation, in itself, is attended with no pain or even inconvenience to the animal in question, that subsequently it eats with its usual appetite, and shows no signs of discomfort.

First, as regards the infection of an animal with the tetanus virus introduced directly into the brain, 
it has been found that very much smaller quantities produce a fatal result than when subcutaneously inoculated. Thus, a rabbit which received two cubic centimetres of the poison under the skin took four days to succumb to tetanus, whilst onetwentieth of the quantity inoculated into the brain sufficed to kill another rabbit of the same size in less than twenty hours.

Another very instructive example of this susceptibility of the nerve-centres for certain poisons is afforded in the case of rats and the toxin of diphtheria. Rats possess a natural immunity from this substance, and can successfully withstand a dose of diphtheria poison introduced under the skin which would infallibly kill several rabbits. This state of immunity, however, entirely disappears when the toxin is brought directly in contact with nervous tissue, for a very small quantity of diphtheria poison - insufficient to cause under ordinary circumstances even a passing swelling at the seat of inoculation - will, when introduced into the brain of a rat, kill the animal.

Again, rabbits are generally credited with possessing high powers of resisting the action of morphia, a large dose of this substance introduced subcutaneously producing no result whatever. A cerebral inoculation, however, of a minute quantity 
of morphia causes an immediate reaction, and the animal, after remaining in a more or less dazed condition for several hours, finally succumbs to this drug. Dr. Roux is inclined to regard this difference in the susceptibility exhibited by animals to one and the same poison as being due to a good deal of the toxin, when subcutaneously introduced, failing to reach the nerve-centres, it having been destroyed or arrested in the system before it could attack them.

What is the nature of the subtle forces which may so beneficially intervene between the toxin and its victim has long been a problem which has excited the interest and ingenuity of some of the most brilliant scientific authorities of the day, and it is one which, even in the hands of men like Metchnikoff, is still awaiting a satisfactory solution!

The important point was next approached by Dr. Roux as to whether an animal, successfully trained to withstand large doses of the poison, as ordinarily introduced, could also resist it when directly inoculated into the brain. Is, in fact, the undoubted immunity to tetanus poison which may be possessed by an animal due to the nerve-centres having become insensible to this substance? The answer to this question would appear to be in the negative, for animals artificially protected from 
tetanus poison introduced under the skin succumbed to a small dose inoculated direct into the brain, which would otherwise have not produced even a slight passing tetanic affection of the limb where the inoculation was made. Immense numbers of experiments were made under varying conditions, but the result was fully confirmed, showing that the nerve-centres had not acquired any immunity to the poison, although the blood serum of the victims to such cerebral inoculations was proven over and over again to be endowed with strong protective properties against tetanus poison.

The endeavour was then made to, in Dr. Roux's words, "place the anti-toxin where the toxin is working," and preserve the vital force of the nervous tissue. To arrest tetanus by substituting cerebral for subcutaneous inoculations of the anti-tetanic serum was the next feat attempted. Several guinea-pigs and rabbits were inoculated subcutaneously with virulent doses of tetanus poison sufficient to kill them in about seventy hours; some were subsequently treated with antitoxic serum introduced in the ordinary way under the skin, whilst others were inoculated with from six to seven drops of this protective serum direct into the brain. The results were extraordinarily successful. Although but a few drops of the anti- 
toxin were used for the cerebral inoculations, the animals survived the otherwise fatal doses they had received of the toxin; whilst out of seventeen guinea-pigs which received subcutaneous inoculations of the anti-toxin only two recovered, and the quantity of the anti-toxin employed reached as much as from ten to twenty cubic centimetres in some of the experiments, contrasting in a remarkable manner with the few drops which sufficed in the case of the cerebral inoculations.

Dr. Roux sums up this splendid result in the following modest words: "Il ne suffit pas de donner de l'anti-toxine, il faut la mettre au bon endroit."

The significance and far-reaching application of this most important discovery cannot easily be overestimated. Hitherto the preparation of an anti-toxin has been the chief point considered, but Dr. Roux and his able coadjutor, M. A. Borrel, have shown how great may be the results which attend its method of administration, and have opened up an entirely new direction for investigation.

Although the subject of immunity is not, as we have seen, by any means wholly a latter-day creation, yet its approach and consideration from a modern point of view, assisted by the resources and equipment provided by modern scientific 


\section{I6 BACTERIA IN DAILY LIFE}

methods, justifiably entitles the nineteenth century to claim it as its own discovery.

However brilliant and successful the labours may be of those who will follow in the future, subsequent generations will know how to venerate those great leaders of scientific thought, amongst whom we must rank Pasteur, to whose genius the world owes so great a debt of gratitude, and the vast extent of whose labours cannot be adequately measured at the present day by reason of the restricted scientific horizon which encircles public opinion in this country.

THE END 


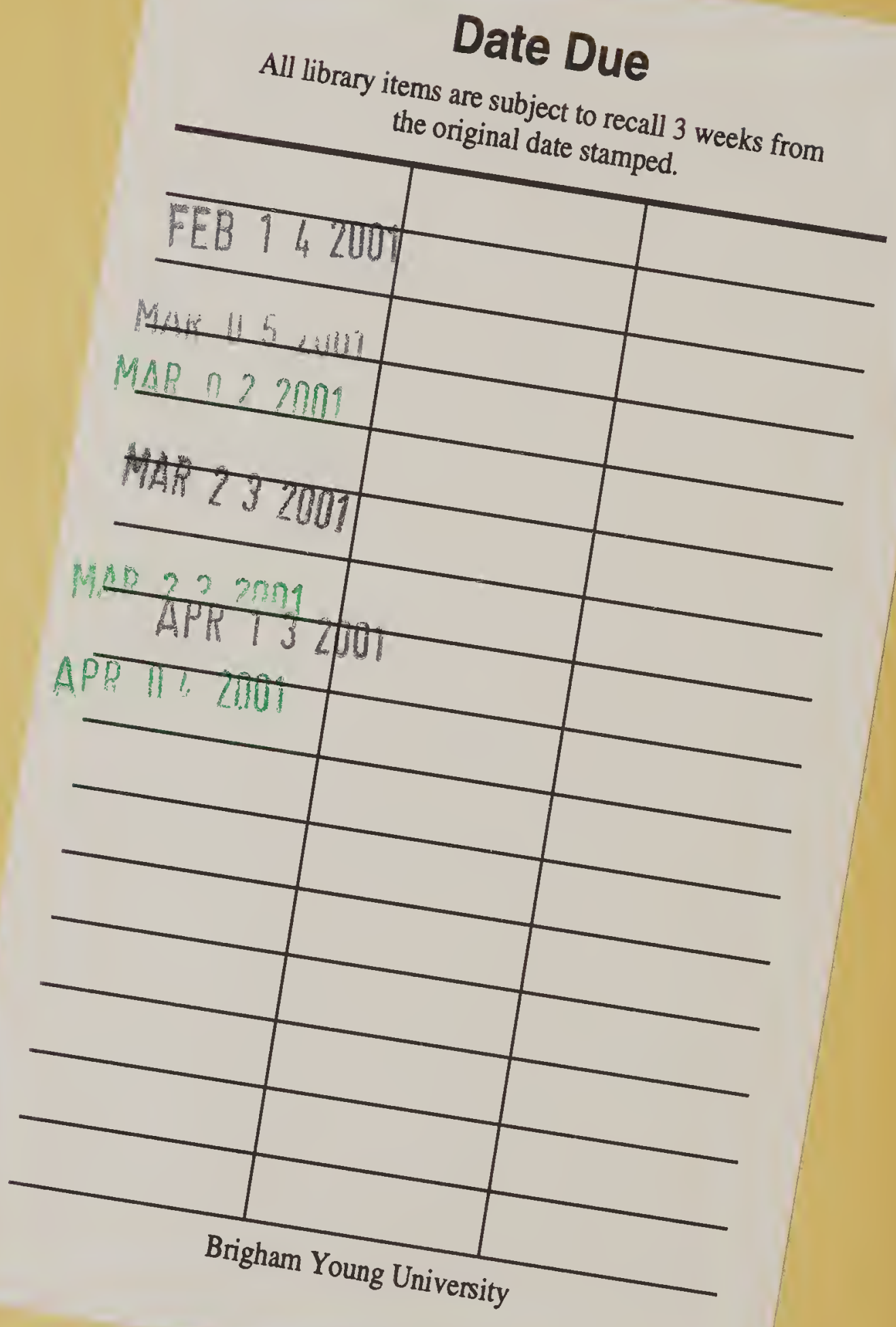




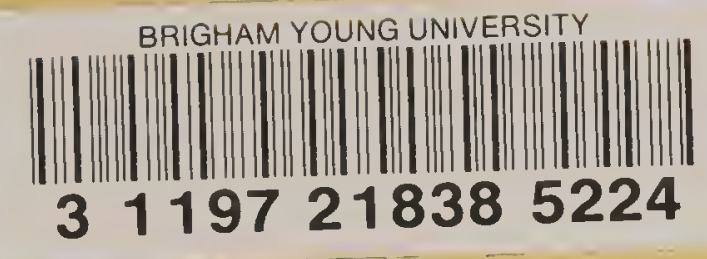




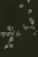

2

$y:$

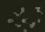

$\because \%$ 